\title{
Stomach and duodenum TU1-TU6
}

USE CF SELF EXPANDABLE STENTS IN THE TREATMENT OF BENIGN PEPTIC OESOPHAGEAL STRICTURES IN THE ELDERLY.

DR D R FOSTER, DEPARTMENTS OF RADIOLOGY AND ENDOSCOPY, PRINCESS OF WALES HOSPITAL, BRIDGEND, SOUTH WALES, U.K.

The use of self-expandable stents in the management of malignant oesophageal strictures has become well established. The majority of benign peptic oesophageal strictures can be successfully managed using endoscopic or fluorosi ipically guided balloon oesophageal dilatation combined with long term drug therapy, particularly using Proton pump inhibitors. Although endoscopic oesophageal dilatation can be performed on an outpatient basis it requires repeated hospital visits. There is a small risk of oesophageal perforation whilst cardiorespiratory complications may be encountered during the use of intravenous sedation in elderly patients. Self-expandable Strecker oesophageal stents (Boston Scientific Corporation, Boston) were used in three elderly female patients aged 91,98 and 100 years respectively. All patients had previously required repeated endoscopic oesophageal dilatations over a 5 year period despite the use of long term Omeprazole therapy. Self-expandable stents were inserted in all patients under mild sedation following preliminary stricture dilatation. All patients have obtained excellent relief of symptoms following stent insertion and have now been followed up for approximately 12 months. They are able to swallow normally and have continued on long term maintenance Omeprazole therapy. There is a theoretical risk of developing an additional peptic stricture above the stent but this is unlikely to be a significan: problem in these patients with the use of long term Omeprazole therapy and their likely life expectancy.

DEGREE (OF SUPPRESSION OF GASTRIC ACII) SECRETION BY OMEPRA\%(OI.E IS REI.ATED TO $H$. PYLORI STATUS. D. Gillen A. Wir\%, K.E.L. McColl. University Dept. of Medicine \& Therapeutics. Western Infirmary, Glasgow, U.K.

Introduction: Proton pump inhibitors (PPIs) are very commonly used drugs. Recent data indicate that they cause more marked elevation of drugs. Recent data indicar intragastric $\mathrm{pH}$ in $H$. $P$-infected individuals. It is not clear whether this is
due to a neutralising effect of ammonia preduced by $H$. pylori urease or 10 due to a neutralising effect of ammonia prod

a more marked inhibition of acid secretion. Aim:

Subjects and Methods: 18 H.P.-ve and 10 H.P.+ve healthy voluntecrs were studied. $H$. pylori status was confirmed by the ${ }^{14} \mathrm{C}$-urea breath test. Prior to commencing the PPI therapy, basal acid output, acid output to gastrin releasing peptide (40)pmol/kg/h) (GRP) and maximal acid output to Gastrin-17 (MAO) were measured on separate days. Omeprazole Gasing separate mornings in the last (wo weeks of this cour

\begin{tabular}{|c|c|c|c|c|c|c|}
\hline Results: & & H.P. & negative & & & positive \\
\hline & $\begin{array}{l}\text { Pre- } \\
\text { Omep. }\end{array}$ & $\begin{array}{l}\text { On } \\
\text { Omep. }\end{array}$ & $\begin{array}{l}\% \\
\text { Inhib. }\end{array}$ & $\begin{array}{l}\text { Pre- } \\
\text { Omep. }\end{array}$ & $\begin{array}{l}\text { On } \\
\text { Omep. }\end{array}$ & $\begin{array}{c}\% \\
\text { Inhib. }\end{array}$ \\
\hline Baxal intragastric pll & 1.61 & $3.74^{*}$ & & 1.50 & 8.04 & \\
\hline $\begin{array}{l}\text { Basal acid output } \\
(\mathrm{mmolh})\end{array}$ & 3.4 & $0.3^{*}$ & $82 \%$ & 3.2 & 0.0 & $100 \%$ \\
\hline $\begin{array}{l}\text { GRP acid output } \\
(\mathrm{mmol} / \mathrm{h})\end{array}$ & 9.6 & $3.8^{*}$ & $64 \%$ & 14.2 & 0.0 & $100 \%$ \\
\hline $\mathrm{M} \wedge \mathrm{O}_{\mathrm{Ci} 17}(\mathrm{mmol} / \mathrm{h})$ & 36.0 & $18.2^{*}$ & $52 \%$ & 34.6 & 7.1 & $80 \%$ \\
\hline
\end{tabular}

Values are medians. *Indicates difference from $H . P .+v e$ at $p<0.05$.

Discilecion and Conclusions: This study indicates that the inhibition of gastric deid secretion produced by PPI therapy is much more profound in H.P. + ve individuals. The magnitude of this effect cannot be explained by the neutralising effect of bacterial ammonia. It may be explained by the body gastritis which develops in H.P.+ve subjects during PPI therapy impairing acid secretory function and thus augmenting the effect of the drug. This profound suppression of acid secretion may have deleterious effects by facilitating gastric bacterial colonisation and consequently predisposing to gastric carcinoma. Eradication of $\boldsymbol{H}$. pylori may be appropriate prior to long-term PPI therapy, but this may reduce the efficacy of PPI therapy in reflux disease.

\section{TU4}

NEW, INTERNATIONALLY APPLICABLE, POLYMERASE CHAIN REACTION-BASED TYPING OF Helicobacter pylori vacA JC Atherton. RJ Twells, CJ Hawkey, RM Peek Jr.*,TL Cover*, MJ Blaser*. Div.Gastroenterology and Institute of Infections and Immunity, University of Nottingham, Nottingham NG7 2UH, *Div. Infectious Diseases, Vanderbilt University and VAMC, Nashville, USA.

Typing $H$. pylori vacA is important because, in the US, vacA structure has been associated with gastric epithelial damage and ulceration. A previous PCR-based typing system successfully classified all U.S. strains tested, but failed to classify vacA mid-regions of Japanese and various other strains. We sought to investigate the extent of vacA mid-region diversity between US strains and strains from other countries, and to devise an internationally applicable typing system.

Methods and Results: We studied $78 \mathrm{H}$. pylori isolates of which 13/13 Japanese, 2/6 Chinese, 3/9 Thai, 1/8 Peruvian and 0/42 US isolates had vacA mid-regions we could not previously classify. We PCR-amplified, cloned and sequenced, extended (1.7Kb) vacA midregions of 1-2 untypeable strains from each country. All proved to be type $\mathrm{ml}$ variants except one Chinese strain which was $\mathrm{ml}$ proximally and m2 distally with a clear crossover site. Annealing sites for the unsuccessful $\mathrm{ml}$ primers had up to $3 / 19$ and $7 / 20$ non-complementary bases, vac $A$ sequence comparisons using these strains, $\mathrm{m} 2$ strains from the same populations, and other published strains, showed that diversity was greater among $\mathrm{ml}$ strains (1-12\% nucleotide differences over 294bp) than $\mathrm{m} 2(0-6 \%)$, but that differences were most marked between $\mathrm{m} 1$ and m2 strains (22-27\%). Next, we devised two new PCR-based typing strategies. The first used conserved primers spanning a 75bp imperfect repeat found only in $\mathrm{m} 2$ strains, and differentiated products by size. The second used four primers in a single reaction: two new $\mathrm{ml}$ primers and two previously described $\mathrm{m} 2$ primers. We applied both strategies to all 78 isolates. Results agreed entirely with previous vacA typing, except that for both strategies all previously untypeable strains were $\mathrm{ml}$. As expected, the Chinese $\mathrm{ml} / \mathrm{m} 2$ strain appeared $\mathrm{ml}$ by strategy 1 and gave a uniquely sized product (of the predicted size) using strategy 2 .

Conclusions: Despite variability in the vacA mid-region, all strains can be typed as $\mathrm{m} 1$ or $\mathrm{m} 2$. Finding an intermediate $\mathrm{m} 1 / \mathrm{m} 2$ type implies in vivo recombination between strains. This typing system will aid studies linking vacA genotype with disease in countries other than the US. 
TU5

VIRULENT HELICOBACTER PYLORI (HP) IN PATIENTS WITH GASTRIC AND OESOPHAGEAL ADENOCARCINOMA. CE Grimley, DE Loft, AG Morris, CU Nwokolo.

Department of Gastroenterology, Walsgrave Hospital, Coventry, UK.

Introduction : Gastric carcinogenesis can be explained by a model based on HP-mediated inflammation facilitating progression from gastritis to atrophy, dysplasia and cancer. Mucosal inflammation which occurs when HP colonises the stomach is more severe when the strains express CagA and VacA. If HPmediated inflammation is the main pathogenetic factor in gastric carcinogenesis then virulent proinflammatory strains of HP should be over represented among patients with gastric cancer when compared to other disease groups in which $\mathrm{HP}$ inflammation is not a factor.

Method : In an unselected series of patients with gastric (GA) or oesophageal (OA) adenocarcinoma, HP status was determined by serology/ $/ 3$ C-UBT/CLOtest/histology. CagA and VacA status of the colonising HP was determined indirectly by detecting antibodies to these proteins in patients sera by an immunoblot assay. Using a novel virulence scoring system, a putative HP virulence load was assigned to each patient depending on whether they were colonised by HP and whether the HP strain they harboured expressed either CagA or VacA or both virulence factors. Virulence load increased in a stepwise fashion: - patients scored 0 if HP-ve, 1 if HP+ve and -ve for CagA and VacA, if HP+ve and also +ve for either CagA or VacA and 3 if $\mathrm{HP}+\mathrm{ve}$ and also +ve for CagA and VacA

Results : GA $(n=26)$ OA $(n=26)$, median age were 74 and 67 respectively In the GA group $21 / 26$ patients were HP+ve and 19/21 harboured strains which were +ve for CagA or/and VacA. In the OA group 14/26 were HP+ve and only $7 / 14$ harboured strains tve for CagA or/and VacA. When our virulence scoring system was used to assign virulence/inflammatory load, patients with GA scored a median of 2 (range 0-3) compared with OA patients who scored 1 (range 0-3), $p=0.0016$ Mann-Whitney U Test.

Conclusion : Compared to an OA control group, the majority of patients with GA are colonised by virulent pro-inflammatory strains of HP. This study supports the HP inflammatory model for gastric carcinogenesis. An altemative interpretation could be that colonisation by virulent HP protects against oesophageal adenocarcinoma.

\section{Stomach and duodenum W7-W32}

W7
VALUE OF THE HELISAL TEST IN SCREENING DYSPEPTIC PATIENTS FOR H.PYLORI INFECTION -. A.Sinha, C.Treharne L.Murray, D.W.Williams, M.J.Dew, Prince Philip Hospital, Llanelli.

Introduction: H.Pylori antibody seropositivity as determined by laboratory based ELISA tests or ELISA kits has been proposed as a screening test for H.Pylori infection in dyspeptic patients without sinister symptoms, especially those below $\mathbf{4 5}$ years, with diagnostic endoscopy offered to only the seropositive group. The Helisal test (Cortecs diagnostics), which is one such Rapid Whole Blood Test, is increasingly being used in general practice for this purpose. This study assesses the reliability of this approach.

Aim: To assess the value of the Helisal test in screening dyspeptic patients for H.Pylori infection

Methods: 207 consecutive patients (102 male, 105 female) referred for Open Access endoscopy were tested immediately before endoscopy Serum samples were obtained for a reference laboratory based ELISA test for H.Pylori antibodies. Infection was confirmed if CLO test at 24 hours and microscopic visualisation of the organism on biopsy were both positive, and excluded if both were negative

Results: . H.Pylori infection found in 69/187 (36.9\%) patients [Age < $45-13 / 39$ (33.3\%); Age $>=45-56 / 138(40.58 \%)]$. The Helisal test had a sensitivity of 0.84 , but a specificity of only 0.46 [ Positive predictive value (PPV) 0.43 , Negative predictive value (NPV) 0.75 ,False positive rate (FPR) 0.54 , False negative rate (FNR) 0.16 , Likelihood ratio (LR) 1.56]. The laboratory ELISA test had a sensitivity 0.84 , but the specificity was 0.79 [ PPV 0.62 NPV 0.82 , FPR 0.21 , FNR 0.16 , LR 4]. Correlation of Helisal test with Laboratory based ELISA test was poor. Both tests performed similarly in the $<45$ group and the $>45$ group.

Conclusion: Of the 122 patients that had a positive Helisal test in this study, $64(52.46 \%)$ were falsely positive. Reliance on a negative Helisal result to restrict endoscopy would have resulted in $16 \%(11 / 69)$ cases of $H$. Pylori infection being missed. The poor performance of this test makes it unsuitable for use in screening for H.Pylori infection.
THE PROLIFERATIVE STATUS OF ENTEROCHROMAFFIN-LIKE (ECL) CELLS IN THE GASTRIC MUCOSA; THE PLOT THICKENS

Neema M Rashid, Irvin Modlin, Laura Tang and Nicholas A Wright, Department of Histopathology RPMS, Hammersmith Hospital, London and Gastric Pathobiology Research Group, West Haven VAMC and Yale.

There has been considerable interest in ECL cell hyperplasia in recent years, mainly because of concern that powerful antisecretory therapy may lead to the development of ECL cell carcinoids. The mechanism of development of ECL cell hyperplasia in chronic atrophic gastritis, whether or not the patient is on antisecretory therapy, has been assumed to be due to proliferation of the ECL cells themselves; this is because of findings in experimental animals that indicate that the ECL cell lineage is a selfrenewing population. There is little or no direct experimental evidence, however, on the proliferative status of this important lineage in the human stomach.

Consequently, we have examined the fundic gastric mucosa of norma humans, patients on long-term antisecretory therapy, and patients with atrophic gastritis showing diffuse, linear and micronodular hyperplasia, atrophic gastritis showing diffuse, linear and micronodular hyperplasia, and with ECL cell carcinoids. In addition, we evaluated fundic mucosa
from Mastomys, an important animal model for ECL cell hyperplasia and neoplasia: control animals, animals with ECL cell hyperplasia and ECL cell carcinoids induced by loxtidine were available. All tissues were double-immunostained using chromogranin $A$ as an endocrine cell marker, and PCNA and MIB- 1 as proliferative markers.

We were unable to demonstrate double-labelled cells in normal human corpus or in patients with diffuse, linear or micronodular hyperplasia, despite counting in excess of 20,000 chromogranin A positive cells in each group. However, ECL cell carcinoids in humans contain numbers of double-labelled cells (up to $0.15 \%$ ). However, Mastomys corpus contains proliferative ECL cells, as previously reported, and we demonstrated that proliferative ECL cells, as previously reported, and we demonstrated that
up to $3 \%$ of chromogranin positive cells were double-stained in ECL cell up to $3 \%$ of chromogranin positive cells were
hyperplasia, and $4 \%$ in ECL cell carcinoids.

We conclude that (i) as assessed by chromogranin A, neither normal no hyperplastic ECL cells in the human stomach appear to have proliferative potential; (ii) Mastomys ECL cells form a renewing population and undergo hyperplasia after loxtidine-induction which involves cell division, which may reflect different rates of cell turnover in each species. These findings indicate (a) that the mechanism of ECL cell hyperplasia in the human stomach (a) nat the mechanism of ECL cell hyperplasia in the although neoplastic ECL cells themselves can divide, and (b) that lineage relationships in the human and animal stomach differ. The mastomys relationships in the human and animal stomach differ. The mastomys
One year follow-up of a randomised trial of pre endoscopy screening for $H$. pylori in the management of dyspepsia

MA Asante, M Mendall, P Patel, L Ballam, and TC Northfield.

Dept. of Medicine, St. George's Hospital Medical School, London. UK.

Background: The safety and savings in endoscopy derived from not endoscoping $H$. pylori seronegative dyspeptic patients has been demonstrated in short term studies of six month duration. The long term outcome of such a management strategy is not clear what. We report the final 12 month follow-up in a prospective randomised trial. for which we reported Interim results of this study has already been presented to the society. Design: 417 patients under the age of 45 years referred to a direct access endoscopy service were screened with a validated questionnaire and $H$. pylori serology (Helico-G ELISA). A cut off level of $6.3 \mathrm{u} / \mathrm{ml}$ had been previously determined to be suitable for screening. 154 patients $(56 \%$ male) had serology titres below $6.3 \mathrm{w} / \mathrm{ml}$ and were randomised to have either endoscopy or no endoscopy. All patients were returned to their GPs for further management. Patients with a history of weight loss of more than $1 / 2$ stone in 6 months, dysphagia, anaemia or persistent vomiting or on regular NSAIDs were excluded. Six and twelve month assessment was carried out by postal questionnaire.

Results: $120 / 154(79 \%)$ and 82/154 (53\%) questionnaires were returned at 6 and 12 months respectively. Table shows results at 12 months expressed as medians.

\begin{tabular}{|l|l|l|l|}
\hline & Endoscopy (43) & No Endoscopy (39) & P \\
\hline Symptom score & 1 & 1 & NS \\
\hline Disability score & 0 & 1 & NS \\
\hline Days off work & 0 & 0 & NS \\
\hline GP visit & 0 & 0 & NS \\
\hline Prescriptions score & 0 & 1 & NS \\
\hline Self medications score & 0 & 1 & 0.05 \\
\hline Specialist referral & $6 / 38(16 \%)$ & $13 / 34(38 \%)$ & 0.06 \\
\hline Endoscopy referral $(\mathrm{n})$ & & $6 / 39(15 \%)$ & \\
\hline
\end{tabular}

Summary: There were no significant differences in symptoms, disability, GP visits and prescriptions between the two groups. $46 \%(6 / 13)$ of the non endoscoped group referred for specialist consultations were endoscoped. At one year $85 \%$ of endoscopies were saved.

Conclusions: It is safe and more cost effective in the long term to manage young $H$. pylori negative dyspeptic patients without endoscopy. 
MARKED REBOUND ACID HYPERSECRETION FOLLOWING OMEPRAZOLE THERAPY IN $H$. PYLORI NEGATIVE SUBJECTS D. Gillen, A. Wirz, K.E.L. McColl. Univ. Dept. of Medicine \& Therapeutics, Western Infirmary, Glasgow, U.K.

Introduction: Rebound hypersecretion of gastric acid is a well established class effect of $\mathrm{H}_{2}$-antagonists. Previous studies have suggested that this phenomenon does not occur with proton pump inhibitors (PPIs). However, the effect may have been masked by PPI induced $H$. pylori body gastritis.

Aims: To establish whether rebound acid hypersecretion occurs with PPIs when subjects are stratified by $H$. pylori $(H . P$.) status

Subjects and Methods: $11 H . P .-v e$ and $7 H . P .+$ ve healthy volunteers were examined. Their $H . P$. status was determined by the ${ }^{14} \mathrm{C}$-urea breath test. Their basal acid output (BAO) and G17 stimulated maximal acid output (MAOG17) and maximal acid output in response to gastrin releasing peptide (MAOGRP) were measured before and 2 weeks after completing a 2 month course of omeprazole $40 \mathrm{mg} / \mathrm{day}$.

Results and Discussion:

\begin{tabular}{|c|c|c|c|c|c|c|}
\hline & $\begin{array}{r}H \\
\text { Pre-omep. }\end{array}$ & $\begin{array}{l}P \text { negati } \\
\text { Post-omep. }\end{array}$ & $\begin{array}{l}\text { ve } \\
\% \text { change }\end{array}$ & $\begin{array}{r}H . P . \\
\text { Pre-omep. }\end{array}$ & $\begin{array}{l}\text { positive } \\
\text { Post-omep. }\end{array}$ & \% change \\
\hline $\begin{array}{l}\text { BAO } \\
(\mathrm{mmol} / \mathrm{h})\end{array}$ & $\begin{array}{c}(\mathrm{n}=11) \\
4.6\end{array}$ & $\begin{array}{c}(\mathrm{n}=11) \\
7.5^{*}\end{array}$ & $+63.0 \%$ & $\begin{array}{c}(n=7) \\
4.9\end{array}$ & $\begin{array}{c}(n=)() \\
4.8\end{array}$ & $-2.0 \%$ \\
\hline $\begin{array}{l}\text { MAOG17 } \\
(\mathrm{mmol} / \mathrm{h})\end{array}$ & 31.6 & $41.2^{*}$ & $+30.4 \%$ & 32.5 & 39.3 & $+21 \%$ \\
\hline $\begin{array}{l}\text { MAOGRP } \\
(\mathrm{mmol} / \mathrm{h})\end{array}$ & 9.8 & $15.5^{*}$ & $+58.2 \%$ & 15.2 & 12.1 & $-20 \%$ \\
\hline
\end{tabular}

In the H.P.-ve subjects there was marked rebound hypersecretion of acid following omeprazole therapy apparent with each of the 3 acid secretion tests. There was no rebound hypersecretion of acid in the H.P.+ve subjects and this may be due to the body gastritis occurring in H.P.+ve subjects during omeprazole therapy impairing gastric acid secretion and thus masking the rebound phenomenon.

Conclusion: There is marked rebound hypersecretion of gastric acid following PPI therapy in $H$. pylori-negative, but not $H$. pylori-positive subjects.

REFLUX SYMPTOMS IN THE LONG TERM FOLLOW UP OF PATIENTS AFTER HELICOBACTER PYLORI ERADICATION AE Griffiths, MR Thursz, D Pryce, MM Walker. Departments of Gastroenterology and Histopathology, Imperial College School of Medicine at St Mary's, Norfolk Place, London W2.

Background Symptomatic relapse after $H$. pylori $(\mathrm{Hp})$ eradication in duodenal ulcer (DU) patients is common and is only rarely due to proven ulcer recurrence. Recent reports suggest that eradication of $\mathrm{Hp}$ is associated with the onset of gastro-oesophageal reflux disease (GORD) one to two years later.

Methods A questionnaire was sent to 85 individuals who had completed a similar questionnaire 2 years previously, just prior to $\mathrm{Hp}$ eradication. This included questions about symptomatology, medication, weight and smoking and alcohol history. Eradication was confirmed by ${ }^{13} \mathrm{C}$ urea breath test at follow up.

Results 45 patients returned the questionnaire (53\% response). 32 were from patients known to have cleared $\mathrm{Hp} ; 20$ of these had DU originally, 19 were male and median age was 55 (range 25-79). The remaining 13 replies were from patients who had not cleared $\mathrm{Hp}$ ( 5 patients) or in whom a breath test result was unavailable ( 8 patients); 3 had DU, 5 were male and median age was 57 (range 32-82). In the Hp eradicated group with DU $9 / 20(45 \%)$ had heartburn/reflux symptoms at 2 years follow up. However $17(85 \%)$ had these symptoms prior to treatment. In the nonDU. Hp eradicated patients the figures were similar with $75 \%$ having heartburn pre-treatment and $42 \%$ at 2 years. In the non-eradicated group the corresponding frequencies of heartburn were $54 \%$ initially and $38 \%$ at 2 years. No individual in any group developed heartburn/reflux symptoms during 2 years of follow up. Other findings were that $65 \%$ of 32 successfully treated patients remained symptomatic at follow up, with $53 \%$ still requiring medication, chiefly antacids. $9 \%$ stated that their symptoms are worse now than they were before treatment. Changes in weight or in alcohol consumption had no bearing on current symptoms though increased cigarette smoking was associated with fewer symptoms. Conclusions Contrary to previous reports we have found no evidence of new symptoms of GORD in the long-term follow up of patients undergoing $\mathrm{Hp}$ eradication for DU or for other Hp related conditions.
RANITIDINE TREATMENT INDUCES DYSPEPSIA IN PREVIOUSLY ASYMPTOMATIC HEALTHY VOLUNTEERS A. Smith, D. Gillen, K. Cochran, E. El-Omar, K.E.L. McColl. University Dept. of Medicine \& Therapeutics, Western Infirmary \& Victoria Infirmary, Glasgow, Scotland.

Background: Dyspeptic symptoms frequently rapidly recur following cessation of $H$ receptor antagonist therapy. We have previously shown that in $\boldsymbol{H}$. pylori +ve healthy volunteers basal and gastrin releasing peptide (GRP) stimulated acid secretion are increased by $96 \%$ and $56 \%$ respectively 3 days after completing a two month course of ranitidine $300 \mathrm{mg}$ nocte compared to pre-treatment values (Am. J. Gastroenterol., 1996; 91: 355-359). It is unknown whether this rebound acid hypersecretion causes dyspeptic symptoms.

Aim: To determine whether cessation of $\mathrm{H}_{2}$ antagonist treatment results in the de novo development and/or aggravation of dyspepsia.

Subiects and Methods: Thirty $\boldsymbol{H}$. pylori positive healthy volunteers were randomised in a double blind fashion to receive either ranitidine $300 \mathrm{mg}$ nocte or placebo tablets for two months. All subjects had $H$. pylori infection confirmed using serology and ${ }^{13} \mathrm{C}$-urea breath test. The two groups were matched for age, sex, body weight, smoking and alcohol consumption. Dyspeptic symptoms were measured using a validated questionnaire. Symptoms were scored for one week prior to entry into the study and for the 10 days following cessation of the treatment.

Results: Compliance was similar in the two groups (active 95\%, placebo $98 \%, p=N S$ ). The mean dyspepsia score before treatment was 0.86 in the active group and 0.53 in the placebo group $(p=N S)$. The mean dyspepsia score for the 10 days after stopping treatment was 5.4 (range $0-30$ ) in the active group and 0.93 (range: $0-9$ ) in the placebr group $(\mathrm{p}<0.03)$. 53\% experienced dyspepsia in the 10 day period following active therapy versus $13 \%$ following placebo.

Conclusions: These results indicate that a two month course of ranitidine $300 \mathrm{mg}$ nocte is followed by the development of new dyspeptic symptoms in $H$. pylori positive healthy volunteers. This finding indicates that rebound acid hypersecretion following withdrawal of $\mathrm{H}_{2}$ antagonist therapy is of clinical significance. It is now important to determine whether the dyspepsia is due to the rebound acid hypersecretion causing acute peptic ulceration.

The higher acid response to gastrin in H.P.+ve DU patients versus infected $\boldsymbol{H}$.V. is predominantly due to a reduced sensitivity to gastrin in the infected HVs when compared with both DU patients and uninfected HVs (i.e. true normals). This reduced sensitivity to gastrin in the infected non-ulcer subjects may be due to $H$. pylori body gastritis. The DU patients also had a slightly increased PCM. There was no evidence of impaired CCK mediated inhibitory control of body function in the DU patients. The apparently enhanced inhibitory control in the H.P.+ve HV can be explained by their lesser sensitivity to gastrin.

Conclusion: The two-fold difference in acid response to gastrin

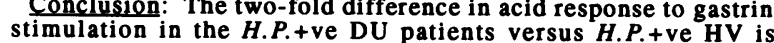
predominantly due to impaired sensitivity to gastrin in the infected HVs. 
NON-STEROIDAL ANTI-INFLAMMATORY DRUGS AND HELICOBACTER PYLORI AS INDEPENDENT RISK FACTORS FOR PEPTIC ULCER BLEEDING GM Hawkey, S Everitt, GM Pearson, WA Stack, CJ Hawkey. GI Trial Service, Division of Gastroenterology, University Hospital, Nottingham NG7 2UH, UK.

INTRODUCTION: Non-steroidal anti-inflammatory drugs (NSAIDs) and Helicobacter pylori both cause peptic ulcer and its complications. Indirect and retrospective data, however, suggest that these two factors may act independently. The Nottingham "NSAID or Helicobacter Outcomes as Peptic Emergency Referral" Study is a large ongoing investigation of the interaction of NSAIDs and H. pylori in peptic ulcer bleeding.

METHODS: Drug history (structured interview) and $H$. pylori serological status (Premier ELISA) were established prospectively in consecutive patients and hospital controls. The controls were matched for age and sex and selected to avoid distortion of background population NSAID usage. We report data from the first 256 subjects.

RESULTS: Cases and controls were well matched for age (Table) and sex. $H$. pylori infection and NSAID use was significantly higher in cases than controls. These subjects were more likely to have a past history $(\mathrm{PH})$ and to report pain prior to admission.

$\begin{array}{lccccc} & \text { Mean Age } & H p+ & \text { NSAID } & \text { PH Pain } \\ \text { Controls } & 68 & \mathbf{4 8 . 1 \%} & 28.3 \% & 13.5 \% & 21.7 \% \\ \text { Cases } & 66 & 77.8 \% * * & 53.8 \% & 24.8 \% * & 62.1 \% * * * \\ & { }^{*} p<0.05, * * p<0.01, * * * p<0.001 & & & \end{array}$

ABO blood group did not differ significantly between cases and controls. Twenty-three percent of patients positive by serology had a negative CLO test, not explained by recent drug use. Half of the NSAID usage in both cases and controls was aspirin, often as low dose cardiovascular prophylaxis.

Logistic regression analysis identified $H$. pylori and NSAIDs as the main determining factors. The relative risk associated with NSAID usage was 4.23 (95\% CI 1.47-12.15, $\mathrm{p}=0.01)$, with $H$. pylori $2.78(0.98-7.97 \mathrm{p}=0.06)$ and for the interaction $0.18(0.02-1.48, p=0.11)$.

CONCLUSIONS: NSAID exposure remains high, is now often due to aspirin and causes substantial ulcer morbidity. H. pylori is a significant risk factor which may be under-diagnosed by CLO test in bleeding patients but which shows no evidence of positive synergy with NSAID usage.

ULCER DEVELOPMENT IN LONG TERM NSAID USERS IN THE PRESENCE OR ABSENCE OF GASTRIC NEUTROPHILS. A DOUBLEBLIND PLACEBO-CONTROLLED STUDY. A S Taha, S Dahill,C Morran, N Hudson,C J Hawkey,F D Loe,R D Sturrock, R I Russell. Departments of Gastroenterology,Pathology,and Rheumatology,Royal Infirmary,Glasgow, and University Hospital ,Nottingham,U.K.

The link between gastric neutrophils and NSAID ulcers remains unclear in humans, particularly the long term users of NSAID. To investigate the effect of base-line gastric mucosal neutrophils on future ulcer development in such patients,gastric antral biopsies were taken from 120 patients using NSAIDs, for a minimum of 4 weeks, who had no ulcers at base-line endoscopy. Patients were followed up with regular endoscopies for 6 months after being randomised, under double-blind conditions, to receive placebo, famotidine 20 or $40 \mathrm{mg}$ bid for ulcer prophylaxis. Biopsies, carrying code numbers, were analysed for neutrophils count(0-3/field), other inflammatory cells and features, and for $H$ pylori (by histology, culture, and urease activity).

Results: The ulcer incidence at the completion of the study, in the absence(NEUT $=0$ ) or presence (NEUT >0) of neutrophils, was as follows:

\begin{tabular}{|c|c|c|c|}
\hline $\begin{array}{c}\text { UT }=0 \text {. Ulcer incidence } \\
95 \% \text { confidence } \\
\text { intervals } \\
\text { Patients with ulcers }\end{array}$ & $\begin{array}{c}\text { Placebo } \\
7.7 \% \\
0.0 \%-22.2 \%\end{array}$ & $\begin{array}{c}\text { Famotidine 20mg } \\
12.5 \% \\
0.2 \%-32.0 \%\end{array}$ & $\begin{array}{c}\text { Famotidine 40mg } \\
0.0 \% \\
0.0 \%-20.6 \%\end{array}$ \\
\hline $\begin{array}{l}\text { TT>0. Ulcer incidence } \\
95 \% \text { confidence } \\
\text { intervals }\end{array}$ & $\begin{array}{r}47.4 \%\left({ }^{*}\right) \\
28.5 \%-66.2 \%\end{array}$ & $\begin{array}{c}12.6 \% \\
0.0 \%-26.0 \%\end{array}$ & $\begin{array}{c}13.0 \% \\
2.8 \%-33.6 \%\end{array}$ \\
\hline Patients with ulcers & $13 / 28$ & $3 / 26$ & $3 / 23$ \\
\hline
\end{tabular}

$\left(^{\star}\right): P<0.001, \log$ rank test. $\mathrm{P}=0.017$, adjusted for treatment differences. Eight of $46(8 / 46,17 \%)$ patients without $H$ pylori had gastric neutrophils, compared with 69/74 (93\%) with both $H$ pylori and neutrophils $(\mathrm{P}<0.001)$.

Conchusions the presence of gastric mucosal neutrophils, with or without $H$ pylori, significently increases the risk of future ulceration in long term NSAID users. However, neutrophils are more likely to exist in the presence of $H$ pylori gastritis.
W16

LOW GASTROINTESTINAL TOXICITY OF MELOXICAM, A SELECTIVE INHIBITOR OF THE INDUCIBLE CYCLOOXYGENASE (COX-2) ENZYME CJ Hawkey, Division of Gastroenterology, University Hospital, Nottingham NG7 2UH, UK, for the International MELISSA Study Group.

INTRODUCTION: Recognition of two cyclooxygenase (COX) isoforms has stimulated development of selective inhibitors of COX-2 (induced in inflammation and responsible for arthritic symptoms), which leave gastro protective COX-1 prostaglandin synthesis unimpaired. We compared meloxicam a selective COX-2 inhibitor with diclofenac for efficacy and safety.

METHODS: Patients with oesteoarthritis requiring pain relief were randomised to receive meloxicam $7.5 \mathrm{mg}$ daily $(\mathrm{n}=4628)$ or diclofenac $\mathrm{SR}$ $(\mathrm{n}=4685) 100 \mathrm{mg}$, both given once daily under double blind conditions for one month. Comparative efficacy was assessed by visual analogue scale, and other measures. All adverse events, including perforations, ulcers, bleeds (PUBs) and hospitalisations were rated for severity and relationship to drug. RESULTS: Both drugs were equally effective (visual analogue scale for pain on active movement $30.3 \pm 27 \mathrm{ml}$ meloxicam vs $32.5 \pm 26 \mathrm{ml}$ for diclofenac) but meloxicam caused fewer adverse events.

$\begin{array}{lcl}\text { All adverse events } & \text { Meloxicam } & \text { Diclofenac } \\ \text { Gastrointestinal adverse events } & 27 \% & 32 \% * * \\ \text { Withdrawal, lack of efficacy } & 13 \% & 19 \% * * \\ \text { Withdrawal, GI adverse events } & 1.7 \% & 1.0 \% \\ \text { PUBs (n) } & 2.7 \% & 5.9 \% * * \\ & 5 & 7\end{array}$

There was significantly less dyspepsia, abdominal pain, nausea/vomiting and diarthoea with meloxicam.

CONCLUSTONS: Meloxicam a selective COX-2 inhibitor, is as effective in oesteo arthritis as diclofenac but associated with fewer GI adverse events. 
RESISTANCE OF HBLICOBACTER PYLORI TO METRONIDAZOLE: AN IMAGINARY PROBLEM?

BATESON, M.C.. WINN, G. \& AHMAD, F.

GENERAL HOSPITAL, BISHOP AUCKLAND, UK.

Concern has been raised that $\mathrm{H}$. pylori might exhibit both primary and secondary resistance to nitro-

imidazoles, making these drugs less useful in therapy.

In 1992/3 102 unselected patients not on antibiotics for at least 2 months had gastric antral forceps biopsy taken at gastroscopy. These were sent in transport medium for micro-aerophilic culture for 5-7 days, and then subcultured with antimicrobial discs for 3 days to test sensitivity. None were resistant to amoxycillin or tetracycline, 2 were resistant to erythromycin and clarithromycin, and 19 were resistant to metronidazole.

In 199694 patients had gastric antral forceps biopsies cultured. Antimicrobial sensitivity was assessed using E-test strips. Metronidazole sensitivity was tested with a 24 hour preliminary anaerobic culture. None were resistant to amoxycillin, 1 to tetracycline, 2 to clarithromycin, and only 2 to metronidazole.

\section{$\frac{\text { RESULTS OF B-TESTING }}{\text { (n }=94 \text { patients) }}$}

\section{ANTIBIOTIC}

SENSITIVITY

\section{MIC $(\mathrm{mg} / 1)$}

Amoxycillin

Tetracycline

Clarithromycin

$100 \%$
$99 \%$
$98 \%$
$98 \%$

$0.016(<0.016-0.64)$

$0.016(<0.016-0.5)$

$<0.016(<0.016-0.016)$

$0.032(0.002-6)$

Because of the discrepancy 37 cultures were tested for metronidazole sensitivity using both micro-aerophilic disc culture and E-testing with preliminary anaerobic culture. Eight cultures showed apparent resistance to metronidazole on disc testing (MIC $>5 \mathrm{mg} / \mathrm{l}$ ), but were all sensitive on E-testing (MIC $0.002-0.5 \mathrm{mg} / 1$ ).

CONCLUSION , - Metronidazole resistance to microaerophilic disc testing is a laboratory artefact, not reflecting true insensitivity to therapy.
HELICOBACTER PYLORI ERADICATION THERAPY COMPARED WITH RANITIDINE MAINTENANCE THERAPY IN PATIENTS WITH CHRONIC DUODENAL ULCER DISEASE: A PROSPECTIVE PHARMACOECONOMIC EVALUATION. A T Prach', $^{1}$ M Malek', D Hopwood ${ }^{3}$, B W Senior 4 , F E Murray' University Departments of Clinical Pharmacology ${ }^{1}$, Pathology ${ }^{3}$ and Medical Microbiology ${ }^{4}$, Ninewells Hospital, Dundee and Department of Management ${ }^{2}$, University of St Andrews.

Although eradicating Helicobacter pylori $(H p)$ infection in duodenal ulcer (DU) disease is widely practised, there are few prospective studies evaluating the cost-effectiveness of this approach. The aim of this study was to compare the health care costs over one year in two groups of patients with chronic DU who received either $H p$ eradication therapy or maintenance therapy using ranitidine. Methods. Patients with active $H p$ infection were randomised to receive either $150 \mathrm{mg}$ ranitidine, daily $[n=$ 58] or, $H p$ eradication [ $n=61$ ] using OAM (omeprazole $40 \mathrm{mg} / \mathrm{d}$, amoxycillin $2 \mathrm{G} / \mathrm{d}$, metronidazole $1.2 \mathrm{G} / \mathrm{d}$; for 14 days), or OC (omeprazole $40 \mathrm{mg} / \mathrm{d}$, clarithromycin $1.5 \mathrm{G} / \mathrm{d}$; for 14 days), if penicillinallergic. Eradication patients underwent ${ }^{13} \mathrm{C}$ urea breath testing to confirm success. Patients in both groups were managed according to good clinical practice and investigated if symptoms worsened. Health care costs in each group were quantified. Results. Hp eradication rates:-

\begin{tabular}{|c|c|c|c|c|c|c|}
\hline & \multicolumn{3}{|c|}{ Per protocol } & \multicolumn{3}{|c|}{ Intention-to-treat } \\
\hline & Eradi & ation rate & $95 \% \mathrm{CI}$ & Era & ation rate & $95 \% \mathrm{CI}$ \\
\hline OAM & $58 / 58$ & $(100 \%)$ & $0.92-1.00$ & $56 / 59$ & $(94.9 \%)$ & $0.85-0.99$ \\
\hline OC & $2 / 2$ & $(100 \%)$ & $0.20-1.00$ & $2 / 2$ & $(100 \%)$ & $0.20-1.00$ \\
\hline Overall & $60 / 60$ & $(100 \%)$ & $0.92-1.00$ & $58 / 61$ & $(95.1 \%)$ & $0.85-0.99$ \\
\hline
\end{tabular}

Two patients failed eradication therapy because of side-effects (and withdrew). Another did not attend for breath testing and was lost to follow-up. At one year, of those randomised to eradication therapy, 49/61(80.3\%; CI 0.68-0.89) no longer took ulcer-healing drugs. The mean annual per patient health care costs were: $£ 249$ for maintenance therapy and $£ 217$ for eradication therapy. Conclusion. Hp eradication saved $£ 32$ in the first year of treatment. The saving in subsequent years is likely to be much greater because of reduced ulcer-healing drug prescribing and investigation costs.

\section{THE OPTIMUM 5 DAY THERAPY AGAINST}

HELICOBACTER PYLORI. P Moayyedi, H Langworthy*,

DS Tompkins**, N Mapstone, DM Chalmers, ATR Axon. Centre for Digestive Diseases, General Infirmary at Leeds, ${ }^{*}$ Lederle

Laboratories, Hampshire, ${ }^{* *}$ Dept. Public Health Medicine, Leeds, UK

Introduction: $H$ pylori therapy is usually given for at least 7 days. A shorter regimen would be cheaper and better tolerated. We have investigated the optimum 5 day therapy with various combinations of lansoprazole $30 \mathrm{mg}$ bd $(\mathrm{L})$, clarithromycin $250 \mathrm{mg}$ bd (C), amoxycillin $1 \mathrm{~g}$ bd (A) and metronidazole $400 \mathrm{mg}$ bd (M). Methods: Patients attending the dyspepsia clinic who were $H$ pylori positive as assessed by histology, rapid urease test, microbiology and ${ }^{13} \mathrm{C}$-urea breath test $\left({ }^{13} \mathrm{C}\right.$-UBT) were randomised to receive 5 days of either LCM, LAC or LACM. The investigator was blinded to the treatment group. Success of treatment was evaluated by ${ }^{13} \mathrm{C}-\mathrm{UBT}$ at least 4 weeks after completion of therapy. Results: 143 patients were recruited to the study (mean age $53 \pm 14$ years, range 21-80, $52 \%$ male). Culture was successful $84 \%$ of cases with $51 \%$ harbouring metronidazole resistant strains. There was no statistical difference in age, gender or smoking between the 3 groups. Eradication rates were higher in the LCM group (38/45 - 84\%) than the LAC group (29/47 - 62\%; $p=0.02$ Fisher's exact test). LCM was less effective against metronidazole resistant organisms (eradication rate $13 / 19-68 \%)$ than sensitive organisms (13/14 - 93\%). Treatment was successful in $46 / 51(90 \%)$ patients taking LACM. There was a trend towards adverse events being more common in the LACM group $(50 \%)$ than the LCM or LAC groups $(36 \%)$ but this did not reach statistical significance $\left(p=0.2 \chi^{2}\right)$. Conclusions: LCM is more effective than LAC in eradicating $H$ pylori. Adding amoxycillin to LCM may improve efficacy but increase adverse events. Five days of LCM appears as efficacious as 7 day regimens for metronidazole sensitive strains of $H$ pylori but is less effective against resistant organisms.
RANITIDINE BISMUTH CITRATE PLUS CLARITHROMYCIN AND TETRACYCLINE: A SEVEN-DAY HELICOBACTER PYLORI ERADICATION REGIMEN. M Williams, J Sercombe, R E Pounder, Royal Free Hospital School of Medicine, London NW3 2QG.

Introduction: The ideal regimen for treating Helicobacter pylori $(H$. pylori) infection needs to be simple, short duration and well tolerated. It should give reproducible and high levels of eradication on an "intention-to-treat" basis. Dual therapy with ranitidine bismuth citrate plus clarithromycin for fourteen days is a highly effective regimen for eradicating $H$. pylori infection.

Aim: To determine whether, with the addition of a second antibiotic, it may be possible to reduce the duration of treatment with ranitidine bismuth citrate to seven days and yet maintain a high eradication rate.

Methods: A total of $\mathbf{4 8}$ dyspeptic patients were enrolled to this open treatment study. All were infected with $H$. pylori, as determined by ${ }^{13} \mathrm{C}$ urea breath test $+/$ - a rapid urease test at endoscopy. Patients were treated with twice daily ranitidine bismuth citrate $400 \mathrm{mg}$, clarithromycin $500 \mathrm{mg}$ and tetracycline hydrochloride $500 \mathrm{mg}$, all for 7 days. $H$. pylori eradication was assessed by ${ }^{13} \mathrm{C}$ urea breath test at least 28 days after the completion of treatment. Adverse events were assessed by patient interview with all events mentioned, either sponteneously or on direct questioning, considered significant.

Results: Successful eradication of $H$.pylori was achieved in $43 / 48$ (90\%). Compliance was $>90 \%$ in $47 / 48(98 \%)$ : 1 patient stopped treatment after 2 days due to vomiting. Minor adverse events were reported by 24 of the remaining 47 patients $(51 \%)$ - these were loose stools $(31 \%)$, nausea $(17 \%)$, taste disturbance $(10 \%)$, vomiting $(2 \%)$, sore mouth (2\%) and vaginal candida (2\%).

Conclusion: Triple therapy with ranitidine bismuth citrate $400 \mathrm{mg}$, clarithromycin $500 \mathrm{mg}$ and tetracycline $500 \mathrm{mg}$, all twice daily for seven days, is a safe well-tolerated treatment regimen that eradicates $H$. pylori infection in $90 \%$ of patients on a strict intention-to-treat analysis. 
EFFECT OF $H$. PYLORI, ASPIRIN \& ANOXIA ON ANTIBIQTIC PERMEABILITY IN THE RAT STOMACH. AF Goddard, PO Erah, JC Atherton, PN Shaw, DA Barrett \& RC Spiller. Division of Gastroenterology, University Hospital, Nottingham. UK.

Background The flux of amoxycillin (AMO) across normal gastric mucosa in vivo and in vitro is $10 \%$ that of metronidazole (MET). The effect of gastric mucosal injury (as in $\mathrm{H}$. pylori ( $\mathrm{Hp}$ ) gastritis) on the flux of either antibiotic is unknown.

Aims To study the effect of mucosal injury caused by toxigenic and non-toxigenic Hp strains on the gastric mucosal flux of MET and AMO and compare this with the effect of aspirin and anoxia.

Methods Gastric mucosal flux $\left(\mathrm{nmol} . \mathrm{hr}^{-1} . \mathrm{cm}^{-2}\right)$ was assessed using a previously validated Ussing chamber method. Serosal to mucosal flux from $1 \mathrm{mM}$ solution of antibiotic was measured over $60 \mathrm{~min}$ under baseline (control) conditions and with the following added to the mucosal chamber $(n=8): 1$ ) sonicate of a toxigenic cagA+ Hp isolate from a DU patient (J258); 2) sonicate of a non-toxigenic cagA- Hp isolate (T×30a); 3) $2 \mathrm{mM}$ aspirin; 4) $20 \mathrm{mM}$ aspirin; 5) $\mathrm{N}_{2}$ instead of $\mathrm{O}_{2} / \mathrm{CO}_{2}$, thus making the mucosa anoxic. Fluxes were compared using non-parametric analysis. Light microscopy was performed to assess mucosal damage.

Results

$$
\text { Flux [mean(SEM)] }
$$$$
\text { Amoxycillin Metronidaz }
$$

$\begin{array}{lrr}\text { Control } & 2.4(0.3) & 20.3(3.5) \\ \text { J258 } & 2.5(0.6) & 35.6(3.1)\end{array}$

J258 (cagAt) $2.5(0.6) \quad 35.6(3.1)^{\star \star *}$

Tx30a (cagA-) $2.1(0.3)$

Anoxia $4.7(0.8)$

$17.8(1.5)$

$2 \mathrm{mM}$ aspirin

$<0.3^{* * *}$

$25.3(4.2)$
$21.2(7.7)$

$17.9(1.6)$

\section{Histological \\ Damage \\ none \\ minimal \\ minimal \\ severe}

* $P<0.02$, ** $P<0.01$, *** $P<0.001$

Conclusions 1) AMO permeates gastric mucosa by a different pathway than MET. 2) Toxigenic cagA+, but not non-toxigenic cagA$H p$ increases MET permeation in vitro. 3) Increased MET permeation is not secondary to epithelial cell junction damage (which is maximal in anoxic and aspirin treated tissue).

AFG is in receipt of an Astra Research Fellowship
ROLE OF HELCOBACTER PYLOR IN GASTRIC ADAPTATION TO REPEATED ASPIRIN ADMANISTRATION IN MAAN. J.W. Konturek, A. Dembinski, W. Fuchs, J.Elbert, S.J. Konturek and W. Domschke. Department of Medicine B, University of Münster, Münster, Germany,
Institute of Physiology, Jagiellonian University, Kraków, Poland, Takeda Pharma, Aachen, Germany.

Background: The phenomenon of gastric adaptation after repeated exposures to ASA is well documented in animals and in humans. The role of Helicobacter pylori (H.pylorn) as a possible pathogenic factor of NSAID. induced gastropatthy remains controversial. Aim: This study was designed 1) to evoke the gastric adaptation in response to repeated exposure to ASA in the same subjects before and after eradication of $H$.pylori and 2) to examine the morphological and functional changes of gastric muccosa during the 14 days treatment with ASA in subjects with and without the presence of H.Pylor infection. Material and lithods: Eight healthy volunteers (age 19-27) with H.pylori infection and no gastrointestinal symptoms, were given ASA $1 \mathrm{~g}$ b. i.d. during 14 days. day using moditied Lanza score. During each endoscopy mucosal blood flow was measured using laser-Doppler fiowmeter. Mucosal biopsies were obtained for estimation of DNA synthesis by measuring $\mathrm{H}$-thymidine incorporation into DNA. Prior to each endoscopy the gastric microbleeding was determined in three consecutive gastric washings. Throe months after successful eradication of H.pylon (amoxicillin + clarithromycin + lansoprazole) confirmed by ${ }^{3} \mathrm{C}$-urea breath test and mucosal rapid urease (CLO) test the same subjects received again the 14 days treatment with ASA at the same dosage and underwent the same examinations as prior to the antimicrobial therapy (lansoprazole+ amoxicillin+clarithromycin). Results: In subjects with H.pylori infection ASA induced acute gastric mucosal damage mainly in gastric corpus; the endoscopic Lanza score reached maximum at 3rd day and remained unchanged at 7 th and 14 th day of ASA treatment. After H.pylori eradication ASA-induced acute gastric mucosal damage also reached its maximum at 3 rd day but then declined to fall on day 14 to about $25 \%$ of initial peak thus contirming the occurrence of adaptation. Mucosal blood flow was significantly higher before than after H.pylori eradication and in both cases it significantly increased on 3rd and 7th day. Before ASA administration DNA synthesis was similar in subjects before and after eradication of H.pylon, however the DNA synthesis rate showed significant increase on day 7 of ASA reached its maximum in the 3 rd day of ASA treat Gastric microbleeding reached its maximum on the 3rd day of ASA treatment being significantly This microbleeding decreased to almost in those with H.pylon infection. This microbleeding decreased to almost normal values by the end of the study in H.pyon-eradicated subjects but remained significantly elevated in H.pylon infected subjects. Conclusions: 1) Gastric adaptation to ASA is impaired in H.pylon-positive subjects but eradication of H.pylori restores tumover in response to ASA synthesis and possibly also mucosal cel and this can be reversed by eradication of $H$.pylori.

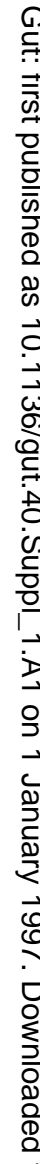

FACTORS ASSOCIATED WITH HELICOBACTER PYLORI INFECTION AND DUODENAL ULCERS IN PATIENTS ATTENDING ENDOSCOPY.

A.Oshowo, A.Botha, H.Mumtaz, D.Gillam ${ }^{1}$, J.Holton', P.Boulos, M.Hobsley. Depts. of Surgery, Microbiology ${ }^{2}$ and Eastman Dental Institute', University College London Medical School, London.

Helicobacter pylori (H. pylori) is associated with peptic ulcer diease. However, associations with $H$. pylori infection itself and with duodenal ulcer (DU) disease itself need to be compared and evaluated for their aetiological significance.

450 case-notes of unselected patients attending the Endoscopy Clinic during the period 1993/94, were retrieved and the following variables were recorded:- sex, age, smoking; diagnosis as DU,oesophagitis, non-ulcer dyspepsia(NUD), other macroscopic lesions; number of endoscopies; previous and present record of diagnosis and treatment of $H$. pylori infection. The results, analysed by logistic regression analysis, were:

\section{Associated with DU: $\quad$ 2. Associated with $H$. pylori:}

$\begin{array}{llll}\text { factor } & \mathrm{p}< & \text { factor } & \mathrm{P}< \\ \text { age } & 0.001 & \text { sex(male) } & 0.0001 \\ \text { smoking } & 0.0001 & \text { no.endoscopies } & 0.0001 \\ \text { H. pylori } & 0.0138 & \text { ocso.(neg.) } & 0.0043 \\ \text { no.endoscopies } & 0.0122 & \text { NUD } & 0.0236 \\ & & \text { DU } & 0.0156\end{array}$

Conclusions: Smoking remains strongly associated with DU. Oesophagitis is negatively associated with $H$. pylori. It is interesting however, that the number of endoscopy a patient has undergone positively influence $H$. pylori status. The nature of this link between $H$. pylori infection and the number of endoscopies is uncertain and requires further investigation, but these facts support a previously published study.
MOTILITIS OF ULCER AND NONULCER ASSOCIATED STRAINS OF Helicobacter pylori. M Worku, L Ashton, RL Sidebotham*, RPH Logan* and QN Karim, Departments of Microbiology and Gastroenterology*, St. Mary's Hospital Medical School, London,

Background Motility is a colonization factor for Helicobacter pylori (Hp). presumably because it enables the bacterium to cross the viscid mucus layer to the mucosal surface where it damages epithelial cells by attachment and cytotoxin release. The density of $H p$ at the mucosal surface in the gastric antrum is significantly greater in patients with duodenal uber (DU) than with non - ulcer dyspepsia (NUD). We have investigated whether this important difference in colonization is due to an inherent difference in motility between ulcer and nonulcer associated Hp strains

Methods Helicobacter pylori were isolated from endoscopic biopsies of patients with DU and NUD and culured in presence of $8 \% \mathrm{CO}$ at $37^{\circ} \mathrm{C}$ in brain heart infision broth supplemented with calf serum and made selective with antibiotics. Bacterial motility was quantitatively measured in real time with a Hobson BacTracker in broth (DU $n=14 ; N U D n=13$ ) at different phases of the growth cycle, and also in methyl cellulose (MC) of molecular weight $14 \mathrm{Kd}$ (DU $n=6$; NUD $n=6$ ), ranging in viscosity from 5 - 50 centipoises (cp) to simulate the high viscosity of the gastric mucus layer. Data are reported as curvilinear velocity (CLV, $\mu \mathrm{m} / \mathrm{s})$, straight line velocity (SLV, $\mu \mathrm{m} / \mathrm{s})$ and track linearity (ratio SLV/CLV). Statistics are by Mamn-Whitney U-test.

Results (1). Motilities of 4 p from DU and NUD patients, when expressed as CVL and track linearity, were not significantly different from each other when measured in broth or in MC. (2). Helicobacter pylori were, however significantly $(p<0.01)$ more motile in broth when in log-phase than in lag or stationary phases of growth [mean CLV; lag phase 5.9 (DU) and 5.9 (NUD) $\mu \mathrm{m} / \mathrm{s}, \log$ phase 28.7 and $28.4 \mu \mathrm{m} / \mathrm{s}$, stationary phase 6.3 and $6.4 \mu \mathrm{m} / \mathrm{s}]$. (3). Motility of $H p$ in $\log$-phase decreased significantly $(p<0.01$ ) when the bacteria were transferred from broth (mean CLV 28.9 (DU) and 26.8 (NUD) $\mu \mathrm{m} / \mathrm{s}$ ), to MC viscosity $30 \mathrm{cp}$ (mean CLV 5.7 and $5.8 \mu \mathrm{m} / \mathrm{s}$ ), and ceased in MC viscosity 50 cp (mean CLV 4.7 and $4.9 \mu \mathrm{m} / \mathrm{s}$ - Brownim movement only). (4). Track linearity of $\mathrm{Hp}$ in $\log$ phase was also significantly greater $(p<0.01)$ in MC viscosity $30 \mathrm{cp}$ [ 0.91 (DU) and 0.89 (NUD)] than in broth (0.38 and 0.34 ).

Conclusion The greater density of $\mathrm{Hp}$ at the antral mucosal surface in DU patients when compared with NUD patients is not due to an inherent difference in motility of the ulcer and non - ulcer associated strains: log phase Hp exhibit slow - limear motility in high viscosity medium irrespective of source. 
BACTERIAL CagA STATUS IS UNRELATED TO GASTRIC FUNCTION INDEXES OR TO THE TYPE EITHER SEVERITY OF SYMPTOMS IN PATIENTS WITH H.PYIORIPOSITIVE NON-ULCER DYSPEPSIA (NUD).

F.Parente, V.Imbesi,G.Maconi,C.Cucino,O.Sangaletti,G.Bianchi Porro. Gastrointestinal Unit, L.Sacco University Hospital, Milan, Italy

It has been widely shown that H.pylori (HP) infection induces disturbances of gastric function in patients (pts) both with duodenal ulcer and NUD. Little is known, however, about a possible relationship between such disturbances and the bacterial strains. Aim of this study was to assess whether gastric function parameters and dyspeptic symptoms are related to CagA status.

Methods. 38 consecutive pts with HP-positive NUD were examined They had suffered from dyspepsia for $>6$ months and none of them had macroscopic lesions at upper GI endoscopy. HP positivity was determined by means of histology and urease rapid test on antral biopsies and ${ }^{13} \mathrm{C}$-urea breath test. No pt had undergone previous antiHP therapy and any medication was discontinued at least 3 weeks prior to the study. Dyspeptic symptoms were classified into 3 different categories according to the predominant complaint, and scored for severity from 0 to 3 . In all subjects basal (BAO) and pentagastrin stimulated acid output (MAO), fasting and meal-induced gastrin concentrations, fasting pepsinogen I (PG I) levels and gastric emptying of solids (by means of ultrasounds) were measured. CagA status was determined indirectly by assaying serum CagA IgG antibodies by commercial Western-Blotting (Helico-Blot,Genelabs).

Results. 17 of 38 NUD pts were CagA seropositive (45\%). Mean BAO and MAO values of CagA seropositive pts $(3.0 \pm 2.8$ and $20.4 \pm 7.6$ $\mathrm{mmol} / \mathrm{h}$, respectively) were comparable to those of seronegative pts (3.8 \pm 2.5 and $23.5 \pm 7.3$ ). No significant differences were found in fasting $(55.9 \pm 14.4$ vs $57.2 \pm 11.6 \mathrm{pg} / \mathrm{ml})$ and stimulated gastrin levels [23370 (AUC) vs 21719] between the two groups. Similarly, gastric emptying of solids as well as the type and severity of dyspeptic symptoms did not significantly differ in the two groups of pts. In contrast, fasting PG I levels were higher in seropositive than seronegative pts $(98.8 \pm 33$ vs $79.4 \pm 32.6 \mathrm{ng} / \mathrm{ml}, \mathrm{p}=0.07)$, concomitantly with a higher degree of antral inflammation at histology.

Conclusions. Our findings indicate that gastric function disturbances associated with HP infection and the type and severity of symptoms in NUD pts are independent of bacterial CagA status
W27

DETECTION OF HELCORACTER PYLORI FROM GI SECR TTIONS USING PCR.

A.Oshowo, J.Holton', D.Gintm ${ }^{2}$, A.Botha, P.Boulos, M.Hobaley.

Depts. of Surgery, Microbiology ${ }^{1}$ and Eastman Dental Institute',

University College London Medical School, London.

Introdnction- Oratord and oratfacesl spread hrve been surgested as the route of tranmiasion of Helicobacter pylori(HP). However, the source and route of transmiscion remin largely uninown.

Ain-To investionte secretions from the upper GI tract for tranemingion potentivl in HP infection.

Method-Sixty patients referred for routine endoscopy for dyapeptic symptom were studied. 3 gatric biopsies were taken for culture and the rapid urease teat. Gaxtric juice and duodena'(D2) aspirate were collocted for culture and PCR

Rearits-

$$
\text { HP previlence }(\%), n=60
$$

$\begin{array}{llll}\text { Gastric biopsy } & \frac{\text { Culture }}{20(33 \%)} & \frac{\text { PCR }}{33(55 \%)} & \frac{\text { Urease test }}{21(35 \%)} \\ \text { Gastric juice } & 0 & 9(15 \%) & - \\ \text { Duodenal asp. } & 0 & S(8 \%) & -\end{array}$

In summary, HP could not be cultured from the secretions, but it was cultured from 33\% of the gastric antral biopsies. In 8 and $15 \%$ of patients, PCR for HP was positive in the duodenal and gastric secretions respectively, but only after centrifugation to produce pellets. These patients were also pocitive by culture of the biopeies.

Conclusion- Gastrointestinal secretions may harbour Helicobacter pylori and play a significant role in the tranemission, especially in vomiting and diarrhoeal diseases. However, it is not known whether the PCR-detected organisms were dead or alive.
CULTURING $H$. PYLORI FROM GASTRIC ASPIRATES: THE EFFECT OF ACID IN VTVO AND IN VTTRO. M Williams', A Lawson ${ }^{2}$ E Slater, R J Owen', R E Pounder', 'Royal Free Hospital School of Medicine, London, ${ }^{2}$ Central Public Health Laboratory, London.

Introduction: Attempted culture of $H$. pylori (Hp) from gastric aspirates yields poor results. Could increased intragastric $\mathrm{pH}$ release Hp from the gastric mucosa into the lumen, facilitating Hp culture from gastric aspirates?

Methods: 6 serial moming gastric aspirates, 3 before and 3 during dosing with omeprazole $40 \mathrm{mg}$ bid were obtained from each of 11 healthy volunteers. 10 were infected with Hp and 1 non-infected, as determined by serology and ${ }^{13} \mathrm{C}$ urea breath test. Aspirates were taken after an overnight fast, via a nasogastric tube inserted $10 \mathrm{~min}$ prior to sampling. pHmetry was performed on each aspirate. $5 \mathrm{ml}$ of aspirate was added to Helicobacter transport medium for culture within 2 hours. Culture was performed blind as to Hp and dosing status. Aspirates were incubated with Sputosol, centrifuged and the resulting pellet resuspended in maximum recovery diluent (MRD). Portions of resuspended aspirate were dihuted for $5 \mathrm{~min}$ either with 1:10 MRD or with 1:10 HCl-KCl buffer ( $\mathrm{pH} 2.2)$ to rectuce contamination with upper respiratory tract flora (URTF). Aliquots from both were inoculated on $10 \%$ Columbia and Dents selective agar. Hp was identified by morphology, urease activity and detection of the ureAB genes by PCR

\begin{tabular}{|c|c|c|c|c|}
\hline \multirow[t]{2}{*}{ Results: } & \multicolumn{2}{|c|}{$\begin{array}{c}\text { Maximum Recovery } \\
\text { Diluent }(n=60)\end{array}$} & \multicolumn{2}{|c|}{$\begin{array}{c}\text { HCl-KCl Buffer } \\
(n=56)\end{array}$} \\
\hline & POS (\%) & NEG (\%) & POS (\%) & NEG (\%) \\
\hline $\begin{array}{l}\text { 3efore omeprazole } \\
\text { Suring omeprazole }\end{array}$ & $\begin{array}{ll}14 & (47) \\
3 & (10)\end{array}$ & $\begin{array}{ll}16 & (53) \\
27 & (90)\end{array}$ & $\begin{array}{ll}20 & (77) \\
20 & (67)\end{array}$ & $\begin{array}{ll}6 & (23) \\
10 & (33) \\
\end{array}$ \\
\hline
\end{tabular}

HCl-KCl buffer gave significantly higher yields of $\mathrm{Hp}$ compared to MRD both before $(p=0.02)$ and during $(p<0.0001)$ omeprazole dosing. Omeprazole reduced the yield of $\mathrm{Hp}$ with MRD $(\mathrm{p}=0.002)$ but had no effect with $\mathrm{HCl}$ $\mathrm{KCl}(\mathrm{p}=0.4)$. All $\mathrm{Hp}$ infected subjects yielded at least 1 positive aspirate for $\mathrm{HCl}-\mathrm{KCl}$, whilst 2 subjects yielded no positive aspirates for MRD. Aspirates from the uninfected subject were all negative by both methods.

Conclusions: 1 . Isolation of $\mathrm{Hp}$ from the gastric aspirates of $\mathrm{Hp}$ infected subjects is inhibited by URTF overgrowing Hp colonies. 2 . The addition of acid in vitro facilitates the isolation of $\mathrm{Hp}$, by inhibiting URTF. 3. Decreasing intragastric acidity in vivo, using omeprazole, does not affect the isolation of $\mathrm{Hp}$ using the $\mathrm{HCl}-\mathrm{KCl}$ method. This suggests that the apparent inhibition of Hp culture by omeprazole is due to competition from URTF.
PROLONGED ACID SUPPRESSION THERAPY AND PROXIMAL MIGRATION OF HELICOBACTER PYLORI H Ihmaidat, CK MacKay, H Kasem, CR Carter, J Going*, JF MacKenzie**, RC Stuart

University Departments of Surgery, Gastroenterology** \& Pathology* Glasgow Royal Infirmary, Glasgow

Intestinal metaplasia at the oesophago-gastric junction(OGJ), present in $15-30 \%$ of dyspeptic patients is a risk factor for adenocarcinoma. Aim: to investigate whether Helicobacter pylori(Hp) or prolonged acid suppression therapy is associated with intestinal metaplasia at the OGJ. Method: At diagnostic endoscopy, biopsies were taken from gastric antrum, body and OGJ in 190 patients. None had Barrett's oesophagus. Hp status was assessed using Cresyl Violet stains. Intestinal metaplasia was defined as the presence of Goblet cells seen on Haematoxylin \& Eosin and Periodic Acid Schiff/ Alcian Blue stains. Patients were interviewed regarding duration of acid suppression therapy. Results: 62 patients had intestinal metaplasia at the OGJ, with $\mathrm{Hp}$ at the antrum in $65 \%$ and $O G J$ in $43.5 \%$. This compared with $42.3 \%(p<0.01)$ and $29.7 \%(p=0.13)$ respectively in the 128 normal patients Helicobacter pylori status

\begin{tabular}{|c|c|c|c|}
\hline $\begin{array}{l}\text { Acid Suppression } \\
\text { Therapy (Months) }\end{array}$ & $\begin{array}{l}\text { Antrum +ve } \\
\& \text { OGJ -ve }\end{array}$ & $\begin{array}{l}\text { Antrum +ve } \\
\& \text { \& } O G J+v e\end{array}$ & $\begin{array}{l}\text { Antrum -ve } \\
\& \text { OGJ -ve }\end{array}$ \\
\hline Total & $\begin{array}{r}3.5^{\star} \\
(0-180)\end{array}$ & $\begin{array}{c}24^{*} \\
(0-216)\end{array}$ & $\begin{array}{c}12 \\
(0-192)\end{array}$ \\
\hline Normals & $\begin{array}{c}4 \\
(0-180)\end{array}$ & $\begin{array}{c}20 \\
(0-216)\end{array}$ & $\begin{array}{c}12 \\
(0-192)\end{array}$ \\
\hline Intestinal Metaplasia & $\begin{array}{c}2 \\
(0-144)\end{array}$ & $\begin{array}{c}24 \\
(0-204)\end{array}$ & $\begin{array}{c}15 \\
(0-168)\end{array}$ \\
\hline
\end{tabular}

Values: Median(range); ${ }^{*} \mathrm{p}<0.05$ by Mann-Whitney $U$ test

Conclusion: Patients with intestinal metaplasia at the OGJ are significantly more likely to be Helicobacter positive. There is evidence of proximal migration of Helicobacter in these patients. Prolonged acid suppression therapy favours the migration of Helicobacter pylori into the proximal stomach. $\dot{H}$. pylori eradication should be considered before starting maintenance acid suppression therapy. 
A NEW MINIMALLY INVASIVE SURGICAL TECHNIQUE FOR GASTRIC LEIOMYOMAS. C.C.Hepworth, J.Muthusami, D.Menzies, R.W.Motson. Colchester District General Hospital, Colchester, Essex UK.

A new surgical technique has been developed for dealing with gastric leiomyomas. This is performed under a general anaesthetic and with the patient supine. The patient is gastroscoped to assess the position of the leiomyoma. A 30 degree telescope is then inserted through a $10 \mathrm{~mm}$ umbilical port. The stomach is visualised and a suture is passed through the anterior abdominal wall directly over the anterior aspect of the stomach. This suture is then passed through the anterior wall of the stomach and then back through the anterior abdominal wall. A second suture is passed in the same way adjacent to the first. Traction on these sutures therefore lifts up the anterior wall of the stomach. A $10 \mathrm{~mm}$ port is placed under direct vision in the left upper quadrant. Using cutting diathermy a transverse incision is made through the anterior wall of the stomach below the sutures. Visualisation by means of the gastroscope ensures that the incision is placed allowing best access to the leiomyoma. The gastric leiomyoma can then be seen and grasped by Johannes laparoscopic graspers. A second port $(12 \mathrm{~mm})$ is positioned in the right upper quadrant. Through this can be placed an endoscopic linear cutter. Traction on the laparoscopic graspers pulls the leiomyoma through the transverse incision in the stomach. The linear stapler can then be placed across the stomach beneath the leiomyoma. Sequential applications and firings of the linear stapler removes the leiomyoma and simultaneously closes the stomach. The anterior gastrotomy is closed with a single layer of maxon.

Regults Eight patients, median age 77 years (range 33-83 years) who have presented with gastric leiomyomas have been treated. No deaths or complications occurred. One patient required conversion to an open procedure as the leiomyoma was very large. Following this procedure patients are mobilising and allowed to drink and eat the following day. The median length of stay in hospital was 5 days (range 4-7 days). The patient requiring the open procedure remained for 8 days. No peri or post operative blood transfusion was required.

Conclusions This is a safe and effective technique. It allows earlier mobilisation than conventional laparotomy.
W30

THE CHANGING PATTERN OF OESOPHAGO-GASTRIC CANCER.

JWrymen, DJ Craig, CS Biguin, SA Raimes and SM Griffin

The Oesephego-Gestric Cemcer Unit, Nowcest benerel Hospitel, Nowcestlo upon Trm. NE4 68E. UK.

The cins of this study wore to seck objoctive evidence for clinically percoived changes in the anatenicel distribution and ape of presentation of cases of oesophago. gestric melionency.

The records of the Merthern Regien Cencer Registry over a ten year poriod from 1984 were oxeminad for cosephegeal and gastric cencer regietration. Data for age at diennosis and precies site of tunour were oxtrected. Incidence was calculated from pultishad amued OPCS lecel pepulation statistics. Chanpe of quinquenium incidence and ese at mosentation wore andyead by the unpeired $t$-test. Results are given as $\max (\operatorname{mon})$

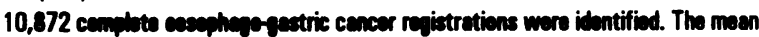

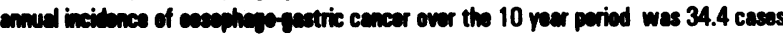

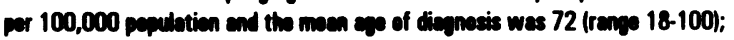
neither cheneved singificently over the peried of the study. The incidence of cosenpegend cancer reas frem $8.82(0.37)$ ceses per 100,000 in the period 1984 to 1888 to 11.24 (1.81) cenes por 100,000 in the peried 1809 to 1891 (P- -0.17$)$. The incilence of gestric cancer foll stidintly frem 25.3 (0.57) cases per 100,000 to 22.4 $(2.99)$ ceses per 100,000 (P-0.10). Pybric end entrel cencers fell mertedly in incidenes frem 2.13(0.70) to $0.84(0.12)$ ceses $\mathrm{pm} 100,000(P-0.02)$. The ratio of gestric cerctio to previe/entrol cencers rese frem 1.08 to $2.03(P-0.01)$ over the two fine verer priods. Petients with cercio cancers wore diennosed at a consistently

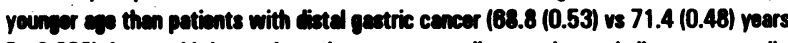

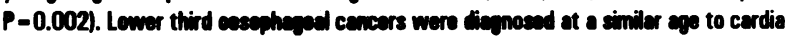
pationts $(60.4(0.45)$ years; $P-0.4) \mathrm{end}$ sinilerty oarfier then distel peetric cancer pationts $(P-0.007)$.

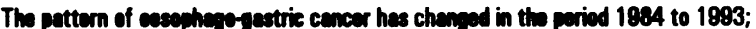
distel gestric cencer hes beceme bese commen. Pationts in the mepertionelly

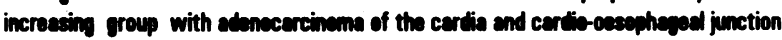
have a veunger ape of presentation.
LONG-TERM SURVIVAL, SYMPTOMS AND DRUG USE AFTER PEPTIC ULCER HAEMORRHAGE

A Fraser", J Masson", L Buckner", G McKnight", P Bramloy", WC Smith", NAG Mowat. GI Unit, Aberdeen Royal Infirmary", Dept. of Public Health Abendeen Untversity" Aberdoen UK

Althouph peptic uloer is the commonest source of upper GI bleeding there are no unselocted publisted data on the long-term follow up.

Over a 2 year period out of a whole community population of $468,000,414$ patients (421 admiasions) bled from peptic ulcess and were admitted to a single dodicated unit in Aberdoen. Of 414 patients 406(98.1\%) were followed up (mean 29.8 mosths) and a detrilod quectionaire completed.

The 30 day mortality was $7.2 \%$ (moen 79 yrs). A further 71 deaths during follow up gave an overall mortality of $24.8 \%$. The mean are at death was 76 years . Life table analyais, comparine are and sex mitched controls, revealed an exceses mortality in the peptic uloer group but only in the first year of follow-up, and by 5 years the overall mortality was equal. Only one death due to bleoding occurred after 30 days. Consumption of Appirin and NSAID in combination (odts ratio 2.4 (1.0-5.6)) but not individually, and blooding with no prior abdominal pain (odds ratio 1.7 (0.9-3.3)) were associated with roduced survival.

At follow-up $50.6 \%$ of petients had no dyepepaia. Maintenance acid suppression therapy was prescribed for $58.4 \%$ of petients. Of those cardiovascular disease patients on low dose aspirin (14.3\%), acid auppression therapy was co-prescribed in $74.3 \%$. Only $2.4 \%$ patients were on NSAIDs. None were on high dose aspirin nor aspirin plus NSAID combination. This contrasts with $21 \%$ taking acid suppression therapy and $45 \%$ taking aspirin or NSAID at the time of their initial presentation.

Twenty-three( $(9.4 \%)$ patients reported upper GI bleoding during follow-up but only $6(2.4 \%)$ required further hospital admission.

In the long-term the majority of patients are asymptomatic. Rocurrent bleeding is rare. After peptic ulcer haemorrhage both early and late mortality are principally related to concurrent disease in an elderly population. Compared to controls there is an initial increased mortality rate which is not sustained past the first year, and by 5 years survival is identical.

DENTAL PLAQUE AS A RESERVOIR FOR HELICOBACTER PYLORI (HP): DOES IMMUNOCHEMISTRY ANSWER THE QUESTION?

M.G..Marinone*, D.Facchinetti, R.Negriniß̧, E.Savoldi*, A.Turanoß̧, P.Sapelli*, A. Lanzini. Medicine 1, Dentistry* and Biochemistry and Virology §. Spedali Civili and University. Brescia. Italy.

Presence of HP in dental plaque is controversial, a discrepancy attributed to differences in methodology. Our aim was to validate and apply for the first time an immunochemical technique to detect $\mathrm{HP}$ in dental plaque.

80 consecutive patients (M:F=44:36, age range 16-87 years) undergoing endoscopy were examined for oral hygiene and a sample of dental plaque was removed before the procedure. Subjects on antibiotics or using antiseptic mouth-washing were excluded. Oral hygiene was classified using the Loe and Silness plaque and gingival index. Dental plaque was obtained with a sterile Gracey curette, from at least 5 dental elements, suspended in sterile saline, smeared on a slide, dried, fixed in ethanol $90^{\circ}$ and stored at $-4^{\circ} \mathrm{C}$ until examination.

All patients had six biopsies taken from antrus, body and fundus for microscopic examination and a sample of blood for detection of HP antibodies. Plaque smears were tested by indirect immunoperoxidase technique based on a mixture of two monoclonal antibodies specific for HP ( Negrini R. Gastroenterology 1989;96:414-20); its sensitivity and specificity were both $100 \%$ when tested on plaque samples artificially enriched with HP.

51 patients (64\%) were HP infected, as diagnosed by concordant histology and serology. All of them had variable degree of active chronic gastritis on microscopy and 15 had peptic ulcer. In none of these infected patients was HP detected in dental plaque. Furthermore the $\mathbf{4 0 0}$ dental plaque samples from the whole study population were all HP negative. No relationship was found between oral hygiene scores and presence of HP in the stomach.

In conclusion, our results using a highly sensitive method for detection of HP in dental plaque suggest that plaque is not a reservoir for HP infection. 
SMALL INTESTINAL CRYPT HYPERPLASIA IN AFRICAN TROPICAL ENTEROPATHY. AM Veitch', P Kelly', N Luo', I Segal $^{3}$, SK Spies4, MJG Farthing. 'Digestive Diseases Research Centre, St Bartholomew's \& The Royal London School of Medicine \& Dentistry, London, 'University Teaching Hospital, Lusaka, Zambia \& Gastroenterology divisions of the Universities of ${ }^{3}$ Witwatersrand and ${ }^{4}$ Pretoria, South Africa.

Introduction and aims: We have previously found evidence of tropical enteropathy in the healthy black population of Lusaka, Zambia, but normal villous architecture in urban black South Africans. In addition, we have demonstrated increased mucosal $T$ cell activation in the Zambian population compared to South Africans. In this study we have sought to determine whether, like other T cellmediated enteropathies, tropical enteropathy is associated with crypt hyperplasia.

Patients and methods: 12 black Zambian subjects, 22 black South Africans and 21 white South Africans undergoing routine upper gastointestinal endoscopy for dyspepsia (GU, DU, diarthoea and AIDS excluded) were studied. Formalin-fixed paraffin-processed biopsies were assessed by computerised image analysis to determine villous height (VH) and crypt depth (CD). Duodenal biopsies, fixed in Carnoy's solution and stored in $70 \%$ ethanol, were stained by the Feulgen reaction. Crypt mitotic counts were determined by direct counting of stained mitotic figures in microdissected crypts.

Results: Median VH was lower in Zambians [283 (262-389) $\mu \mathrm{m}$ ] than black South Africans [412 (235-456) $\mu \mathrm{m}]$ or white South Africans [377 (285-530)] $\mathrm{p}=0.03$, but $C D$ was not significantly different between the groups. Median mitoses/crypt was greater in Zambians [3.7 (1.9-7.9)] than black South Africans [2.4 (0.2-3.7)] or white South Africans compared [2.1 (1-3.7)] $\mathrm{p}=0.003$.

Conclusions: We have confirmed the presence of tropical enteropathy in urban black Zambians, and its absence in urban black and white South Africans. Our data suggest that tropical enteropathy is associated with crypt hyperlasia, although this was not accompanied by an increase in crypt depth.
INHIBITION OF CHOLERA TOXIN BUT NOT E.COLI ENTEROTOXIN-INDUCED SECRETION BY SUBSTANCE P (SP) ANTAGONIST. Turvill JL, Farthing MJG. DDRC, St Bartholomew's \& The Royal London School of Medicine, UK.

Introduction. SP is known to evoke neurally mediated small intestinal fluid secretion in several animal models. Furthermore, SP antagonism inhibits the inflammatory enteritis caused by $C$. difficile toxin A.

Aim. We investigated whether SP mediates the non-inflammatory secretory state induced by cholera toxin (CT) and Escherichia coli heat labile (LT) and heat stable enterotoxins (STa) in vivo.

Methods. CT and LT experiments: Anaesthetised male Wistar rats $(180-220 \mathrm{~g})$ were pre-treated with the selective SP antagonist D Pro D Trp ${ }^{7,9}$ SP (PTT-SP) $3.0 \mathrm{mg} / \mathrm{kg}$ ip. $20 \mathrm{~cm}$ small intestinal segments were isolated between cannulae into which $25 \mu \mathrm{g}$ CT or $25 \mu \mathrm{g}$ LT in $2 \mathrm{ml}$ saline was instilled and incubated. After $2 \mathrm{~h}$, in situ perfusion was performed with plasma electrolyte solution $(\mathrm{Na} 140, \mathrm{~K} 4, \mathrm{Cl}$ $\left.104, \mathrm{HCO}_{3} 40 \mathrm{mmol} / \mathrm{l}\right)$ containing $\left[{ }^{14} \mathrm{C}\right]$-polyethylene glycol as a non-absorbable marker. After an equilibration period, $3 \times 10 \mathrm{~min}$ collections were made and net fluid and electrolyte movement determined.

STa experiments: After pre-treatment with $3.0 \mathrm{mg} / \mathrm{kg}$ PTT-SP, the jejunal segment was perfused with PES containing $\left[{ }^{14} \mathrm{C}\right]-\mathrm{PEG}$ to which $200 \mu \mathrm{g} / \mathrm{ST}$ (equivalent to 50000 mouse units) had been added.

Results. CT-induced net water secretion (median $-94.0 \mu \mathrm{l} / \mathrm{min} / \mathrm{g}$ dw [IQR -106.5 to -63.0$] ; n=11$ ) was significantly reduced by pretreatment with PTT-SP $(-10.4[-42.5$ to -4.1$] ; n=7, p<0.002)$. LT induced a similar degree of sesretion $(-67.6[-89.4$ to -33.0$] ; n=16$, $\mathrm{p}=0.08$ compared to CT control) which, by contrast, was no inhibited by PTT-SP $(-50.7[-67.6$ to -35.3$] ; n=16, p=0.3)$. In the same way, STa-induced secretion $(-65.3[-83.2$ to -54.6$]$, $n=6)$ was not effected by PTT-SF (-77.4 [-81.9 to -76.2$]$; $n=5)$. Electrolytes paralleled water

Conclusion. The finding that the SP antagonist PTT SP significantly inhibits CT but not LT or STa-induced secretion is consistent with the observation that there are fundamental differences in the way these three enterotoxins activate a secretory reflex arc in the host.
DETECTION OF INTRALUMINAL SEROTONIN (5-HT) IN PATIENTS WITH HIV-RELATED DIARRHOEA. Kelly $P$ Turvill $\pi$, Farthing MJG. Digestive Diseases Research Centre, $S t$ Bartholomew's \& The Royal London School of Medicine \& Dentistry, London, UK

Introduction: The pathogenesis of HIV-related diarrhoea remains unknown and the role of 5-HT as an endogenous secretagogue or prokinetic in this condition is unexplored. Enterochromaffin cells, when activated by enterotoxins, are known to release 5-HT into the intestinal lumen, where it can act as a secretagogue. We investigated whether excess 5-HT is released into the small intestinal lumen in patients with HIV-related diarrhoea.

Methods: Duodenal aspirates were obtained at upper gastrointestinal endoscopy from an unselected group of 69 HIV infected patients with persistent diarrhoea, and from 8 diarrhoea-free control patients being investigated for dyspepsia. Aspirates were collected into protease inhibitors, frozen to $-80^{\circ} \mathrm{C}$, and $5-\mathrm{HT}$ collected into protease inhibitors, frozen to $-80^{\circ} \mathrm{C}$, and
concentrations determined by HPLC with fluorimetric detection

Results: 5-HT concentrations were close to the limits of detection in all of the control aspirates $(0-0.53 \mathrm{nmol} / /)$. $5-\mathrm{HT}$ concentrations were markedly elevated in a sub-group of the patients with HIV related diarrhoea (range $0-224 \mathrm{nmol} /$ ). Of the patients with HIV related diarrhoea, $45(61 \%)$ had 5-HT concentrations at control levels, whereas $27(39 \%)$ had markedly elevated concentrations compared to controls ( $\mathrm{p}=0.04$ by Fisher's exact test). Aspirate $\mathrm{pH}$ was not related to 5-HT concentration and some of the higher values were seen in aspirates with $\mathrm{pH}>7.0$. The group of patients with high 5-HT concentrations was not defined by enteric infection, immunoglobulin or soluble tumour necrosis factor concentrations in serum, immunoglobulin concentration in duodenal aspirate, nutritional status or severity of enteropathy.

Conclusion: In a sub-population of patients with HIV-related diarrhoea intraduodenal concentrations of 5-HT were up to three orders of magnitude higher than in controls. While the clinical relevance of this observation is as yet unclear, similar concentrations have been detected in jejujnal perfusates of human volunteers with cholera toxin-induced secretion. These observations raise the possibility that 5-HT may mediate some of the pathophysiological disturbances which underlie this disorder, suggesting novel approaches for therapeutic intervention.
PARAOXETINE INHIBITS CHOLERA TOXIN INDUCED SECRETION BY DEPLETING NEURONAL BUT NOT ENTEROCHROMAFFIN (EC) CELL 5-HT. Turvill JL, Farthing MJG. Digestive Disease Research Centre, St Bartholomew's \& The Royal London School of Medicine, UK.

Introduction. Depletion of the secretagogue and neurotransmitter 5-HT, from the small intestine partially inhibits cholera toxin CTinduced secretion. Since a substantial proportion of this secretion is neuronally mediated we postulated that a greater anti-secretory effect neuronally mediated we postulated that a greater anti-secretory effect may result from the selective depletion of neuronal 5 -HT from the small intestine. We investigated whether the selective serotonin reuptake inhibitor, paroxetine, would cause neural but not EC cell depletion and whether this

induced secretion in vivo. for three days with paroxetine $3 \mathrm{mg} / \mathrm{kg}$ in $1 \mathrm{ml}$ water or water alone, and then anaesthetised. In the first oroup, the mucosa was gently and then ans determined by HPLC with fluorimetric detection. In the second group, $25 \mu \mathrm{CT}$ in $2 \mathrm{ml}$ saline was incubated in $20 \mathrm{~cm}$ small intestinal group, $25 \mu \mathrm{g} \mathrm{CT}$ in $2 \mathrm{ml}$ saline was incubated in $20 \mathrm{~cm}$ small intestinal segments, isolated between cannulae. After $2 \mathrm{~h}$, in situ perfusion was performed with plasma electrolyte solution (Na 140, K $4, \mathrm{Cl} \mathrm{104,}$ to determine and net water and electrolyte movements. Whole brain was then removed for determination of 5-HT levels as described above.

Results. Mucosal 5-HT levels (med 81.0pmol/mg dw [IQR 65.3 to 85 ]; $n=9)$ were unaffected by pre-treatment with paroxetine (87.5 [74.3 to 112]; $\mathrm{n}=6, \mathrm{p}=0.4 \mathrm{MW}$. By contrast, brain 5-HT levels [74.3 to 112$] ; \mathrm{pmol} / \mathrm{mg}, \mathrm{8.7}$ to 10.1$] ; \mathrm{n}=8$ ) were significantly reduced by (9.4pmol/mg $[8.7$ to 10.1$] ; n=8$ ) were significantly reduced by paroxetine $(0.9$ [0.8 to 1.0$] ; n=7, p<0.001)$. In keeping with these findings, $\mathrm{CT}$-induced net water secretion $(-101.2 \mu \mathrm{l} / \mathrm{min} / \mathrm{g}$ dw $[-146.5$ to -74.9$] ; n=14)$ was inhibited by pre-treatment with paroxetine (Summary and conclusion. Paroxetine depletes neuronal 5-HT, as demonstrated by a reduction in brain 5-HT, but not EC cell 5-HT levels within the small intestinal mucosa. We postulate that the associated inhibition of CT-induced secretion results either from (i) the depletion of 5-HT within the myenteric plexus or (ii) the the depletion of s-Hut the 5-HT released from activated EC cells. 


\section{ISCHAEMIA-REPERTUSION INJURY FOLLOWING} SYNGENEIC SMALL DOWEL TRANSPLANTATION INDUCES APOPTOSIS

KA Shah S Shurey, CJ Green (introduced by AB Price) Department of Surgical Research, Northwick Park Institute for Medical Research, Northwick Park Hoepital, Harrow, Middlesex, HA1 3UJ, UK

Two components cause graft injury following small bowel transplantation; the damage induced by cold ischsemic storage and exacerbation of this following reperfusion. The combined manifestation, termed ischacmia-reperfusion injury, has been described morphologically as causing villous destruction and crypt loss. Many of these cellular changes have been attributed to necrosis.

In a morphological study on syngeneic small bowel transplantation in Lewis rats, grafts were stored in saline $(n=6)$ or University of Wisconsin (UW) solution $(n=6)$ for 24 hours and transplanted with portal venous drainage. Samples of the graft obtained before harvest, after cold ischaemic storage and after 1 hour of reperfusion were processed for light (LM) and electron microscopy (EM) using conventional protocols.

Graft storage resulted in loss of villous integrity (saline worse than UW), but adequate crypt preservation. Apoptosis of some denuded villous epithelial cells was noted; there was no increase in crypt cell apoptosis compared to normal.

After one hour of reperfusion, there was extensive villous destruction. Variable crypt loss was observed, with saline stored grafts showing more damage than UW stored ones. The preserved crypts showed karyorrhectic debris and chromatin margination on LM suggestive of apoptosis, which was confirmed on EM. Some crypt cells exhibited condensation with nuclear and cytoplasmic features of "dark cells". A minor increase in acute inflammatory cells was noted in the lamina propria. Only an occasional crypt cell showed ultrastructural features of necrosis.

This study has identified apoptosis as a prominent mode of cell death following ischaemia-reperfusion injury in transplanted small bowel. This has possible implications on general intestinal ischaemic injury and on the development of specific therapeutic interventions.
INTESTINAL PERMEABILITY AND ABSORPTIVE CAPACITY IN PATENTS RECEIVING PARENTERAL NUTRITION. WS Wassif, R Crane, $H$ Thadani, L Thompson, C Wicks, WJ Marshall, I Bjarnason. Department of Clinical Biochemistry King's College School of Medicine \& Dentistry, London

Background: It has been suggested that there is a dual supply for enterocyte nutrition, namely luminal during absorption and blood bome during fasting. In rats parenteral nutrition leads to alterations in motility and villus atrophy, but the effect of fasting and parenteral nutrition in man is largely unknown. Aim: To assess small intestinal permeability and absorptive capacity in patients requiring parenteral nutrition following prolonged fasting and responses to re-feeding. Methods: Weokly assessments of intestinal permeability (lactulose/L-rhamnose) and absorptive capacity (3-0-m-D-glucose, D-xylose, Linamnose) were made in 9 patients requiring parentera nutritional support (for 15 median, range 8-29 days). Recults: Six of seven patients having been nil by mouth for at least a week had significantly $(p<0.01)$ increased intestinal permeability (differential urinary excretion of lactulose/L-mamnose $0.18 \pm 0.13)$ as compared with healthy controls $(0.03 \pm 0.02)$ and the two who had some oral intake $(0.03 \pm 0.01)$. Furthermore absorptive capacity was significantly $(p<0.05)$ impaired in the fasting patients (3-0-m-D-glucose $26.5 \pm 19.5 \%, \mathrm{D}$-xylose $14.2 \pm 12.2 \%$, L-hamnose $3.7 \pm 2.8 \%$ ) as compared with controls (44.6 $7.7 \%, 30.7 \pm 7.3 \%$ and $10.5 \pm 2.5 \%$, respectively). There was a further deterioration in intestinal permeability and absorptive capacity in patients on total parenteral nutrition without oral intake, but not in those concomitantly receiving ora supplementation (500-800 kcal/24 hours). Within a week of reestablishing oral intake intestinal permeability retumed towards the reference range $(0.066 \pm 0.02)$ and absorptive capacity was restored (3-0-m-D-glucose 48.1 $\pm 21.3 \%$, D-xylose $26.9 \pm 11.5 \%$, L-ihamnose $8.5 \pm 3.9 \%$ ). Conclucions: Blood bome nutrition during total fasting is insufficient to maintain gastrointestinal integrity in man which may have implications for microbial translocation and endotoxaemia. As small amounts of food prevent this deterioration every effort should be made to maintain some enteral intake in these patients.
ATYPICAL PRESENTATION OF COELIAC DISEASE: A RETROSPECTIVE REVIEW OF ONE INSTITUTION'S EXPERIENCE

RMS Mitchell, TJ Robinson. Dept. of Medicine, Craigavon Area Hospital, Northern Ireland

It is known that only a minority of patients with coeliac disease present classically with diarthoea, steatornhoea and features of malabsorption; features at presentation are more likely to be red cell abnormalities such as persistent macrocytosis or increased red cell distribution width, weight loss or concurrent associated diseases. In our population the prevalence of coeliac disease is high and often presents atypically.

Clinical and laboratory data were collected from 127 consecutive patients diagnosed histologically with ghuten sensitive enteropathy with special reference to the ages at which the patients first developed significant manifestations of the disease, when the disease was diagnosed and the cause of the delay.

70 (50 female) of the 127 patients had a significant delay in diagnosis. Mean age at diagnosis of those diagnosed at initial presentation was 43.6 years (males 45.1, females 42.9); mean age in those whose diagnosis was delayed was significantly higher at 48.5 years (males 48.9, females 48.4, $p<0.03$ ); in this group the mean delay was 107.3 months (range 6-480). In 44 patients (33 female) red cell abnormalities only were present; 15 patients had an isolated persistent macrocytosis which resolved on gluten-free diet. 17 patients ( 9 female) had gastrointestinal symptoms of malabsorption but presented late. 2 patients presented with a concurrent associated disease and $5 / 50$ female patients only had symptoms during pregnancy.

In conclusion, the majority of our patients did not present classically, therefore a high index of suspicion is required to diagnose these patients, especially in patients with refractory red cell abnormalities in populations where the condition has a high prevalence. child sibling pairs and two adult patients had a parent with $C D$

Table: Annual incidence per 10,000 population.
\begin{tabular}{|l|c|c|c|}
\hline Patient Group & $1981-1985$ & $1986-1990$ & $1991-1995$ \\
\hline CD-Children & 2.08 & 2.53 & 2.15 \\
\hline CD-Adults & $1.32^{*}$ & 2.15 & $3.08^{*}$ \\
\hline DH & 0.43 & 0.43 & 0.3 \\
\hline
\end{tabular}

Conclusion, In South Glamorgan the incidence of CD in children and DH in adults has remained constant over the past 15 years however there has been a significant increase in the number of adults diagnosed with $C D$, the

diagnosis being more common in adult women

Presentation and Incidence of Coeliac Disease in Sonth Glamorgan. Hawkes N.D, Swift G.L, Davies A ,Rhodes J,Smith P.M,Jenkins H.R. (Departments of Child Health \& Gastroenterology, University Hospital of Dermatitis Herpetiformis (DH) and the symptoms at presentation in both adults and children between $1^{\text {th }}$ January 1991 and $31^{\text {st }}$ December 1995 for the resident population of South Glamorgan. 2) To compare incidence rates with comparative data for the period 1981-1990 diagnosed during the study period were identified from hospital activity analysis data, pathology and dietetic records, letters circulated to local General Practitioners and through the local Coeliac Society. All had

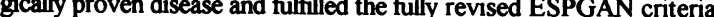
Glamorgan were then used to calculate incidences.

Rexults. A total of 59 new cases of CD were identified ( 9 children, 50 adults) and 5 cases of DH(all adults). In the children ( 4 boys, 5 girls) the mas at diagnosis was 76 years (range $1.7-14.9$ ) $77 \%$ presented with children presented with failure to thrive and two cases were identified through family screening. In the adults with $\mathrm{CD}$ there was a significant difference in the sex ratio ( 13 males, 37 females) $[p<0.05]$ with a mean age at diagnosis of 50.0 years (range 26.0-88.2, no difference between males and females). $80 \%$ presented with abdominal symptoms (with anaemia $48 \%$ ), $20 \%$ with anaemia alone. Of the DH cases 3 were male, 2 female with a mean age at diagnosis of 53.2 years (23.9-74.8). There were two 
COELIAC DISEASE IS ASSOCIATED WITH NONSMOKING AND CESSATION OF SMOKING.

D.Todi, H.H. Tsai.

Gastroenterology Department, Castle Hill Hospital, Castle Road, Cottingham, E. Yorkshire. U.K. HU16 5JQ.

The association between ulcerative colitis and non-smoking is well known. Coeliac disease is an allergic mucosal disease which also have an inflammatory component and is associated with inflammatory bowel disease. We investigated patients with coeliac disease to see if they share the same epidemiological characteristic.

Methods: A total of 330 patients with a definitive diagnosis of coeliac disease were prospectively interviewed by a standardised questionnaire. 114 controls were recruited from accident and emergency department and were matched for age and sex.

Results: 37 out of $330(11.2 \%)$ patients with coeliac disease were smokers compared to 48 out of $114(42 \%)$ control patients. This is a significant finding ( $P<0.0001$; OR:0.174 95\% CI $0.105-0.288)$. There were $90(27.3 \%)$ ex-smokers amongst the coeliac group compared to $3(2.6 \%)$ in the control group. This is also a highly significant finding ( $P<0.0001$; OR:13.88 $95 \% \mathrm{CI}$ 4.30-44.80). 16 of the patients who were ex-smokers stopped smoking after diagnosis of coeliac disease. Exclusion of these patients from the analysis, patients with coeliac disease were still more likely to be ex-smokers compared to controls ( $\mathrm{P}<0.0001$; OR $10.70,95 \%$ CI $3.30-34.65)$.

Conclusion: Coeliac disease, like ulcerative colitis is associated with non-smoking, although the relative risk is lower than that quoted for ulcerative colitis. The strikingly large number of ex-smokers amongst coeliac patients is not due to increased medical contact. These findings are unexplained and deserve further study.
INSULIN INDEPENDENCE FOLLOWING COMBINED TOTAL PANCREATECTOMY AND ISLET AUTOTRANSPLANTATION

SA White, PRV Johnson, S Swift ${ }^{\dagger}$, NP Kopiker*, JE Davies", ACB Wicks*, AC Burden*, SS Ubhi, NMM London ${ }^{\dagger}$, AR Dennison

Departments of Surgery and Medicine* Leicester General Hospital and Department of Surgery University of Leicester ${ }^{\dagger}$.

Total pancreatectomy is a radical procedure for chronic pancreatitis but renders the patient insulin dependent. Over a 3 year period 14 patients (11 F : 3 M) have undergone total pancreatectomy combined with islet autotransolantation in an attempt to prevent diabetes. Following pancreatectomy islets were immodiately isolated using collagenase distension combined with a semi-automated pancreas digestion. In 10 patients islets were also purified on a continuous density gradient. The islets were then transported beck to the operating theatre for autotransplantation.

In 12 patients the islets were embolized directly into the liver via the portal vein (median volume $9 \mathrm{mls}$ ) in addition 2 of these patients also received islets into the spleen and 2 patients received a splenic autotransplant alone. Post-operative islet autograft insulin secretion was assessed by serum C-peptide levels.

One patient died of a stroke 4 weeks post-operatively. Of the remaining i3 C-peptide levels are available on 12 and are all within the normal range (median $1.29 \mathrm{ng} / \mathrm{ml}$ ). Four patients developed insulin independence post-operatively but only two patients are currently insulin independent (over 1 year follow-up).

In conclusion insulin independence can be achieved following total pancreatectomy when combined with islet autotransplantation but cannot be predicted by post-operative basal serum C-peptide levels that are within the normal range.
W42

AUDIT OF THE MANAGEMENT OF ACUTE PANCREATITIS IN WESSEX. S.K.C.Toh, S.Phillips, D.Slade, C.D.Johnson. University Surgical Unit, Southampton General Hospital, Southampton SO16 6YD.

In the course of conducting a multicentre trial of a new treatment for acute pancreatitis (AP), prospective data on the management of patients admitted with AP was collected from 8 hospitals in Wessex between Nov.1994-Nov.1995. Recent evidence-based national guidelines for the management of AP have been proposed by the British Society of Gastroenterology. Aim:To compare the results of our audit with the proposed audit goals. Methods: All patients were seen within $24 \mathrm{hrs}$ of admission and APACHE-Il scored. Follow-up data was subsequently obtained through review of the notes after discharge. Results: 186 patients were admitted with AP: 80 women, 106 men. Age 15-98yr (median 54), aetiology-gallstone(GS) $33 \%$, alcohol $20 \%$, other $15 \%$, idiopathic $32 \%$. There were 60 severe cases( $32 \%)$. The following table summarises the audit findings compared with audit goals:

\begin{tabular}{|l|l|l|}
\hline & Findines (00.) & Audit Goals \\
\hline Mortality & $\begin{array}{l}9.1 \%(17) \\
(28 \% \text { severe AP) }\end{array}$ & $\begin{array}{l}<10 \% \\
(<30 \% \text { severeAP) }\end{array}$ \\
\hline Diagnosis < 48hrs & $98.4 \%(183)$ & $100 \%$ \\
\hline Severity Stratification < 48hrs* & $19 \%(35)$ & $100 \%$ \\
\hline Percentage of Idiopathic Cases & $32 \%(60)$ & $20-25 \%$ \\
\hline DefinitiveRx GS in mild AP<4 weeks & $33 \%(15 / 45)$ & $100 \%$ \\
\hline Severe AP in HDU or ITU & $67 \%(40 / 60)$ & $100 \%$ \\
\hline $\begin{array}{l}\text { Radiological Facilities available } \\
\text { (USS, CT, Angiography) }\end{array}$ & $100 \%$ & $100 \%$ \\
\hline $\begin{array}{l}\text { Dynamic CT in severe AP between } \\
\text { Day 3 - 10 }\end{array}$ & $33 \%(20 / 60)$ & $100 \%$ \\
\hline Urgent ERCP in severe GS AP & $41 \%(7 / 17)$ & $100 \%$ \\
\hline
\end{tabular}

\section{* Using Glasgow, APACHE-II or C-Reactive Protein criteria.}

Conclusions:This prospective audit has identified shortcomings in the management of AP. The principal deficiencies were the poor use of objective severity stratification on admission, delayed treatment of gallstones in mild GS AP, and difficulties in providing a 24-hour service for urgent ERCP and bile duct decompression in severe GS AP.
W44

IS PANCREATIC SURGERY SAFE IN A SMALL DISTRICT GENERAL HOSPITAL ?

C.E.Millson, C.J.Mitchell, J.MacFie.

The Combined Gastroenterology Service, Scarborough Hospital, Woodlands Drive, Scarborough, Yorkshire YO12 6QL.

It has been suggested that pancreatic surgery should only be performed in larger, specialist units. We reviewed our District General Hospital (DGH) experience over 6 years of 50 consecutive patients (32 males) aged 31-84 yrs(mean 62) undergoing pancreatic surgery. The indications for surgery were pancreatic cancer 25 $(50 \%)$, acute pancreatitis and its complications $16(32 \%)$, chronic pancreatitis $6(12 \%)$ and others $3(6 \%)$. The procedures performed included; Whipples $12(24 \%)$, Triple bypass $12(24 \%)$, sub-total pancreatectomy 11 (including 3 with cyst drainage) (22\%), pylorus preserving pancreatico-duodenectomy $5(10 \%)$, total pancreatectomy $3(6 \%)$, palliative choledocho-jejunostomy $4(8 \%)$ and necrosectomy $3(6 \%)$.

Thirty-day mortality was $6 \%$. Complications included 8 patients with respiratory (2) or cardiac failure (!), pleural effusions (3), arterial bleeding (1) or a bile leak (1); two required re-operation. Median length of hospital stay was 15 days (range 8-77). Median survival for the 27 patients with malignant disease was 8 months (range 1 to 23 months). The 23 patients with benign disease have been followed for a median of 3 years; 3 have died, one from recurrent acute pancreatitis and two others from unrelated causes. Of the 20 surviving, 4 have developed pancreatic insufficiency and a further 2 have recurrent pain.

We conclude that successful pancreatic surgery can be periormed safely in a DGH setting. Patient selection and expertise are more important than numbers. 
DIFFERENCES IN PERCEPTION OF QUALITY OF LIFE ISSUES BETWEEN PANCREATIC CANCER PATIENTS AND HEALTH PROFESSIONALS.

D Fitzsimmons, CD Johnson, S George, S Payne,

Pancreas and Billiary Research Group, Southampton General Hoepital

Despite advances in modical and surgical interventions the outlook for the pancreatic cencer patient remains gloomy. Recently, attention has focused on the quality of life (QOL) of auch patients. Yat little research has been undertaken and no disease specific QOL questionnaire exists. During development of a pancreatic cencer module to supplement the European Organisation for Research and Treatment of Cancer (EORTC) core cancer questionnaire, the QLQ-C30, we have noted differences in perception between health profeseionals and patients. Methods: We used guidelines published by the EORTC QOL study group. An extensive literuture review was performed to identify relovant issues. 40 pancreatic cancer peticats and 18 health profeseionals have been asked to identify the most important and relevant QOL iseues. Of these, 21 patients and 6 health proferecionals were interviewed to gain insight into why such iseues were importent in pamcreatic cencer. Interviews were semi- structured and were analysed using a grounded theory approach.

Resultu: The literature review was largely unproductive. The conten of data gathered from profeseionals and patients were similar. A list of 42 relevant and specific iseues was generated suitable for inchusion in a pancreatic cancer module. These inchuded specific symptoms such as pruritus, jaundice, indigestion and abdominal pain as well as additional QOL issues related to fear of future, body image and support. However, the context in which these issues were identified differed between the two groups. Health professionals took a mechanistic approach and perceived a direct relationship between severity of symptoms and overall QOL, whereas patient's perception related to the need to introduce or alter existing coping strategies. The success or otherwise of these coping strategies influenced $\mathrm{QOL}$ perception.

Conclusion: Many QOL instruments are designed from the viewpoint of the health professional. This work demonstrates the importance of a qualitative patient centred approach to initial development. Patient's perceptions should be inchuded in all stages of $Q O L$ instrument development. A 27 item module has now been constructed, refined and approved by the EORTC for multi-lingual pretesting and field-testing.

LEXIPAFANT, A PLATELET ACTIVATION FACTOR(PAF) ANTAGONIST, REDUCES MORTALITY IN A RANDOMISED PLACEBO-CONTROLLED STUDY IN PATIENTS WITH SEVERE ACUTE PANCREATITIS. S.K.C.Toh For the British Acute Pancreatitis Study Group (18 Centres). University Surgical Unit, Southampton General Hospital, Southampton

The complications and early deaths associated with acute pancreatitis appear to involve inappropriate immune system activation. PAF is a central mediator of this response. Our aim was to investigate the effect of lexipafant, a potent PAF antagonist, in a randomised, double-blind, placebo-controlled study, in patients predicted to develop complications.

Patients with acute pancreatitis and APACHE II score $>6$ were randomised within $72 \mathrm{hrs}$ of onset of symptoms to receive an infusion of lexipafant $(100 \mathrm{mg} /$ day for 7 days $)(n=139)$ or identical placebo $(n=151)$. Seven patients who died were excluded (wrong diagnosis, $n=3$; unrelated cause of death, $n=3$; protocol violation (cancer of pancreas), $n=1$ ). Overall and attributable mortalities were not significantly less after lexipafant $(n=18,12 \%)$ and $(n=14,9 \%)$ than after placebo $(n=24,17 \%)$ and $(n=21,15 \%) ;(0.1<p<0.2)$ However, $11(10 \%)$ of 107 patients treated within $48 \mathrm{hrs}$ of onset died, significantly less than $20(20 \%)$ of 98 given placebo within $48 \mathrm{hrs}(\mathrm{p}=0.04)$. Attributable mortality in these patients was significantly less with active treatment $(8$ of $104,8 \%)$ than placebo $(17$ of $95,18 \%) ;(p=0.03)$. Median change in organ failure score on day 3 was significantly different in the two groups (lexipafant $-1(-1$ to 0$)$, placebo $0(-1$ to 0$) ; p=0.04)$ and there were fewer local complications in the lexipafant group $(30 / 148,20 \%$ vs $41 / 138$, $30 \% ; \mathrm{p}=0.065$ ).

Lexipafant appears to reduce complications and death in patients predicted to have severe pancreatitis. This effect is most marked in patients treated within $48 \mathrm{hrs}$ of onset of symptoms, consistent with the supposed mode of action of the drug.
THE PAROTID GLANDS ARE NOT VULNERABLE TO FACTORS RESPONSIBLE FOR CHRONIC PANCREATITIS AJK Piorrowicz, A Dzik-Jurasz, EA Stoner and CA Ainley. St Bartholemew's and Royal London School of Medicine and Dentistry.

BACKGROUND: The parotid glands share many functional and morphological characteristics with the pancreas, suggesting they may also be vulnerable to factors responsible for alcoholic and idiopathic chronic pancreatitis (ACP and ICP). Previous studies have investigated this potential association by measuring changes in salivary composition or antibodies against salivary gland antigens in CP and reached differing conclusions. The aim of the present study was to test this hypothesis directly by determining the prevalence of parotid gland abnormalities in patients with CP by ultrasonography. This technique is sensitive in detecting parotid duct ectasia and the presence of intraductal stones and glandular calcifications.

METHODS: The parotid glands of 23 patients with CP diagnosed on the basis of abnormal ERPs (suspected aetiologies: alcohol; $n=9$, idiopathic; $n=7$, gallstones; $n=7$ ) together with 15 teatotal controls were scanned using a linear sector $7.5 \mathrm{MHz}$ probe on a ATL HDI 3000 scanner. All machine parameters were set for optimal scanning at glandular depth. A search was made for major (Stensen's duct) and minor ductal ectasia and calcification.

RESULTS: Stensen's duct was visualised in all control subjocts, measuring $0.5-1 \mathrm{~mm}$ in diameter. There was no difference in duct diameter between controls and patients with CP. Similarly, ultrasonography did not detect any duct ectasia or glandular calcification in either the controls or any of the patients with pancreatitis.

CONCLUSIONS: According to the parameters assessed, parotid gland morphology in patients with ACP and IPC is unchanged compared to that of controls and patients with gall stone CP. This suggests that development of ACP and ICP depends on factors particular to the pancreas, rather than on any antigenic or metabolic characteristic it may share with the parotid.

\section{Liver W48-W72}

W48

\section{ONDANSETRON IN THE TREATMENT OF THE PRURITUS} OF CHOLESTASIS: A RANDOMISED CONTROUED TRIAL.

J.W.O'Donohue, "C. Haigh, Roger Williams. Institute of Liver Studies, King's College Hospital, London and "GlexoWelloome, Uxbridge

Conventional drug treatment of the pruritus of cholestacis may be unsuccesefil. Serotomin receptors on dermal sensory nerve-endings mey play a role in the perception of pruitus, and case reports have suggested benefit from the 5-HT 3 receptor antagonist, ondensetron. Aim. To define the efficacy of ondensetron in the pruritus of choloctasis. Patienta. 19 patients (16 female, medien age 59 y) were enrollod (17 PBC, one chronic rejection post orthotopic liver transplentation, one hepatitis C). All had prurius resistant to treatment with cholestyramine, ursodiol (each five patients), anthistamines (4), temoxifen (2), cyclosporin-A and rifumpicin. Anti-pruritic modications were stopped 3 days before study entry. Methoda. Perception of itch was recorded (hourty by day) using a visual analogue score (VAS), and scrutching activity (SA) (independent of timb movements) measured by means of a pieso-eloctric crystal attachod to the nail Both were recorded for 24 hours pro- and post-treatment and the VAS was continued for ane week. Patients were randomieed, doublobind, to receive cither ondengetron or plecebo. A single intrivenous bohs of $8 \mathrm{mg}$ ondensetron / phoctor was followed by oral ondensectron $8 \mathrm{mg}$ / placebo twice daty for five days. Momingfill relief was defined as reduction to $<50 \%$ of bascline pruritus on day 1 . Recullas. Treatement and placebo groups were well-meched for age, sex, diagnosis, sevecity of liver disease, previous anti-pruritic modication and bescline pruritus burden and SA. Pruitus showed diumel verixtion, with evening exacerbetion. Pruritus burden (the area under the curve of VAS $v$ time) was rectuced on the first treatument day comparod to beseline in both ondensetron and plecebo groups $(p<0.05)$ but there were no significant differences at any timopoint between the groups in pruritus burden, SA or in the time to meaningfil relief. Summary. Ondensetron has no adventage over placebo in the treatment of the pruritus of cholestasis. 
JAUNDICE ASSOCIATED WTH AUGMENTIN: THE TIP OF THE ICEBERG? *J.W. O'Donohue "*K. Oien, R. C. Brown, P. Bramley, K. M. Cochran, R.W. Crofton, W.S. Hislop, R. Park **R.N.M MacSween, *P. R. Mills. Depts. of *Gastroenterology and **Pathology, Western Infirmary, Glasgow and West of Scotdend Hospitals

Augmeatin (amoxycillin and clavulmic acid) is among the most commonly prescribed antibjotics worldwide. Cholestacis aseociated with Augmentin in the absence of other known cause was first recognised in 1988. Aims. To estimate the incidence, patient profile and outcome of Augmentin-associated cholestasis in the West of Scothnd (pop. 2.5m) from 1992-1996. Case finding methoda. Direct postal questioning of 23 gastroenterologists in the West of Scotland, search of coded discharge dingnoses in the Ghegow arean, and search of pathology records (K.O.) Results. 19 cases of jaundice were identified (ten male, mean age 57.8y, range 44-91y). Full clinical details were available in 15 patients. In no patient was a causative link with the drug suspected at time of referral Duct dilatation was excluded by ulrasound and hepatitis serology was negative in all patients. Medion interval between start of drug therapy and development of jaundice was 14.5d (range 6-46d). Median peak

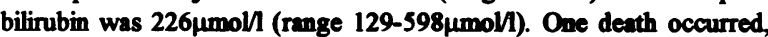
from unrelated causes, in a 91 yo patient who had mild, resolving jaundice. Cholestasis resolved after medim 93d (range 35-186d) in all but one patient, in whom a mild transaminitis has persisted for 4 years. Duration of jaundice correlated with the length of interval between drug exposure and onset of jaundice $(r=0.76)$, but not to age, sex, dose or duration of treatment. The implied frequency in the West of Scotland in 1996 was one case of cholestasis per 22,000 Augmentin prescriptions. Liver biopsy, performed in eight patients, showed portal tract chronic inflammation, cholestasis, eosinophilia and varying degrees of cholangiopathy in all cases. Granulomatous inflammation was present in one. Conclusions. Jaundice associated with Augmentin is increasingly recognised, may be severe and prolonged, and is frequently delayed after drug exposure which may hinder diagnosis. Complete recovery is usual.
LIVER FUNCTION TESTS AND LIVER DAMAGE IN HAEMOCHROMATOSIS. D K George, D H C Crawford and L W Powell (introduced by R I Russell). The Liver Unit, Queensland Institute of Medical Research, Brisbanc, 4029, Australia.

Hacmochromatosis (HC) is an inherited disorder of iron metabolism which can cause hepatic cirmosis. The prevalence in most Caucasian populations studied is approximately 1 in 300 though the disorder remains under diagnosed. One reason for such under diagnosis may be that liver function tests (LFT) are often normal. The significance of abnormal LFT in HC has not previously been studied.

50 HC patients were analysed with respect to abnormalities of transaminases at diagnosis, age, sex, transferrin saturation, serum ferritin, hepatic iron concentration (HIC), Schever grade of fihrosis and the presence of other histological hepatic features.

$56 \%$ had normal LFT at diagnosis compared to $44 \%$ with abnorma LFT. There were no significant differences between thi two groups in terms of agc, transferrin saturation or HIC. The group with abnormal LFT however had significantly higher serum ferritin levels $(1812 \pm 986$ vs $669 \pm 407, p<0.0001)$ and a greater male preponderance $(p<0.05)$. $29 \%$ of patients with normal LFT had no histological abnormalities other than increased iron stores. 35\% of patients with normal LFT had hepatic fibrosis without histological inflammation, steatosis or other histological abnormalities. All patients with abnormal LFT had histological abnormalities other than increased hepatic iron stores. Patients with abnormal LFT were more likely to have fibrosis than those with normal LFT $(82 \%$ vs $54 \%, p<0.05)$ and to have a more severe grade of fibrosis $(1.9 \pm 1.4$ vs $0.8 \pm 0.8, p<0.001)$.

Liver damince can develop in HC due to increased iron stores alone and in the presence of normal LFT. However, HC patients with abnormal LFT are morc likely to have fibrosis and at a more advanced stage. Therefore, although abnormal LFT indicate the presence of hepatic complications in haemochromatosis, normal LFT do not preclude the presence of hepatic damage. Recently the HC gene has been cloned and a genetic diagnostic test may soon be available. However, in general liver biopsy is still indicated in haemochromatosis for diagnosis and assessment of hepatic complications.
FINDINGS ON LIVER BIOPSY FOR ABNORMAL LIVER FUNCTION TESTS IN THE POST HEPATITIS C TESTING ERA. $G$ Vautier, $P$ James and S Ryder. Departments of Gastroenterology and Pathology, Queen's Medical Centre, Nottingham, NG7 2UH.

Background. Abnormal liver function tests are relatively common but their significance In the presence of negative serological tests is uncertain.

Methods. We have prospectively studied 210 consecutive patients aged 18 to 78 undergoing investigation for abnormal liver function tests, defined as persistent elevation of ALT or GGT over 6 months, in whom serology for hepatitis B and C. autoantibodies, serum ferritin, alpha-1-antitrypsin, copper studies (where appropriate), and ultrasound scanning were normal/negative. Alcohol histories were taken from patients and corroborating relatives and if consumption $>4 \mathrm{~g}$ per day patients were excluded.

Results. 8 patients refused liver biopsy. 9/202 (4.5\%) were cirrhotic on biopsy and a further $19(9.4 \%)$ had increased fibrosis. Final diagnoses were Non-Alcoholic steatohepatitis 68 [34\%], fatty liver without inflammation 74 [37\%], alcohol related liver disease 6 [3\%], autoimmune hepatitis (steroid responsive) 4 [2\%] drug induced $31[15 \%]$, primary biliary cirrhosis $1[0.5 \%]$, haemochromatosis $2[1 \%]$, amyloidosis $1[0.5 \%]$ and normal liver 15 [7.5\%]. Complications of liver biopsy (non U/S guided, menghini needle) were 4 patients with post biopsy pain and one with a bile leak requiring 6 days hospitalisation. No patients suffered haemorrhage.

Conclusions. Liver biopsy for abnormal liver function tests produces a diagnosis of potentially progressive liver disease in $55 \% .13 \%$ of patients had significant fibrosis or cirrtosis at the time of biopsy. Clinical management was altered in $\mathbf{4 3}$ patients (21\%) and only one significant complication of liver biopsy was seen. Patients with persistent abnormalities of their liver function tests should be offered liver biopsy.
THE EFFECT OF HORMONE REPLACEMENT THERAPY ON SERUM AND URINARY MARKERS OF BONE TURNOVER IN PRIMARY BILIARY CIRRHOSIS. SP Pereira', J O'Donohue', C Moniz $^{2}$, C Mackintosh ${ }^{2}$, H Abraha ${ }^{2}$, M Buxton-Thomas ${ }^{3}$, Roger Williams'. 'Institute of Liver Studies, and Depts. of ${ }^{2}$ Clinical Biochemistry and ${ }^{3}$ Nuclear Medicine, King's College Hospital, Londor. SES 9RS.

Evidence from retrospective studies suggests that hormone replacement therapy (HRT) is well-tolerated and may be helpful in retarding the rate of bone loss in primary biliary cirrhosis (PBC). However, there have been no prospective studies in PBC of the effect of HRT on bone mineral density or serum and urinary markers of bone tumover. Methods: 42 postmenopausal women with PBC (median age $57 \mathrm{yr}$, range 52-63 yr) were treated with calcium+vitamin $D$, either alone $(n=22)$ or together with topical HRT ( $n=20$; Estracombi, Ciba). Bone densitometry (Lunar) of the femoral neck and L2-L4 vertebrae was performed at baseline, and serum and urinary markers of bone turnover measured at three-monthly intervals. We report here our baseline and three-month findings. Results: The two groups were well-matched for age, year of menopause $(49 \mathrm{yr}, 43-51 \mathrm{yr})$, histological stage, serum bilirubin level (median $15 \mu \mathrm{M}$, range 4-65 $\mu \mathrm{M}$ ) and bone densitometry scores. In the 42 patients, spinal or femoral osteopaenia (T score -1 to -2.5 ) was present in $16(38 \%)$, while 7 others (17\%) had established osteoporosis $(T<-2.5)$. Baseline serum osteocalcin and adjusted calcium concentrations were 7.0 $\mu \mathrm{g} /(4.2-14.9 \mu \mathrm{g} /)$ and 2.4 $\mathrm{mM}(2.2-2.6 \mathrm{mM})$, respectively, which did not change significantly at three months in either group. In the controls, urinary calcium and creatinine levels, and urinary deoxypyridinoline:creatinine ratios, were similar baseline and three months. In contrast, urinary calcium concentrations fell significantly in the HRT group, from $2.5 \mathrm{mM}$ to $1.2 \mathrm{mM}(p<0.05)$. Overall, HRT was well-tolerated, with no increase in cholestasis and only one withdrawal due to minor side-effects. Conclusions: The initial results of this prospective study confirm that osteoporosis is common in postmenopausal women with PBC, and that topical HRT is well-tolerated. Compared with calcium+vitamin D alone, supplemental HRT is associated with decreased urinary calcium excretion -- a sensitive marker of bone turnover. 


\begin{tabular}{|c|c|c|c|c|}
\hline \multicolumn{5}{|c|}{ 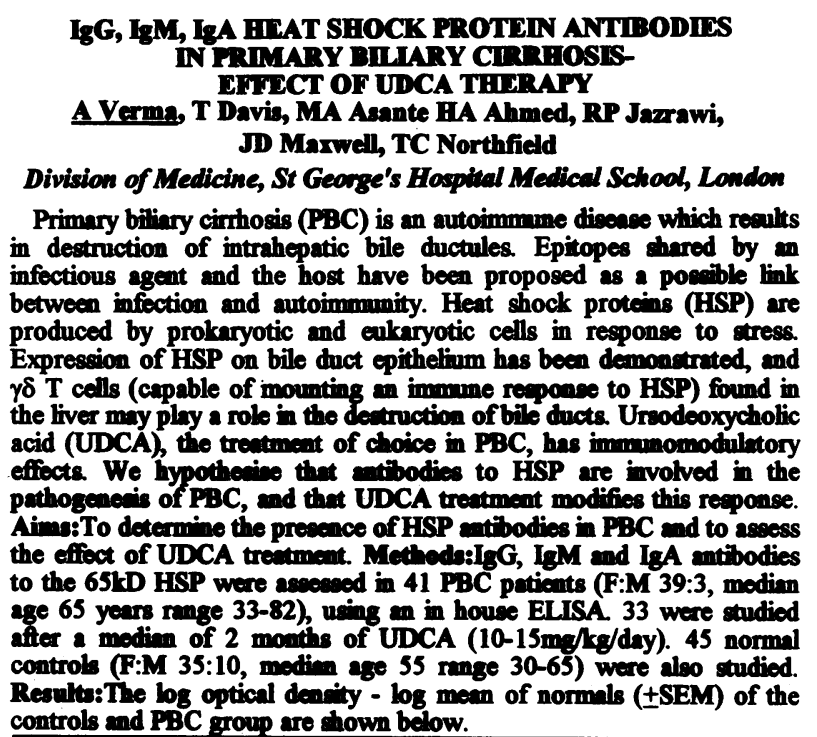 } \\
\hline & & & & \\
\hline & & & & \\
\hline & $05 \pm 0$. & $0.065 \pm 0.015^{*}$ & & \\
\hline & & & & \\
\hline
\end{tabular}
${ }_{p}^{*}<0.02$ compared with normal controls $p<0.03$ vs early $P B C$ UDCA treatment did not alter HSP antibody levels in any stage of PBC for all classes of Ig. Conclusion:Antibodies to HSP are elevated in PBC. Short term UDCA therapy does not affect this response. The presence of antibodies to HSP may suggest a role for this protein in the pathogenesis of PBC. Further studies to define their role in the pathogenesis and as possible markers of disease activity with longer treatment with UDCA are needed.
W55

BCL-2 AND WAF PROTEIN EXPRESSION IN CHRONIC LIVER DISEASE

P. Papakyriakou*, M. Tsardi**, P. Kanavaros"* and E.Kouroumalis*.

Depts of Gestroenterciogy* and Pathology * Univeraity Hospital Hercklion, Crete, Greece.

Apoptosis is a poseible mechanien of cell decth in liver disecese. Its role has not been adequately studied. Apoptosis is controlled by eeveral genes whose protein products either inhibit or accelerate epoptocis.

We therefore studied the protein expression of one intibiting gene (bct-2) and one promoting gene (waif).

Liver biopeies from 10 petients with primary bilery cirnoais (PBC). 10 with chronic hepatitis C and 10 with chronic hepetitis B, were studied by immunocytochemictry using monoctonal antibodies goninst bet-2 and wef proteins.

Bct-2 was expreased in billo ductular cells of all patients studied, but in PBC it was either overexpresesed or not expresesed in most intrehopetic bile ductules.

There wes profound infitration of portal trects by bcl-2 positive Iymphocytos in PBC and to a leceer extent in chronic hepectitis. Moreover meny poaltive intralobular lymphocytes were identified. By contrast waf protein expreseion was identifiod in nuctei of hepatocytes near arees of pioce meel necrosis only in chronic hepatitis either B or C. In PBC no positive nuclei were noted.

Conclusions: 1) Apoptosis controlling proteins are expressed in liver disease. 2)Clones of epoptocis resistant infiltrating lymphocytes expressing bcl-2 are predominant in chronic liver expreasin

3) Apoptosis promoting proteins are expreseced in 3) Apoptosis promoting proteins are expressed in
hepatocyte nuclei in viral hepatitis but not in PBC.
URSODBOXYCHOLIC ACID THERAPY FOR PRIMARY BILIARY CIRRHOSIS: 10 YEARS' POPULATION-BASEI EXXPRIEICE BATESON, M.C. \& GEDLING, P.

GENERAL HOSPITAL, BISHOP AUCKLAND, UK.

From 1981 all symptomatic cases of primary biliary cirrhosis (PBC) in a health district of 153,000 residents have been identified by the local gastroenterologist and liver biopsy performed in all but one. After April 1987 all cases seen were offered treatment with ursodeoxycholic acid (UDCA) $750 \mathrm{mg}$ daily. The 37 treated with UDCA were followed up at $1,2,4,6,9, \& 12$ months and then 6 monthly. Results were compared with historical local controls and published data in other series.

There was a uniform early improvement in abnormal "liver function" tests, maximal at 4 months. There was an early improvement in histology in 3 out of 8

rebiopsied at 4 months. Twenty-eight patients reported improvement or cure in symptoms, 7 had no change, and in 2 patients there was a prompt exacerbation which led to immediate cessation of treatment.

Overall survival was significantly improved, though it was still less than the general population and the effect was only seen after 2 years' treatment. Histological stage I disease, lower age and lower initial bilirubin. and to a lesser extent serum IgG and haemoglobin levels predicted better survival. In stage I disease median follow- up was 4 years. Survival was normal in the 14 allocated to UDCA, and 1 case followed for 7 years lost all clinical evidence of disease and may have been cured. In stage II to IV disease median follow-up was $2 \frac{t}{2}$ years: in the 23 allocated to UDCA there was a sustained trend to improved survival ( 378 v. $28 \%$ at 7 years, KaplanMeier analysis). Most deaths related to liver disease and by chance none of the patients has proceeded to liver transplant, so these are true absolute life tables.

CONCLUSION - UDCA is effective and easy to use, avords the need for more toxic drugs in PBC, and should be offered to all cases not imminently expecting transplant. There may be a case for treating pre-symptomatic disease.
NITRIC OXIDE RELEASE IN THE SPLANCHNIC CIRCULATION OF CIRRHOTIC RATS

AI Sarela \& RT Mathie (Introduced by RCN Williamson). Department of Surgery, Royal Postgraduate Medical School, Hammersmith Hospital, London W12 ONN

Enhanced splanchnic vascular nitric oxide (NO) activity has been implicated in the pathogenesis of portal hypertension associated with cirrhosis of the liver. However, the portal venous concentration of total nitrite and nitrate (nitric oxide metabolites, NOx), which is established as a reliable indicator of NO production, has not been previously studied.

Experimental micro-nodular cirrhosis was induced in adult male Wistar rats by the administration of phenobarbitone and carbon tetrachloride $(n=7)$. Age- and weight-matched rats $(n=5)$ and phenobarbitone treated rats $(n=5)$ served as controls. We assayed portal venous concentrations of NOx and total biochemical activity of nitric oxide synthase (NOS) in the liver and mesentery of both groups.

Cirrhotic rats had significantly higher mean portal pressure than controls $\{11.00$ (S.E.M. 1.22) vs. $4.80(0.96) \mathrm{mmHg}$. $P=0.002\}$. Portal venous concentrations of NOx were significantly lower in cirrhosis than in controls $\left\{75.33(16.54)\right.$ vs. $\left.128.34(15.66) \mu \mathrm{mol} . .^{-1} ; P=0.02\right\}$. There was a significant negative correlation between portal pressure and portal venous NOx concentrations $\{r=-0.57 ; P=0.04\}$. Total NOS activity in the mesentery was higher in cirrhosis than controls $\{6.17(1.19)$ vs. 3.30 $(0.68)$ pmol. $\left.\mathrm{g}^{-1} \cdot \mathrm{min}^{-1} ; P=0.04\right\}$. In contrast, hepatic total NOS activity was similar in both groups $\left\{11.79(2.14)\right.$ vs. $10.06(1.42)$ pmol..$^{-1} \cdot \mathrm{min}^{-1}$; $P=0.60$ ).

These results imply that total NO release in the portal venous drainage territory of cirrhotic rats is decreased, although mesenteric NOS activity is enhanced. We speculate that NO release in the splanchnic viscera may be downregulated in response to the overactivity of another putative vasodilator which is NO-independent. The inverse relationship between portal pressure and portal venous NOx concentration would support this hypothesis 
EFECT OF TIPSS ON RENAL BLOOD FLOW IN CIRRHOTIC PATIENTS.

A. Stanley, DN Redhead", IAD Bouchier, PC Hayes.

Depts. Medicine and Radiology*, Royal Infirmary of Edinburgh, UK.

It has been suggested that an acute increase in portal presaure can cause an immediate reduction in renal blood flow (RBF) via an hepato-renal reflex. In addition, transjugular intrahepatic portosystemic stent-shunt (TIPSS) can improve renal function by mechanisms that remain unclear. We used TIPSS placement as a model to investigate the effect of an acute reduction in portal pressure on RBF and other haemodynamic parameters.

Methods: 10 cirrhotic patients (8 alcohol related; 6 male; mean age 59.5(4.6) yrs; mean CPS 8.3(1.1)) were studied during elective TIPSS procedure ( 8 for variceal haemorrhage, 2 for refractory ascites). Unilateral RBF (thermodilution method) was measured prior to and at $5,15,30,45$ and 60 minutes after shunt placement. Right heart catheterization was undertaken prior to and 30 minutes following shunt placement to measure cardiac output (CO), systemic vascular resistance (SVR) and mean pulmonary artery pressure (PAP). Heart rate (HR), mean arterial pressure (MAP) and right atrial pressure (RAP) were also measured at these times.

Results: See table. No change was observed in RBF at any time point after TIPSS. Porto-atrial pressure gradient fell by a mean of $16.7(1.6) \mathrm{mmHg} \quad(p<0.001)$. RAP rose from $2.0(1.2)$ to $8.4(1.2) \mathrm{mmHg}(\mathrm{p}<0.001)$, but no change was seen in HR or MAP.

\begin{tabular}{|l|l|l|l|l|}
\hline & $\begin{array}{l}\text { RBF } \\
(\mathrm{ml} / \mathrm{min})\end{array}$ & $\begin{array}{l}\text { CO } \\
(\mathrm{l} / \mathrm{min})\end{array}$ & $\begin{array}{l}\text { SVR } \\
(\mathrm{DS} / \mathrm{cm})\end{array}$ & $\begin{array}{l}\mathbf{P A P} \\
(\mathrm{mmHg})\end{array}$ \\
\hline pre-TIPSS & $252.1(66.8)$ & $5.8(1.0)$ & $1313.5(111.8)$ & $13.1(2.1)$ \\
\hline$+30 \mathrm{mins}$ & $277.2(69.0)$ & $7.5(1.1)$ & $932.8(111.6)$ & $25.2(2.0)$ \\
\hline p value & NS & $\mathrm{p}<0.005$ & $\mathrm{p}<0.005$ & $\mathrm{p}<0.001$ \\
\hline
\end{tabular}

Conclusion: There is no acute increase in RBF in response to the acute drop in portal pressure caused by TIPSS. Any improvement in renal function following TIPSS does not appear to involve an immediate increase in RBF.
W59

A NEW AUTOANTIGEN IN AUTOIMIMUNE LIVER DISEASE: ARGININOSUCCINATE LYASE

Pelli $N^{\prime}$, Cancado $E^{\prime}$, Mieli-Vergani $G^{2}$, Vergani $D^{1}$. Institute of Hepatology ${ }^{1}$, University College London Medical School, London; Depts of Child Health, King's College Hospital ${ }^{2}$, London

Autoantibodies have a central role in the diagnosis and classification of autoimmune liver diseases (AILD). $\mathrm{LCl}$ antibody (LC1-ab), second marker of a severe form of autoimmune hepatitis (AIH), is often associated with LKM-1 and is detected by immunofluorescence (IFL) double dimension immunodiffusion (DDI) and Western blotting (Wb) Ultracentrifugation and immunofluorescence studies show the $\mathrm{LCl}$ antigen to be present in the cytosol of periportal hepatocytes, its molecular nature remaining unknown. To investigate the target of $\mathrm{LC1}$ $a b$, we have used two LCl-ab +ve sera (one ANA and one LKM-1+ve) to screen a panel of 18 periportal enzymes by DDI. These enzymes, with a median degree of homology with the human counterpart of $78 \%$, included: lactic dehydrogenase, arginase, argininosuccinate lyase (ASL), beta-glucuronidase, malic enzyme, pyruvate kinase, fructose1,6-diphosphatase, alcohol dehydrogenase, 6-phosphogluconic dehydrogenase, malic dehydrogenase, hexokinase, cytochrome oxidase, aspartateamino transferase, alanineamino transferase, adenosine-5-triphosphatase, gamma-glutamyl-transpeptidase, glutathione peroxidase and alkaline phosphatase. Both sera recognised ASL, a cytosolic enzyme involved in the urea cycle and gave a line of complete identity between themselves. ASL and $\mathrm{LC1}$ antibodies were tested in 120 patients, age range 1-77 years (median 20), 74 with AILD (25 AIH type I, 32 AIH type II, 17 PBC), 15 chronic HBV infection, $13 \alpha 1$ anti-trypsin deficiency, 18 extraepatic autoimmune disorders (16 connective tissue disease, 1 autoimmune thyroiditis, 1 autoimmune haemolytic anaemia) and 24 healthy controls, age range 5-20 years (median 15). Thirteen were positive for ASL: 2 AIH type I (8\%), 7 AIH type II $(22 \%)$ and 4 PBC $(23 \%)$. All other patients and healthy controls were negative. There was no correlation between ASL and $\mathrm{LC} 1$ positivity.

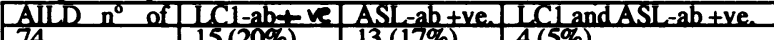

Under high resolution DDI conditions (0.8\% Agarose and 3\% PEG) using the two LC1-ab reference sera and testing simultaneously each serum against ASL and $\mathrm{LCl}$ substrates, two lines were formed against $\mathrm{LCl}$, one of which was of partial identity and the other of non identity with ASL. In conclusion a new autoantigen - ASL- is present in AILD. The molecular nature of $\mathrm{LCl}$ remains still to be defined.
A PROSPECTIVE STUDY OF SPEEDBAND VERSUS STEIGMANNGOFF IN ENDOSCOPIC LIGATION OF OESOPHAGEAL VARICES. T. Wong, S. Pereira, A. McNair, P. Harrison. Institute of Liver Studies, King's College Hospital, London SE5 9RS.

Endoscopic ligation is the treatment of choice for oesophageal varicea obliteration; however the use of an overtube leads to significant morbidity and mortality. Recent advances in endoscopic technology have led to development of multiple banding devices that do not require the application of an overtube. In the present study we prospectively examined the safety and efficacy of one such device: Speedband against the conventional Stiegmann-Goff (Bard) ligator.

Patients and Methods. We prospectively studied 99 variceal banding sessions in $\mathbf{4 5}$ patients. Speedband ligation was performed in 60 sessions, and Bard in 39 sessions. Parameters examined included sedation dosage, patient discomfort (mild, moderate, or severe), upper oesophageal damage immediate band slippage, total time of banding session, total time required for band application (first to last band), and average time of application per band. Variceal ligation sessions were randomly assigned to one of the 4 endoscopists experienced in both methods of band application, and the Olympus Q200 endoscope was used for all procedures.

Results. Patients were well matched at time of endoscopy with respect to number of varices (mean 3.3 vs 3.4), grade of varices (1.8 vs 1.7), age (49 yrs vs 50.4 yrs), number of bands applied (4.0 vs 3.4), and Child's-Pugh score ( $64 \%$ vs $68 \%$ Child's-Pugh A), Speedband vs Bard respectively. The use of Speedband was associated with a significant reduction in midazolam (7.3 $\mathrm{mg}$ vs $9.2 \mathrm{mg}, \mathrm{p}=0.03)$, and pethidine $(10.4 \mathrm{mg} \mathrm{vs} 24.3 \mathrm{mg} \mathrm{p}=0.01)$ requirements. Patients undergoing Speedband application experienced less discomfort $(90 \%$ vs $66 \%$ mild discomfort, $p<0.001)$, and less upper oesophageal damage $(76 \%$ no damage vs $55 \%, p<0.01)$. One patien undergoing Bard ligation died due to an oesophageal rupture from the overtube, and in a further 2 cases ligation was abandoned due to oesophageal haemorrhage; no such complications occurred in the Speedband group. The total time of the endoscopic session was reduced in the Speedband group ( $7 \mathrm{~min} 58 \mathrm{secs} v \mathrm{~s} 11 \mathrm{~min} 33 \mathrm{sec}, \mathrm{p}<0.001$ ), as was the time required for band application $(2 \mathrm{~min} 52$ secs vs 5 min 9 secs, $\mathrm{p}<0.00 \mathrm{I}$ ), and average time taken per band application (46 secs vs $1 \mathrm{~min} 32$ secs, $p<0.01$ ). There were no differences between the groups with respect to immediate band slippage ( $18 \%$ vs $33 \%, p=0.09)$

Conclusions Speedband ligation is safer, quicker, and associated with less patient discomfort and morbidity when compared with Bard ligation. On the basis of this data a multiple banding device is the method of choice for endoscopic variceal ligation.
Detection of anti conformational CYP2D6 antibodies in patients with autoimmune liver disease and $\mathrm{HCV}$ infection using a novel radioligand Ma $\mathrm{Y}^{1}$, Gäken $\mathrm{J}^{3}$, Bianchi $\mathrm{F}^{4}$, Mieli-Vergani $G^{2}$, Vergani $D^{1}$. Institute of Hepatology ${ }^{1}$, University College London Medical School, London; Depts of Child Health', Molecular Medicine ${ }^{3}$, King's College Hospital, London, UK and Semeiotica Medica ${ }^{4}$ University of Bologna, Italy

LKM-1 antibody is the diagnostic marker of autoimmune hepatitis (AIH) type 2 and is also found in a proportion of patients with
hepatitis C virus (HCV) infection. Cytochrome P4502D6 (CYP2D6) hepatitis C virus (HCV) infection. Cytochrome P4502D6 (CYP2D6) LKM-1 positive AIIH sera recognise the prokaryotically expressed cytochrome. In contrast, only a minority of $L K M-1 /$ anti-HCV positive sera do so. In order to investigate the target of LKM-1 in HCV infection, we have established a highly sensitive and specific radioligand assay using eukariotically expressed CYP2D6 as target. A $1.2 \mathrm{~kb}$ human CYP2D6 cDNA was isolated from a human liver CDNA library and subcloned into an in vitro transcription vector pSP64 Poly(A). Recombinant CYP2D6 protein was then produced using an in vitro transcription/translation and metabolically labelled with ${ }^{35} \mathrm{~S}$ methionine. This served as target in the immunoprecipitation assay. Antibodies that bound radiolabelled CY P2D6 were immunoprecipitated using protien A-Sepharose beads and their levels assessed as cpm in a liquid scintillation analyzer. A total of $53 \mathrm{LKM}-1$ positive sera from 22 children with AIH (median age 10 range 1 to 20 yrs) and 31 adults with $\mathrm{HCV}$ infection (median age 49 , range 16 $20 \mathrm{yrs}$ ) and 31 adults with HCV infection (median age 49, range 16 to 71 yrs) were tested. One hundred and twenty five LKM-1 negative
sera from 101 age matched children with liver disease $(9$ HCV sera from 101 age matched children with liver disease (9 HCV
infection, $23 \mathrm{HBV}$ infection, 19 AIH type 1,18 autoimmune sclerosing cholangitis, $19 \alpha 1$-antitrypsin deficiency and 13 Wilson's disease) and 24 adults with systemic lupus erythematosus and sera from 37 healthy children and 20 adults were also tested. Amongst LKM-1 positive sera, reactivity to ${ }^{35}$ S labelled CYP2D6 was observed in all sera from AIH and in 26 (84\%) from HCV infection. The cpm in both conditions were significantly higher than in normal controls $(P<0.0001)$, and were correlated with the immunofluorescence titres of LKM-1 in AIH $(r=0.84, P<0.001)$ but not in HCV infection
$(\mathrm{r}=0.26)$. No reactivity to ${ }^{35} \mathrm{~S}$ labelled CYP2D 6 was observed in patients negative for LKM-1 and in normal controls. In conclusion: a) CYP2D6 is a major target antigen in both AIH and HCV infection bu the antibody affinity is different; b) the novel radioligand assay is highly sensitive and specific. 
W61

THE IMPACT OF CHRONIC HEPATITIS C INFECTION ON HIV DISEASE AND PROGRESSION IN INTRAVENOUS DRUG ABUSERS. GH Haydon', CS Blair', PJ Flege ${ }^{2}$ RP Brettle', SM Burns', PC Hayes'. Departments of Modicine' and Infectious Diseases', University of Edinburgh and Regional Virus Laboratory ${ }^{3}$, City Hospital, Edinburgh.

It is unclear whether co-infoction with hepatitis $\mathrm{C}$ virus (HCV) can influence HIV related morbidity or mortality, either by accelereting HIVrelated disease progression, or by contributing to end stage liver discase. The aim of this study was to examine the effect of HCV infection on the severity and proeression of HIV disease in a cohort of Edinburgh IVDAs Methods: In 240 (47\%) out of 508 patients in the Edinburgh IVDA cohort, HIV seroconversion dates (midpoint between last negative and first positive test) and anti-HCV serology were available. Comparison of the anti-HCV positive and anti-HCV negative groups was performed by Chi-square analysis; progrecsion from date of HIV seroconversion was calculated by Kaplan-Meier survival analysis. Parnmeters aseceseod included clinical end points (time of developmeat of siemificant symptoms attributable to HIV (CDC stage IV), time of development of AIDS (CDC 1993 criteria), and time of death) and immunological end points (time of $\mathrm{CD4}^{+}$counts dropping below $200 / \mathrm{mm}^{3}, 100 / \mathrm{mm}^{3}$ and $50 / \mathrm{mm}^{3}$ respectively).

Reeults: 202 out of 240 paticnts (84\%) had positive antiHCV serolosy. There was no significant difference in the frequency of clinical and immunological endpoints between the anti-HCV positive and negative groups. Progression analysis from HIV seroconversion to HIV related clinical endpoints indicated that anti-HCV serology was not a significant factor influencing the rate of HIV progression (relative risks (RR) for antiHCV positive group: seroconversion to CDC IV: 1.01 ; seroconversion to AIDS: 1.05; seroconversion to death: 0.90). Likewise HCV serostatus did not significantly affect progression to immunological end points (RR for anti-HCV positive group: seroconversion to CD4t<200: 1.04; seroconversion to CD4t<100: 1.13 ; seroconversion to CD4 $+<50: 0.97$ ). Conclusions: This study demonstrates that HCV coinfection does not influence the rate of progression to either clinical or immunological end points in our population of HIV-infected drug users. Further data are required to assess the effect of HIV on the progression of HCV-related liver disease.
W63

LOWER PREVALENCE OF MARKERS OF AUTOIMMUNITY IN CHRONIC HEPATITIS C IN NORTH-EAST OF ENGLAND.

F.Zappala', MF Bassendine.

Dept. of Medicine, University of Newcastle upon Tyne, UK.

Background: It has been suggested that there is an interaction between HCV and autoimmunity, in some case series of chronic hepatitis C high overall prevalence of serum antitissue antibodies (41-66\%) and theumatoid factor $(70-76 \%)$ have been reported. Aim: to estimate the prevalence of markers of autoimmunity in pts affected by chronic hepatitis $C$ living in the North-East of England. Patients and methods: 101 antiHCV+ve pts by second-generation ELISA or RIBA ( 59 male, 42 female, mean age 43+10, range 24-88) with chronic hepatitis $C$ diagnosed on the basis of persistently elevated ALT, HCV RNA positivity (Roche Amplicore) and liver histology were tested for: antismooth muscle antibodies (SMA), anti liver/kidney microsomal antibodies (LKM), antinuclear antibodies (ANA), anti-mitochondrial antibodies (AMA), anti-thyroid microsomal antibodies and theumatoid factor (RF). All pts were caucasian and bom in the UK. Results: all pts were AMA and LKM negative

\begin{tabular}{|l|c|c|c|}
\hline & ANA & SMA & thyroid \\
\hline male & $0 / 59$ & $2 / 59^{*}$ & $1 / 59$ \\
\hline female & $1 / 42^{*}$ & $2 / 42^{*}$ & $2 / 42$ \\
\hline tot/\% & $1 / 101(1 \%)$ & $4 / 101(4 \%)$ & $3 / 101(3 \%)$ \\
\hline & $\mathrm{RF}<40$ & $40<\mathrm{RF}<640$ & $\mathrm{RF}>640$ \\
\hline male & $14 / 59$ & $6 / 59$ & $1 / 59$ \\
\hline female & $8 / 42$ & $4 / 42$ & $7 / 42 \#$ \\
\hline tot $/ \%$ & $22 / 101(21.4 \%)$ & $10 / 101(10.2 \%)$ & $8 / 101(7.1 \%)$ \\
\hline
\end{tabular}

*titre $<40, \# p<0.01$ (female vs male)

In SMA+ve and ANA+ve pts the overall biochemical profile did not show features of autoimmune chronic hepatitis. 2/4 SMA+ve and the ANA+ve pt had liver biopsies which confirmed HCV etiology. Conclusions: 1) The prevalence of antitissue antibodies among our pts is very much lower than overseas case series. 2) Although the prevalence of RF was lower than elsewhere it was detectable in $37.7 \%$ of pts in keeping with the hypothesis that $\mathrm{HCV}$ can cause a benign proliferation of $B$ cells.
INTERFERON (IFN) SPARING EFFECT OF ADJUVANT TAUROURSODEOXYCHOLIC ACID (T-UDCA) FOR TREATMENT OF CHRONIC HEPATITIS C. RESULTS ON LIVER HISTOLOGY.

MG Pigozzi, R Sorbara, A Reggiani, M De Tavonatti, L Bettini, GP Lorini, C Lazzari, A Cominotti*, M Favret*, S Sosta, A Lanzini

Co-ordinating Centres: Medicine I and Pathology II*, Spedali Civili. Brescia. Italy.

Long-term IFN administration combined with a dose tapering strategy has been reported to be the most effective treatment for chronic hepatitis C (Hepatology 1995; 22: 700-6). Based on a dose tapering strategy, we have previously reported an IFN sparing effect of adjuvant t-UDCA administration (Hepatology 1996; 24; 403A) as judged on serum transaminases, but the effect on liver histology was not assessed.

The aim of the present study was to assess the effect on liver histology of a strategy combining t-UDCA adjuvant therapy with 6 months full dose IFN followed by further 6 months IFN dose tapering.

121 patients with chronic hepatitis $\mathrm{C}$ have been randomised to receive either lymphoblastoid IFN alone ( $3 \mathrm{MU} / \mathrm{m}^{2} /$ t.i.w. (regimen A) or IFN $+\mathrm{t}$ UDCA $(10 \mathrm{mg} / \mathrm{kg} / \mathrm{day})$ (regimen B) for 6 months, followed by further 6 months IFN dose topering for responders (ALT $<1.5$ upper limit of normal) Control liver biopsies were carried out 6 months after stopping IFN, while tUDCA was maintained for regimen B. Disease grading and staging was assessed by the Ishak score system ( J Hepatol 1995; 22: 696-9).

68 patients have been presently followed up for 18 months, and the proportion of responders was similar for regimens A and B (19/32 and 21/36 respectively, NS). 43 patients have had repeat biopsy at 18 months Histological grading decreased from $7.5+0.8$ pre-treatment to $5 \pm 0.9$ during regimen $\mathrm{A}(\mathrm{n}=22, \mathrm{p}<0.03)$ and from $7.3 \pm 0.8$ to $4.9 \pm 0.8$ during regimen $B(n=21, p<0.03)$. Staging remained unchanged before and during treatment at $2.2+0.4$ vs $2.0+0.4$ respectively for both regimens. As a result of dose tapering, 6 month curnulative IFN dose was higher in patients treated with IFN alone $(583 \pm 21 \mathrm{MU})$ than in those treated with IFN + t-UDCA $(505 \pm 8$ MU, $\mathbf{p}<0.002$ ).

Our results indicate that adjuvant t-UDCA has an IFN sparing effect, with improvement of liver histology similar to that achieved with higher IFN doses. We conclude that it may be worth further testing the IFN sparing effect of t-UDCA by extending the dose tapering strategy to the whole treatment period.
PLASMA TMP-1 LEVEIS INCREASE WITH SEVERITY OF LIVER DISEASE IN CHRONIC HEPATITIS C.

Wolinh K.M.,Timme P.M².,Campbell S, MacSween R.N.M², Morrb A.J.

Department of Gastroenterology and Human Nutrition, Glaegow Royal Inflemary;Blochomiatry Dept, Stobhill Houpital ${ }^{1}$ and Patholosy Dept, Western Infirmary ${ }^{2}$, Glasgow U.K.

BACKGROUND A non-invasive and easily repeatable test of liver disease activity in chronic hepatitis $C$ would be valuable, especially in patients with bleeding disorders in whom liver biopsy has increased risks. As chronic liver disease progresses, there is an imbalance between synthesis and breakdown of extracellular matrix (ECM). Tissue inhibitor of metalloproteinaise-1(TIMP-1) is one of a group of enzymes which inhibits metalloproteinases and are involved in the breakdown of ECM. We have measured TIMP-1 activity in patients with chronic hepatitis $C$ and compared this with liver histology.

METHODS: Plasma TIMP-1 levels were measured using a specific sandwich enzyme immunoassay kit (Amersham UK) in 10 patients with mild chronic hepatitis, 9 patients with severe chronic hepatitis or cirrhosis and 14 controls with normal liver function tests. Liver biopsies on the patients with hepatitis $\mathrm{C}$ were scored for a histological activity index by an independent observer, blind to clinical details or TIMP-1 results.

RESULTS: Plasma TIMP-1 levels in patients with severe liver disease $(846.5 \mathrm{ng} / \mathrm{ml}+351.2)$ and with mild liver disease $(533.1 \mathrm{ng} / \mathrm{ml} \pm 313.6)$, were elevated compared to controls $\left(187.1 \mathrm{ng} / \mathrm{ml}^{-} \pm 62.2\right)$, p<0.05. TIMP-1 levels in patients with severe liver disease were significantly higher than in those with mild liver disease, $p<0.05$. (mean + S.D.)

CONCLUSION: Plasma TIMP-1 levels increase with severity of liver disease in chronic hepatitis $C$. The data suggest that plasma TIMP-1 measurements maybe used as a non-invasive indicator of disease activity in chronic hepatitis $\mathrm{C}$. 
OUTCOME OF ORTHOTOPIC LIVER TRANSPLANTATION IN HAEMOPHILIA

FH. Gordon ${ }^{1}$, PK Mistry', CA Sabin² and CA Lee (introduced by JS Dooley). Liver Transplantation and Hepatobillary Medicine Dept.', Prinary Care and Population Statiotics Dept. ${ }^{2}$ and Haemophilia Centre ${ }^{3}$, Royal Free Hoopital School of Medictice, Rowland Fill Street, London NW3 2PF.

Introduction Many hacmophiliacs have developed cirthosis or hepatocellular carcinoma (HCC) due to chronic hepatitis B and/or C virus infection (HBV/HCV) transmitted from clotting factor concentrates; the outcome of those who have required orthotopic liver transplantation (OLT), is assessed .

Methods Transplant centres of patients identified by medical database search were contacted and survival data assessed by Kaplan-Meier analysis.

Results Twenty-five male haemophiliacs, mean age 39 years (range 563 years) underwent OLT in 15 centres between 1982 and 1996. Indications for transplantation were HCV cirhosis (68\%), HBV cirnosis $(16 \%)$, HCC $(12 \%)$ and biliary atresia (4\%). Six patients (24\%) were HIV positive pre-OLT; one had suffered an AIDS-defining illness. Post-OLT, the mean time to normal clotting factor levels was 18 hours (range 0-48 hours) and exogenous clotting factors were stopped at a mean of 49 hours (range 0-480 hours). Four patients had bleeding complications despite normal clotting values. The 1 and 3 year survival of $6 \mathrm{HIV}$ positive recipients $(67 \%$ and $23 \%)$ was significantly less $(p=0.0003$ each timepoint) than that of $19 \mathrm{HIV}$ negative recipients (90\% and $83 \%$ ); 2 of the 5 HIV positive deaths were due to HIV-unrelated causes. Coagulopathy was cured in all 23 patients who survived more than 10 days post-OLT Six of 16 patients (37\%) with HCV cirrhosis pre-OLT developed biopsyproven HCV at a mean of 9 months post-OLT. Three of the $4 \mathrm{HBV}$ positive patients also developed disease recurrence.

Conclusions OLT cures the coagulopathy of haemophilia. HCV cirrhosis is the commonest indication for OLT but outcome may be complicated by the effects of HIV co-infection or by graft-recurrence of HCV.
ABERRANT EXPRESSION OF P53 AND KI-67 DURING ACUTE AND CHRONIC REJECTION FOLLOWING ORTHOTOPIC LIVER TRANSPLANTATION

MM Dollinger ${ }^{1,2}$, JN Plevris', A Graham ${ }^{2}$, SEM Howie', PC Hayes', DJ Harrison'. (1) Department of Medicine, The Royal Infirmary, Edinburgh, EH3 9YW, (2) Department of Pathology, University Medical School, Edinburgh, EH8 9AG, Scotland, UK.

Apoptosis and proliferation are important in regulating immune responses such as allograft rejection. Unlike apoptosis, proliferation and its role have not been investigated in hepatic graft rejection thusfar. $\mathrm{Ki}-67$ is a common marker of cell growth, while p53 is able to inhibit cell growth and induce apoptosis as a response to DNA damage. Aim: To study the expression of p53 and $\mathrm{Ki}-67$ in the liver tissue during acute and chronic rejection (AR/CR). Methods: Paraffin-embedded liver biopsies of 10 patients with AR before/after treatment with i.v. steroids and of 13 patients with CR were studied by immunocytochemistry, using mononuclear antibodies against p53 and $\mathrm{Ki}-67$. Results were assessed semi-quantitatively and compared to normal controls. Results: p53 was expressed in hepatocytes, bile ducts $(B D)$ and cells of the inflammatory infiltrate during $A R$ and $C R$, while no reactivity was detectable in normal controls. Treatment with steroids did not affect the expression. Staining for Ki-67 showed an increased expression in inflammatory cells and hepatocytes during both types of rejection compared to controls, while bile ducts reacted sporadically only during chronic rejection. Steroid treatment reduced the number of Ki-67 positive cells of the inflammatory infiltrate. Conclusion: The expression of $\mathrm{Ki}-67$ indicates, that during acute and chronic rejection proliferation is upregulated in both infiltrating inflammatory cells and parenchymal cells. Additional immunosuppressive therapy suppresses the proliferation of the inflammatory cells. p53 seems to be implicated in the immune response, either as a response to the increased proliferation rate or to accumulation of genome damage.
SERUM GLUTATHIONE-S-TRANSFERASE $\propto$ (GST) IN ACUTE LIVER ALLOGRAFT REJECTION A. Nagral, P. Butler, C.A.Sabin, * B.R. Davidson, K. Rolles,

A.K. Burroughs. Liver Transplantation, Primary care and Population Sciences, ${ }^{*}$ Royal Free Hospital, London NW3 2QG, UK

Introduction/Aim: GST has been suggested as a sensitive marker of cellular rejection. This study was performed to determine the utility of GST as a marker of acute rejection. Methods: Daily measurements of serum transaminases and GST (enzyme immunometric assay, Biotrin) were prospectively recorded in 23 consecutive liver transplant recipients for the first 20 days post transplantation. 56 liver biopsies performed following clinical/biochemical deterioration in liver function; 38 showed acute rejection.

Results: GST peaked on the 2nd day (median $125 \mu \mathrm{g} / \mathrm{l}$, range $75-321 \mathrm{\mu g} / \mathrm{l})$ after transplant and preceded the ALT peak by one day. GST levels then steadily declined, reaching baseline by day 6 and plateauing till day 8. Even after the initial peak, GST correlated well with the ALT in the majority of patients median correlation coefficient of 0.6 (IQ range $0.45-0.77$ ); and with the bilirubin, median corelation coefficient 0.47 (IQ range 0.14 to $0.6)$. There was no significant difference in the GST levels between rejection and other causes of hepatic dysfunction on each of 3 days preceding, and the biopsy day. ALT levels had a high sensitivity for rejection $(97.4 \%)$ but a low specificity (16.7\%) GST did not improve these values. In 16 patients treated for moderate/severe rejection, the improvement in the histological score of rejection was not associated with a consistent change in GST.

Conclusion: GST does not offer any advantage compared to ALT in diagnosing rejection or determining response to treatment of rejection.
GRAFT DYSFUNCTION ASSOCIATED WITH AUTOIMMUNITY IN PAEDIATRIC LIVER TRANSPLANATION.

N Kerkar', N Hadzic', ET Davies', B Portmann ${ }^{3}$, M Rela ${ }^{4}$, ND Heaton ${ }^{4}$, D Vergani ${ }^{5}$, and G Mieli-Vergani ${ }^{1}$. Depts of Child Health ${ }^{1}$, Institute of Liver Studies ${ }^{3}$, Transplant Surgery \& Immunology ${ }^{2}$, King's College Hospital, Institute of Hepatologys, University College, London, UK.

Over a five-year period of observation seven children (3\% of 220 liver transplant recipients) developed an unexplained but characteristic form of graft dysfunction. Five were male and the median age at presentation was 10.3 years (range 2-19.4). The median period after surgery was 24 months (range 6-45). The indication for transplantation were extrahepatic biliary atresia (4), Alagille's syndrome (1), drug induced fulminant liver failure (1) and alpha-1antitrypsin deficiency (1). Four were on triple immunosuppression with cyclosporin A, azathioprine and prednisolone, while three were on tacrolimus. Infectious and surgical complications were excluded. Liver biopsy showed the histological changes of chronic active hepatitis including portal and periportal hepatitis with lymphocytes and plasma cells, bridging collapse, perivenular cell necrosis without changes typical of acute or chronic rejection. All patients had increased levels of immunoglobulin $\mathrm{G}$ [median $23.7 \mathrm{~g} / \mathrm{L}$ (range 17.234.4)] and elevated titres of autoantibodies. All but one responded to prednisolone $2 \mathrm{mg} / \mathrm{kg} /$ day and increase or addition of azathioprine $(1.5-2 \mathrm{mg} / \mathrm{kg} / \mathrm{day})$ within a median period of 22.5 days and remained in remission on a reduced dose of prednisolone $(0.05-0.1 \mathrm{mg} / \mathrm{kg} / \mathrm{day})$ and the same dose of azathioprine during follow up (median 250 days).

Our data show that manifestations diagnostic of autoimmune hepatitis, and responsive to the classical treatment for this condition, can appear in liver transplant patients while on immunosuppression. Whether autoimmune manifestations precede, and may be the cause of, graft dysfunction remains to be established in a prospective study. 
W69 DISEASES

Baker A, Rela M, Gibbs P,Muiesan P, Vilca-Melendez, H, Ball C, MieliVergani G, Heaton ND College Hospital, London SE5

Liver transplantation has been used successfully to replace the defective or missing enzyme/protein or receptor site in liver-based metabolic disorders. The majority of these disorders produce cirrhosis and total liver replacement Crigler-Najiar Syndrome Type 1 (CNS1) where although liver replacement has been successful, auxiliary liver transplantation (ALT) offers the prospect of correcting the metabolic defect, whilst retaining sufficient native liver to support life if the graft fails and also retains the potential for gene therapy in the future.

5 children with CNS1 and 1 child with propionic acidemia (PA) underwent ALT, median age 8 years (range 1-13); median weight $25 \mathrm{~kg}$ (range 10-49). Median serum bilirubin at ALT for CNS1 was $270 \mathrm{umol} / 1$ (range 222-418) despite 16 hours of phototherapy daily. The child with PA had recurrent hyperammonemic coma on a protein-restricted diet with ammonia levels of $80 \mathrm{umol} / 1$

Orthotopic left lateral segment ALT was performed in 4 cases and right orthotopic ALT in 1 patient with CNS1 and in the child with PA. Patients with CNS1 had median serum bilirubin levels on day 5 post-transplant of 50 umol/1(range 32-92) and $30 \mathrm{umol} /$ (range 20-45) at a median follow-up of 16 months (range 6-39). The child with PA is on a normal diet with normal serum ammonia levels at 6 months.

Complications included severe acute rejection in 3 patients requiring conversion to FK506 and the late dovelopment lymphoproliferative disease (LPD) in one due to EBV infection. He was retransplanted successfully after the first ALT but died 4 months later from extensive LPD. We have shown that it is possible to correct the metabolic errors abnormalities in CNS1 and PA with ALT. Other non-cirnhotic inborn errors of metabolism are also suitable for ALT, but the volume of liver tissue required for a successful outcome may depend on the disease.
AUXILIARY LIVER TRANSPLANTATION FOR METABOLIC

Department of Child Health and Liver Transplant Surgical Service, King's is required. There are, however, some non-cirrhotic disorders, such as

W71

LONG-TERM SURVIVAL AND ALCOHOL RELAPSE AFTER LIVER TRANSPLANTATION FOR ALCOHOLIC LIVER DISEASE . S.P. Pereira', P. Muiesan', L. Howard', M. Rela', N. Heaton', Roger Williams'. 'Institute of Liver Studies, ' 2 iver Transplant Surgical Service and ${ }^{3}$ Department of Psychological Medicine, King's College Hospital, London SES 9RS

Short-term survival rates after orthotopic liver transplantation (OLT) for end-stage alcoholic liver disease (ALD) are reported to be similar to those for other chronic liver diseases. However, the frequency of alcohol relapse, and its effects on long-term graft and patient survival, remain unclear. Aims: To review the outcome of transplantation for ALD in a single centre over the past 10 years, with particular emphasis on survival and recidivism after OLT. Methods: From Jan 1987 to Sept 1996, 111 patients (98M, $13 \mathrm{~F}$; mean age $51 \mathrm{yr}$, range 33-69 yr) underwent OLT for Child's B or C alcoholic cirrhosis, after an alcohol abstinence of $>6$ months. In 89 patients $(80 \%)$, alcohol was the only aetiological factor, while $20(18 \%)$ also had chronic B or C hepatitis and $17(15 \%)$ had developed hepatoma as a complication of ALD. Post-transplant, alcohol relapse was assessed by outpatient and case note review, and by a Severity of Alcohol Deperdence Questionnaire sent to transplant survivors. Results: 19 deaths (all males) occurred in the first 3 months -- due to sepsis or cardiac complications in 14 (74\%). A further 12 patients (10M, 2F) died 0.9-7.5 yr (median $1.6 \mathrm{yr}$ ) post-transplant, most frequently due to hepatoma recurrence $(n=3)$ or other malignancies $(n=4)$. The actuarial survival rate for the 111 patients was $79 \%$ at one year, and $64 \%$ at 5 years -. compared with figures of $76 \%$ and $69 \%$ in 700 patients transplanted for other chronic liver diseases. Of the 92 patients who survived at least 3 months post-transplant, 18 (20\%) reported at least one episode of drinking $>3$ units daily, while a similar number admitted to 'social' drinking, after a median period of abstinencr of 9 months. Five patients developed recurrent alcoholic cirmosis/graft failure within 5 years -- two of whon died at 10-24 months. Conclusions: Longterm survival after OLT for ALD is similar to that for other liver transplant recipients. In our experience, alcohol relapse occurs in a large minority of patients, though at lower levels of alcohol intake than previously. In those with problematic drinking post-transplant, graft damage occurs rapidly.

CLINICAL OUTCOME AND FLOW CYTOMETRIC (FACS) IGG CROSSMATCH IN LIVER TRANSPLANTATION. $M$ McCarthy, PT Donaldson, $M$ van Dam*, and Roger Williams. Institute of Liver Studies, King's College Hospital, London SE5 9RS, and *Dept of Tissue Typing, St Mary's Hospital, London W2.

Introduction: The role of preformed donor-specific IgG alloantibodies. in kidney and heart grafts is well established. However, although a number of recent studies have suggested that these antibodies may increase the risk of both rejection and early graft failure in liver transplants, ${ }^{1,2}$ this remains controversial. ${ }^{3}$ The differences between studies may simply reflect variations in the sensitivity of methods used to detect these antibodies. In the present study we have sought correlation between preformed IgG antibodies and clinical outcome using two different crossmatch techniques. Methods: Between May 1995 and June 1996, 82 adult liver allograft recipients (34 females, 48 males) were examined for the presence of pre-formed donor-specific IgG allo-antibodies using flow cytometry (82 cases) and a standard microcytotoxicity assay (65 cases). Results: A flow cytometric crossmatch was detected in 18/82 (22\%), however only $9 / 15$ flow cytometric antibody positive patients were antibody positive by cytotoxicity assay. Patients with FACS positive crossmatches were more likely to develop two or more episodes of acute cellular rejection $(4 / 18$ cf $4 / 64, p=0.044, R R=4.29)$, and more likely to develop hepatic artery thrombosis $(3 / 18$ cf $1 / 64, p=0.009, R R=12.6)$. At follow-up survival was $80 \%$ in those who were FACS negative and $67 \%$ in those with FACS positive IgG antibodies. However, despite a clear trend the survival analysis did not reach statistical significance $(p=$ 0.31 ). Conclusions: These results confirm the greater degree of sensitivity of flow cytometry for the detection of $\operatorname{IgG}$ positive crossmatches and suggest that flow cytometry may help predict those at risk of developing severe graft rejection or hepatic artery thrombosis.

'Takaya et al. Transplantation 1992; 53: 400

${ }^{2}$ van Hoek et al. Semin Liver Disease 1992; $12: 41$.

${ }^{3}$ Donaldson et al. Transplantation 1995; 60: 1016.
EFFECT OF ABRUPT ALCOHOL WITHDRAWAL ON LIVER S Campbel| ${ }^{(1)(4)}$, PM Timms ${ }^{(2)}$, P Maxwell ${ }^{(2)}$, E Docherty ${ }^{(3)}$, MZ Rah$\operatorname{man}^{(3)}$, MEJ Lean ${ }^{(4)}$, BJ Danesh (1)

Departments of Gastroenterology ${ }^{(1)}$, Biochemistry ${ }^{(2)}$, Psychiatry ${ }^{(3)}$, Stobhill Hospital, Glasgow. Department of Human Nutrition ${ }^{(4)}$, Glasgow Royal Infirmary.

Introduction: It has been suggested that liver function tests (LFT's) may worsen in alcoholics following abrupt withdrawal from alcohol but evidence for this is limited. We assessed LFT's and two markers of hepatic fibrosis; pro-collagen III peptide (PIII) and tissue inhibitor of metalloproteinase 1 (TIMP1) in patients admitted to an alcohol rehabilitation unit

Method: We recruited 24 patients with a history of alcohol abuse, but no evidence of liver disease of another cause. Seven consecutive daily blood samples were obtained. Measurements of nutritional status and withdrawal severity were made. Our arbitrary criteria for worsening of LFT's were: a $50 \%$ rise from baseline value with the elevated value above the laboratory normal reference range

Results: 7 out of the 24 subjects (29.2\%) showed worsening of their LFT's (95\% confidence interval $11.0 \%-47.4 \%$ ). These patients all showed a rise in both AST and ALT of similar proportion, but not of gamma GT, bilinubin, alkaline phosphatase, creatine kinase or CRP. There was no significant difference between the group who showed worsening and the others who te:nded to show improving transaminases with respect to baselinc linical, nutritional or laboratory findings, or short-term outcome.

PIIIP levels increased in both gro: ns from day 1 to day $7(P=0.05)$ TIMP1 levels tended to rise in the group with worsening transaminases, but tended to fall in the other group. $(P=0.09)$ ening of AST and ALT is common in alcohol withdrawal. Alcohol withdrawal is associated with a rise in PIIIP, and a rise in TIMP1 in withdrawal may be associated with an increase in hepatic fibrosis. TRANSAMINASES AND MARKERS OF LIVER FIBROSIS

Conclusion: This study confirms the clinical imprescion that worsthose with worsening transaminases. We conclude that acute alcohol 


\section{Nutrition W73-W82}

\section{WHY DO PATIENTS WITH WEIGHT LOSS HAVE A WORSE OUTCOME WHEN UNDERGOING CHEMOTHERAPY FOR GASTROINTESTINAL MALIGNANCIES?}

H.J.N. Andreyev, A.R. Norman, J. Oates, D. Cunningham. (HNA is funded by the BDF) the Gastrointestinal Unit, Royal Marsden Hospital \& the CRC Centre of Cancer Therapeutics, Institute of Cancer Research, Sutton, Surrey.

Aims: To examine whether weight loss at presentation for chemotherapy for gastrointestinal carcinomas influences outcome and whether nutritional intervention could be worthwhile.

Methods: Data were gathered prospectively. The outcomes were compared of patients with or without weight loss treated for locally advanced or metastatic tumours of the cesophagus, stomach, pancreas, colon or rectum

Results: Of 1,555 consecutive patients included, weight loss was reported more commonly by men $(51 \%)$ than women $(44 \%)$ at presentation $(p=0.01)$. Patients with weight loss received less chemotherapy but developed more frequent and more severe dose limiting toxicity - plantar-palmar syndrome $(p<0.0001)$ and stomatitis $(p<0.001)$ - than patients without weight loss. Consequently, patients with weight loss on average received 1 month less treatment $(p<0.0001)$. Weight loss correlated with shorter failure free $(p<0.0001$, Hazard Ratio $=1.25)$ and overall survival $(p<0.0001$, Hazard Ratio $=1.63)$, decreased response $(p=0.006)$, quality of life $(p<0.0001)$ and performance status $(p<0.0001)$. Patients who stopped losing weight had better overall survival $(p=0.0004)$. Weight loss at presentation was an independent prognostic variable (Hazard Ratio $=1.43$ )

Conclusions: The poorer outcome from treatment in patients with weight loss appears to occur because they develop more toxicity, have more breaks from treatment and receive significantly less chemotherapy rather than any specifically reduced tumour responsiveness to treatment. Randomised nutritional support intervention studies are urgently required in these groups of patients.

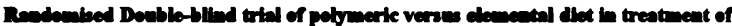
settue Crebre's dibease.

\section{S Verme, $S$ Brom, MH Ginfie}

Department of Gatroentereley, Royal Hull Hoenials NHS Trux, Aminby Read, Hull

Exteral nutrition is now socepied as a primery tharipy for sctive Crobe's discase. Open

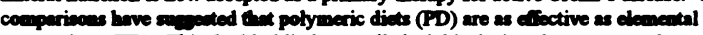

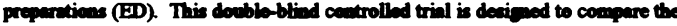
thermentic eficacy of a multi-protein polymeric diat with $m$ amino-acid beed

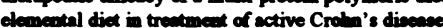

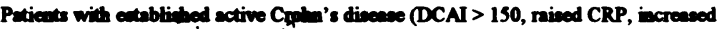

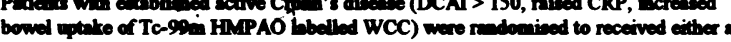

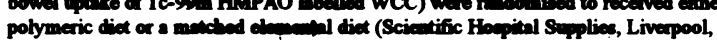

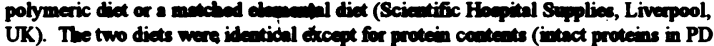
UK). The two diets were identidal droept for protein contents (intict proteins in and free aminoecids in the ED). Enteral nutrition wa delivered vis a fine bore

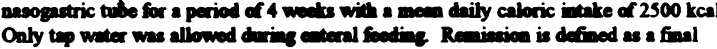

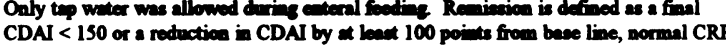
levels and avoidence of steroids or mireny.

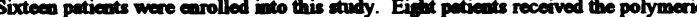
diet and mother cight an elemental preparation. There was no significent difference between the two treetment groups at entry in respect of age, discanse locention, initin

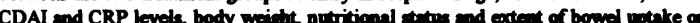

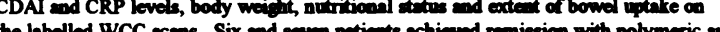
the labelled WCC scans. Six mo seven patients achioved remiesion with polymeric shown below:

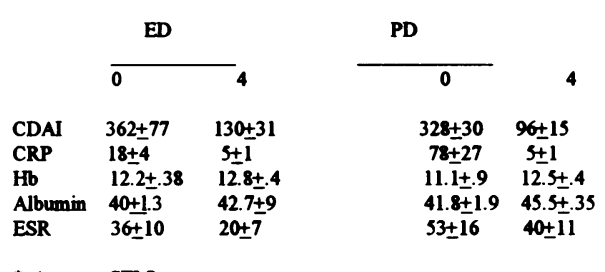

* (mean \pm SEM)

The fall in bowel sativity on Tc-99m HMPAO imates was not different in the two groups. The over all remission rate achieved with enteral nutrition was $85 \%$.

Enteral nutrition is well tolerated and effective in control of active Crobn's disease. Differences in protein content of enteral feods are not relevant to their therapeutic efficiency as polymeric and elemental diets are equally effective.
SERUM LEPTIN IN INFLAMATORY BOWEL DISEASE (IBD): IMPLICATIONS FOR THE PATHOGENESIS OF ANOREXIA AND WEIGHT LOSS. AB Ballinger, EM. Hallyburton, R Besser, EM Aktead, MUG Farthing Digestive Diseases Research Centre, St Bartholomew's \& The Royal London School of Medicine \& Dentistry, London UK

INTRODUCTION: IBD is frequently associated with loss of appetite and body weight. Healthy individuals, however, adjust their appetite and maintain their body weight within a narrow range. It is proposed that this control is due in part to leptin, a newly described hormone, which is secreted by fat cells and acts in the CNS to suppress appetite. In animals, corinistration of IL-1 $\beta$ and TNF- $\alpha$, which are both implicated in inflammatory explore the hypothesis that patients with IBD in relapse fail to increase their appetite in response to weight loss due to inappropriately raised serum leptin concentrations. METHODS: Serum leptin concentrations were measure by radioimmunoassay in 35 (17 men) control subjects and 72 patients (34 men; 52 Crohn's, 20 UC) with IBD. Body mass index and \% body fat was recorded. Loss of appetite was assessed on a 4 point scale from "not at all" (score 0) to "very much" (3). Disease activity was assessed clinically and by measurement of the ESR and C-reactive protein. RESULTS: Serum leptin concentration [interquartile range]) and $4.8(2.6-10.1 \mathrm{ng} / \mathrm{ml})$ in the IBD patients. Serum leptin concentrations were highly correlated with \% body fat (figure) in the control group $(r=0.84, P=0.03)$ and IBD patients $(r=0.82, P 0.006)$ the difference in leptin concentrations between the two groups was accounted for by lower body fat in the IBD patients.

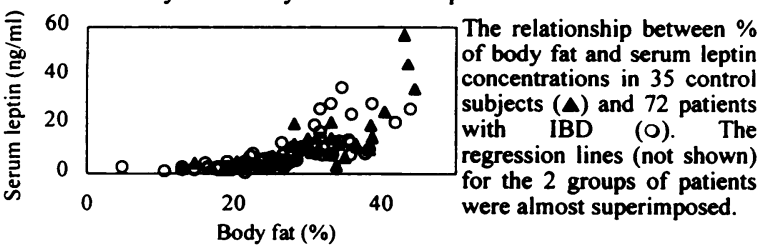

12 patients (6 men) had moderate/severe anorexia (grade 2/3) associated with a disease relapse (ESR $>30 \mathrm{~mm} / \mathrm{h}, \mathrm{CRP}>40)$. Serum leptin of these patients $(4.3[3.2-8$. Ing/ml]) was no different when compared to healthy and quiescent disease controls $(5.3[3.5-10.6 \mathrm{ng} / \mathrm{ml}])$ matched for sex and $\%$ body fat (mean $24.2 \%$, range $4.8-43.9$ ). CoNCLUSION: Serum leptin is $\%$ body fat (mean $24.2 \%$, range $4.8-43.9$ ). CONCLUSION: Serum leptin is the animal work this study does not support a role for leptin in contrast to associated with IBD.
RAPID COLONIC FERMENTATION IS ASSOCIATED WITH SYMPTOMS IN IBS AND CORRECTED BY EXCLUSION DIET.

*T.S. King, TM. Elia, *J.Q. Hunter. *Department of Gastroenterology, Addenbrooke's Hospital, 'Dunn Clinical Nutrition Centre, Cambridge.

Introduction: Use of an exclusion diet reduces symptoms in 50\% of IBS patients. Food intolerance is unlikely to be immunologically mediated but may be related to colonic fermentation. Methods: 5 female IBS patients and 4 female controls followed two fixed diets (12.5g NSP, $128 \mathrm{~g}$ starch, $3.6 \mathrm{~g}$ resistant starch/day; $8 \mathrm{MJ} / \mathrm{d}$. adjusted to estimated TEE; protein:carbohydrate:fat 15:45:10) : a standard western diet (STD) followed by an exclusion diet (EXN), in which common sources of food intolerance were prohibited. Subjects followed each diet for 14 days, with a 2 week wash-out period. Food diaries were filled daily and all meals were provided from a metabolic kitchen for the last 7 days of each diet. A symptom score was calculated daily. On the last day of each diet total excretion of hydrogen $\left(\mathrm{H}_{2}\right)$ and methane $\left(\mathrm{CH}_{4}\right.$ were measured for 24 hours in a purpose-built and validated $1.4 \mathrm{~m}^{3}$ whole-body calorimeter. Breath $\mathrm{H}_{2}$ and $\mathrm{CH}_{4}$ concentrations following $20 \mathrm{~g}$ lactulose were also measured on each diet. Results:

\begin{tabular}{|c|c|c|c|c|c|}
\hline & $\begin{array}{l}\text { mean } \\
\text { symptom } \\
\text { score }\end{array}$ & $\begin{array}{c}\text { mean } \\
\text { total H } \\
\text { ml/24hrs } \\
\text { stp }\end{array}$ & $\begin{array}{c}\text { mean } \\
\text { total } \mathrm{CH}_{4} \\
\text { mV/24hrs } \\
\text { stp }\end{array}$ & $\begin{array}{c}\text { mean } \\
\text { total rate } \\
\mathrm{m} / / \mathrm{min} \\
\mathrm{stp}\end{array}$ & $\begin{array}{c}\max \\
\text { total rate } \\
\mathrm{m} / \mathrm{min} \\
\mathrm{stp}\end{array}$ \\
\hline patients std & 8.3 & 361 & 152 & 0.4 & 2.5 \\
\hline $\operatorname{exn}$ & 5.9 & 90 & 84 & 0.1 & 0.4 \\
\hline controls std & 1.3 & 147 & 266 & 0.3 & 0.7 \\
\hline $\operatorname{exn}$ & 1.5 & 86 & 480 & 0.4 & 1.2 \\
\hline
\end{tabular}

Rapid gas excretion in the calorimeter was associated with onset of symptoms. Breath concentrations of $\mathrm{H}_{2}$ and $\mathrm{CH}_{4}$ after lactulose altered in parallel with changes in 24-hour gas excretion in 4/5 patients and 3/4 controls. Conclusions: 1) Symptoms are associated with rapid excretion of $\mathrm{H}_{2}$ and $\mathrm{CH}_{4}$, and improvement of symptoms by diet coincides with reduced excretion. 2) The effect of diet on methanogenesis is variable. 3) The reduction in $\mathrm{H}_{2}$ excretion with exclusion diet is consistent with the expected low colonic availability of easily digestible rice starch. However changes in gas excretion during lactulose breath tests demonstrate that qualitative changes in colonic fermentation also occur. These factors may explain the efficacy of exclusion diets in IBS. 
A RANDOMISED DOUBLE BLIND PROSPECTIVE STUDY OF LONG CHAIN TRIGLYCERIDE (LCT), MCT/LCT AND MEDIUM CHAIN TRIGLYCERIDE (MCT) DURING PARENTERAL NUTRITION

\section{A Dennison* J Jameson*, K Maden**, N Bird** and R Law** *Department of Surgery, Leicester General Hospital and ** University} Department of Surgery, Royal Hallamshire Hospital, Sheffield UK.

The best non-nitrogen calorie source during parenteral nutrition remains controversial. This study was performed to establish whether the use of a $20 \%$ MCT emulsion would demonstrate significant advantages over conventional LCT

Following a volunteer study establishing the safety of a $20 \%$ MCT emulsion (B.Braun Melsungen) ethical committee approval was obtained for a prospective study. Fifty seven patients were randomised to receive conventional $20 \% \mathrm{LCT}, 10 \% \mathrm{MCT} / 10 \% \mathrm{LCT}$ or $20 \% \mathrm{MCT}$ as $50 \%$ of their non-nitrogen calories during routine TPN. Patients were studied for 10 days after which all patients reverted to our standard TPN regimen.

Results were analysed by analysis of covariance of the final day measurement with respect to the initial value for each variable, prior to breaking the randomisation code. There were no adverse clinical reactions in any of the groups. Cardiovascular and respiratory parameters and routine haematological, biochemical and acid base measurement were unchanged. Differences were demonstrated in bilinubin levels where LCT $(72.3 \pm 31 \mathrm{mmol} / \mathrm{mean} \pm \mathrm{sem})$ was significantly higher than MCT $(19.6 \pm 6.1)$ or MCT/LCT $(23.4 \pm 12.5)$, $(p=0.025)$. Levels of free glycerol were also reduced in the LCT group $(1.28 \pm 0.1 \mathrm{mmol} / \mathrm{l})$ compared with MCT $(2.48 \pm 0.23$ and MCT/LCT $(2.67 \pm 0.27) p<0.001)$. There was also a trend towards a higher white blood cell count in the LCT group.

This study demonstrates that $20 \%$ MCT emulsions are safe for routine clinical use and also suggests that MCT or MCT containing emulsions have advantages metabolically and on liver function.
GASTROESOPHAGEAL REFLUX IN PATIENTS FED BY PERCUTANEOUS ENDOSCOPIC GASTROSTOMY (PEG) - SCINTIGRAPHIC DETECTION. KK Balan, S Vinjamuri, J Bennett* and M Critchley, Departments of Nuclear Medicine and Gastroenterology*, Royal Liverpool University Hospital, Liverpool L7 8XP U.K.

Percutaneous endoscopic gastrostomy (PEG) is the method of choice for long-term enteral nutrition in patients unable to swallow due to a variety of medical conditions. PEG eliminates the need for surgical gastrostomy and nasogastric tubes, is easily performed with few demands on health service resources. Aspiration pneumonia may complicate PEC insertion but there are few studies on gastroesophageal reflux (GOR) in PEG patients.

Methods: 22 patients ( $14 \mathrm{M}, 8 \mathrm{~F}$, age $43-83$ yrs, median 69) with PEG underwent radionuclide GOR studies. 13 patients had neurological and 9 had mechanical dysphagia. They received $100 \mathrm{ml}$ of orange juice containing $25 \mathrm{MBa}$ of $\mathrm{Tc} 99 \mathrm{~m}$ tin colloid followed by $30 \mathrm{mml}$ of normal saline through the PEG tube. Patients lay supine under the gamma camera linked to a digital computer system. $4 \mathrm{~min}$. and $4 \mathrm{~h}$ images over stomach, oesophagus and lungs were examined for GOR and lung aspiration.

Results: 10 patients, 8 of whom with neurological dysphagia and 2 of whom with mechanical dysphagia, had severe GOR. 2 other patients with neurological dysphagia had mild GOR. One patient with severe GOR also had lung aspiration at $4 \mathrm{hrs} .10$ patients had normal studies.

Conclusions: 1) Radionuclide imaging is useful in assessing GOR in PEG patients 2) GOR appears to be a major problem in patients with PEG and 3) PEG patients with neurological dysphagia appear to be at greater risk for GOR than those with mechanical dysphagia.
OPTIMISING CATHETER SURVIVAL IN PERIPHERAL PARENTERAL NUTRITION: A RANDOMISED CONTROL TRIAL B.M.Dobbins, P.Deady, G.V.Miller, M.J.Tighe, I.G.Martin and M.J.McMahon. University Department of Surgery, The General Infirmary at Leeds, Great George Street, Leeds, LSI 3EX

Peripheral vein thrombophlebitis (PVT) is a major obstacle to successful and prolonged administration of peripheral intravenous nutrition (IVN). This study assesses the impact of glyceryl trinitrate (GTN), heparin \& hydrocortisone and a combination of both therapies on the incidence and time to onset of PVT during the administration of standard $(1200 \mathrm{osm} / \mathrm{kg})$ peripheral IVN via a fine bore polyurethane catheter. One hundred and eleven patients were randomised to receive standard peripheral nutrition with either a $5 \mathrm{mg}$ GTN patch directly over the catheter tip (Group 1, $n=42$ ), heparin 1500 iu \& hydrocortisone $15 \mathrm{mg}$ added to the infusate (Group 2, $\mathrm{n}=40$ ) or a combination of all three interventions (Group 3, n=29). Limbs were examined daily and catheters removed if any signs of PVT became evident (pain, swelling, erythema, tenderness, increase in temperature, or a palpable venous cord). The three groups were matched for age, gender, indications for IVN and total duration of nutritional support.

The use of a GTN patch alone (group 1) was associated with a shorter time to onset and higher incidence of PVT than either of the other groups (median catheter suvival 6days (group 1) vs 10 days (groups $2 \& 3$ ); $<0.03^{*}$ ). There was no additional benifit of GTN in addition to heparin \& hydrocortisone alone ( $p=n s^{*}$ Group 3 vs Group 2). In addition, choice of vein significantly influenced catheter survival, since significantly lower incidence of PVT and longer duration to develop PVT was observed when the basilic vein was used (compared to the cephalic vein) in all 3 study groups (median catheter survival 10 days (basilic vein) vs 6 days (cephalic vein); $p<0.01^{*}$ ).

In conclusion, a GTN patch alone, and the addition of a GTN patch to heparin \& hydrocortisone in the infusate, offer no benefit in terms of peripheral catheter survival. We would recommend peripheral feeding using heparin \& hydrocortisone in the infusate using the basilic vein whenever possible to optimise catheter survival and reduce morbidity. (*Chi squared and Log Rank statistics)

\section{SWALI BOWEL JOICE DISACCBARIDE ACTIVITY IN THE} PRE-TYWU IIFANT

Cade $A$, Walters $M$, Puntis $J$ W L

Department of Paediatrics \& Child Health,

Clarendon Wing, Leeds General Infirmary, LS2 9NS.

Conflict exists regarding the efficiency of lactose hydrolysis in the premature newborn. Lactase activity in the foetus appears low, but preterm infants fed lactose containing formula usually grow without losing carbohydrate in the stool. Bxperimental data both supporting and refuting efficient lactose hydrolysis is generally derived using indirect assessments. A more direct approach is to measure disaccharidase activity in duodenal fluid or mucosa. One study of 8 infants from $26-29$ weeks gestation suggested that during the first 3 weeks of life, lactase activity increased and from the outset was comparable with older children. We have obtained duodenal aspirates from preterm infants over the first 2 months of life. 40 infants were studied; median (range) gestational age 29 weeks $(24-40)$ and birthweight $1260 \mathrm{~g}(600-2550)$. 31 were appropriately grown and 9 were small for gestational age. Disaccharidases were measured by a 2 step colourimetric assay using a standard Boehringer Mannheim kit. 34/56 (61t) of lactase, $44 / 56$ (79t) of maltase and $23 / 56(42 t)$ of sucrase activities fell below the lower published reference range for older children. There was no apparent increase in enzyme activities or fall in sucrase: lactase ratio with increasing postnatal age. Despite this, none of the children showed clinical evidence of carbohydrate malabsorption. We conclude that disaccharidase activities are frequently low in the preterm enterally fed newborn compared with older children, however, the absence of clinical evidence of lactose malabsorption suggests that undigested lactose is assimiliated in the colon. There is probably no reason for preterm formula milks to contain less lactose than breast milk as many do at present. 
W81

Inteatinal transit and release characteriatics of pancreatin entyme microspheres.

${ }^{1} S$ Ghosal, 'CJ Taylor, ${ }^{2} \mathbf{P}$ Hillel. 'Dept of Paediatrics, ${ }^{2}$ Dept of Medical Physics, University of Sheffield, UK

Mismatch in gat transit between food and pancreatin may be relevent to recent reports of colonic strictures in cystic fibrosis (CF) petients. We investigated the gastric emptying and small bowel transit of food and pancreatin in 10 pencreatic insufficient CF patients aged 9 to 38 years (of whom four in group 1 had good and six in group 2 had suboptimal nutritional status). Twin-chennel scintigraphy combined with breeth hydrogen sampling was used to track the concurrent movement of indium labelled pancreatin microspheres and an standard technetium labelled semi solid teet meal. Small bowel transit time for food was eatablished by incorporating a hydrogen source within the test meal.

\begin{tabular}{|l|l|l|l|l|}
\hline $\begin{array}{l}\text { Patient } \\
\text { group }\end{array}$ & $\begin{array}{l}\text { Median } \\
\text { Wt SD } \\
\text { score }\end{array}$ & $\begin{array}{l}\text { Median small } \\
\text { git transit } \\
\text { time }\end{array}$ & $\begin{array}{l}\text { Median 50\% } \\
\text { emptying } \\
\text { FOOD }\end{array}$ & $\begin{array}{l}\text { gastric } \\
\text { time: } \\
\text { ENZYME }\end{array}$ \\
\hline $1(\mathrm{n}=4)$ & +0.4 & $2.8 \mathrm{hr}$ & $88 \mathrm{~min}$ & $99 \mathrm{~min}$ \\
\hline $2(\mathrm{n}=6)$ & -2.6 & $4.0 \mathrm{hr}$ & $133 \mathrm{~min}$ & $36 \mathrm{~min}$ \\
\hline
\end{tabular}

Small bowel transit for food was delayed ( $>6$ hours) in 3 subjects. The difference in gastric 1/2 emptying time between enzymes and food was significantly greater (range 47-195 min) in patients with suboptimal nutritional status $(p=0.03, \mathrm{df}=1$, Fishers exact probability test). Enzyme "hot spots" in 2 subjects were visualised in the colon by 2 hours. This discrepancy in transit of pancreatic enzyme microspheres and food boluses could account for continuing malabsorption in some CF patients and identify a mechanism whereby intact microspheres reach the colon.

B VITAMIN DEFICIENCIES MAY BE COMMON IN THE ACUTE INPATIENT POPULATION.

CP Jamieson, OA Obeid, J Powell-Tuck,

Rank Department of Human Nutrition, Royal London Hospital, Whitechapel, London E1 1BB.

110 patients were selected at random from those admitted via the Accident and Emergency department over 3 days. Erythrocyte transketolase (ETK), glutathione reductase (EGR) and aspartate aminotransferase (EAA) enzyme assays were used to determine thiamin, riboflavin and pyridoxine deficiencies respectively. A deficiency state was diagnosed when the percentage activation with added coenzyme was greater than the conventionally accepted limits of $23 \%, 20 \%$ or $86 \%$ for ETK, EGR, and EAA assays respectively.

$77 \%$ of patients were under the care of the directorate of General Medicine, $15 \%$ General Surgery and $8 \%$ Orthopaedics. $56 \%$ of the study group were men, $73 \%$ Caucasian, 20\% Asian and 7\% Afro-Carribean. A total of 66 patients $(60 \%)$ had at least one biochemical B vitamin deficiency. Of the 17 patients who had a body mass index (BMI) below the desired range of $20-25 \mathrm{~kg} / \mathrm{m}^{2}, 15$ had one or more deficiencies. The majority of deficient patients, however, had BMI values within the desired range. The median age of the deficient patient group was lower at 59y compared with $69 y$ in the non-deficient group $(p=0.002$, Mann Whitney $U$ test). Overall the prevalences of specific deficiencies were $9 \%, 41 \%, 35 \%$ and $22 \%$ for thiamin, riboflavin, pyridoxine and multiple deficiency states respectively. Four patients were admitted with alcohol related disease; of these two were thiamin deficient and one had combined riboflavin and pyridoxine deficiencies.

$B$ vitamin deficiencies seem common in the acute inpatient population and are not limited to those patients with protein-energy undernutrition.

\section{Inflammatory bowel disease W83-W104} W83

HIGH PREVALENCE OF UNDETECTED INFLAMMATORY BOWEL DISEASE (IBD); DATA FROM THE NOTTINGHAM FAECAL OCCULT BLOOD (FOB) SCRBENING TRIAL

G.F. Howarth, M.H.E. Robinson, D. Jenkins*, J.D. Hardcastle, R.F.A. Logan**. Departments of Surgery, ** Public Health \& Epidemiology and *Pathology, University Hospital, University of Nottingham, NG7 2UH.

The severity of symptoms from IBD can vary from devastating to none and a previous study from the Nottinghnm FOB screening trial suggested that the prevalence of asymptomatic IBD might be substantial (GUT 1989;30:481-483). The screening trinl has now been completed. The aim of this study is to reassess the prevalence of IBD detected in the trial.

FOB tests were performed by 44,838 of the 75,253 subjects aged 49-74 offered screening. Patients known to have IBD were excluded from FOB screening. All subjects FOB positive on one or more occasions $(n=1778)$ were investigated by colonoscopy or flexible sigmoidoscopy and berium enema. 94 were found to have IBD at endoscopy and confirmed by histology. 57 subjects had previously undetected IBD (55 ulcerative colitis (UC), 2 Crohn's disease (CD)). The remaining 37 (31 UC, $6 \mathrm{CD})$ had had a previous diagnosis of IBD but this had not been recognised when they were invited to be screened. The prevalence of previously undetected IBD in those offered screening was 73/105 (95\%cl 54 $92 / 10^{5}$ ) for UC and $2.7 / 10^{5}$ (95\%cl 0.3-10/105) for CD. Based on those accepting screening the prevalence of undetected UC was $123 / 10^{5}$ (95\% cl 90-155/10') and for CD $4.5 / 10^{5}$ (95\%cl 0.5$16 / 10^{5}$ ). The prevalence of undetected UC was higher in the over 60 s and also was almost two-fold higher in men than women (164 v.87/10 $)$. Proctosigmoid UC accounted for 54\% (31/57) of cases and pan colitis for $20 \%$ (11/57). 82\% (47/57) had some symptoms but had not consulted or had not been referred for investigation; 62\% reported rectal bleeding and 60\% had mild diarnoea.

The prevalence of undetected UC is much greater than previously reported. Prevalence is higher in men, increases with age, and low-grade symptoms are common. Increased detection of prevalent UC needs to be allowed for in studies of comparing UC incidence.
MORTALITY IN INFLAMMATORY BOWEL DISEASE: THE CASE FOR A NATIONAL CONFIDENTIAL ENQUIRY. FH Gordon, SM Montgomery, MI Hamilton and RE Pounder. Inflammatory Bowel Disease Study Group, Royal Free Hospital School of Medicine, Rowland Hill Street, London NW3 2PF, UK.

Introduction Mortality due to inflammatory bowel disease (IBD) has decreased steadily since 1950 , but population-based cohort studies suggest that IBD patients continue to have a higher mortality rate than expected, partly due to a higher incidence of gastro-intestinal malignancies. Records held by the Office for National Statistics since 1993 permit detailed analysis of mortality in IBD patients, including calculation of the number continuing to die from complications of the disease itself or from colorectal malignancies.

Methods Patients who died in England and Wales between January $1^{\text {st }}$ 1993 and $31^{*}$ December 1995 inclusive and whose death certificates included the codes 555 (Crohn's disease/CD) or 556 (ulcerative colitis/UC) were identified from Office for National Statistics records.

Results IBD was listed as a cause of death in 2581 patients, of which $1146(44 \%)$ had CD and (1435) $56 \%$ had UC. CD was the underlying cause of death in $462(\mathbf{4 0 . 3 \%})$ of patients with $C D$ on their certificate, whereas the figure for UC was $509(35.0 \%)$. The mean age at death for those with CD was 68.2 and 72.3 years (male and female respectively) and 70.7 and 76.0 years (male and female) for those with UC. Of those patients who had CD or UC as their underlying cause of death, $54(12 \%)$ and $25(5 \%)$ were less than 50 years-old, respectively. Colorectal carcinoma accounted for the deaths of $9(8 \%)$ and $23(24 \%)$ of CD and UC patients under 50 years-old, respectively.

Concluaions At least 300 IBD patients per annum in England and Wales continue to die from their disease and its complications despite improved treatment and endoscopic follow-up. Most deaths occur in elderly patients, but a surprisingly high number of younger patients continue to die either from their disease (CD patients) or from colorectal carcinoma (UC patients). Further study, such as by national confidential enquiry, may identify reasons for these deaths and lead to improved survival of IBD patients. 


\section{INFLAMMATORY BOWEL DISEASE IN A} NATIONAL BIRTH COHORT

SM. Montgomery, D. Morris, N. Thompson, J. Subhani, S. Ebrahim, RE. Pounder, and AJ. Wakefield. Inflammatory Bowel Disease Study Group, Department of Medicine, Royal Free Hospital School of Medicine, London.

Aima: A birth cohort with prospectively collected data was used to investigate the prevalence of inflammatory bowel disease (IBD) at age 26 years and the association of childhood diseases with subsequent diagnosis of IBD.

Methods: The 1970 British Cohort Study (BCS70) is a longitudinal study of everybody born in Great Britain between 5 - 11 April 1970. A survey of Crohn's disease and ulcerative colitis was conducted at the age of $25 / 26$ years, with 9,800 (85\%) responding. Diagnosis of IBD, using standardised criteria, was confirmed by cohort members' physicians and by histology. Reports of otitis media and eczema were collected prospectively at the ages of 5 and 10 years.

Results: By age 26 years, 24 cases of Crohn's disease and 20 cases of ulcerative colitis had been diagnosed, representing prevalence rates of 2.45 and 2.04 per 1,000 respectively. The earliest diagnosis of IBD had been made at age 12 years. Otitis media at 5 years was significantly associated with ulcerative colitis (relative risk $=4.00,1.20$. 13.30), but not Crohn's disease (0.44, 0.06 - 3.31). Eczema at 10 years was associated with ulcerative colitis $(4.88,1.85$. 12.86), but not Crohn's disease (0.81, 0.19 - 3.53).

Conclusions: A very high prevalence of IBD, particularly Crohn's disease, was found amongst British 26-year olds. Otitis media and eczema were significantly associated with future ulcerative colitis, but not Crohn's disease.

\section{SOCIAL IMPLICATIONS OF CHILDHOOD CROHN'S} DISEASE;

\section{GA Moody, JA Eaden \& JF Mayberry.}

A validated questionnaire investigating quality of life was mailed to the parents of all child members of Crohn's in Childhood (CICRA) (age 5-17). 64 questionnaires were returned along with 35 from patients in the adult age range (not analysed). The mean age of patients interviewed was 14.1 \pm 2.8 , (range 6-17), with equal numbers of males to females. The mean duration of illness was $4.9 \pm 3.3$ years; patients had $1.4 \pm 0.7$ operations (range $0-6$ ). Of the children investigated over half had significant absences from school $(60 \%)$, with a mean of $3+2.8$ months off school in the previous year. Many felt their teachers knew nothing about CD $(53 \%)$ and that they were unsympathetic $(50 \%)$. Of the 24 who had taken examinations $80 \%$ thought they had underachieved because of ill health.

Patients were asked whether they were able to perform several everyday childhood activities. The following table summarises their responses;
Play outside with their friends

Go out

Take part in sport

Go on holiday

Stay overnight at a

friends house

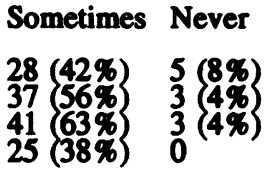

Always

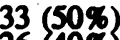
$2640 \%$ $22(23 \%)$ 33 (49\%)
The commonest guestions asked by the children were (i) what is CD? $(50 \%)$, (ii) why me? (64\%), (iii) will it affect my schooling (52\%) and (iv) will it affect my chances of getting a job (67\%)

In conclusion children with $C D$ have a significantly impaired quality of life, they fear every day chilchood activities and their future. They need sympathetic management and effor should be concentrated on improving their day to day existence to enable them to lead a normal a life as possible.
TREATMENT OF REFRACTORY INFLAMMATORY BOWEL DISEASE WITH GRANULOCYTE APHERESIS

BJ Rembacken, HE Newbould, MF Dixon, RS Bury, M Hendrikse, DM Chalmers, ATR Axon. Centre for Digestive Disease, The General Infirmary, Leeds, UK

Uncontrolled studies have suggested that leucocyte apheresis may be a useful in the treatment of inflammatory bowel disease (IBD). We report the results of a pilot study evaluating the use of granulocyte apheresis in patients who had failed to respond to standard medical therapy.

Eighteen patients with active ulcerative colitis (UC) and six with active Crohn's disease (CD) were recruited. These patients had not responded to prednisolone and, in most cases, azathioprine and 5-ASA compounds. Granulocyte apheresis was performed weekly using a column (G1, Otsuka Pharmaceutical Co. Ltd). Response was assessed by symptom indices, sigmoidoscopy, histological scoring and leucocyte scintiscanning.

In UC, 3 patients went into remission and the overall clinical symptom score for all patients, fell from a median of 9 on entry to 3.5 after four weeks (Wilcoxon P-value $=0.012$ ). There was a statistically significant improvement in the mucosal appearance at sigmoidoscopy at entry compared to after four weeks treatment (mean change -0.53 , Wilcoxon P-value $=0.016$ ). The histological score also improved from a median of 5 to 4 (Wilcoxon Pvalue $=0.096$ )

One patient with $C D$ withdrew due to dizziness, 1 achieved remission and there was a reduction in the median CDAI score from 306 to 177.5 after four weeks treatment (Wilcoxon P-value $=0.09$ ). The leucocyte scintigraphy score also improved from a mean value of 2.5 at entry to 1.5 after four weeks (Wilcoxon test, $P$-value $=0.25$ ). There were no significant change in median haemoglobin, white cell or platelet counts during the study. There were no changes in laboratory values that caused concern and the procedure was well tolerated both by in- and out-patients.

This is the first study looking at granulocyte apheresis in patients with steroid resistant IBD. Our data suggests that the treatment is both feasible and safe and may have be effective in both UC and CD. However, larger, controlled studies are required.

DOUBLE-BLIND, PLACEBO CONTROLLED TRIAL TO DETERMINE THE EFFICACY OF ESSENTIAL FATTY ACID SUPPLEMENTATION IN THE TREATMENT OF ULCERATIVE COLITIS

S.J. Middleton, P.J. Roberts, J.T. Woolner, S. Naylor, M. Shorthouse, J.O. Hunter. Department of Gastroenterology, Addenbrooke's NHS Trust, Cambridge CB2 2QQ

In ulcerative colitis (UC) the colonic mucosa contains proinflammatory prostaglandins and leukotrienes. HGA (eicosanoic acid $0.3 \mathrm{~g}$; gammalinolenic acid $1.6 \mathrm{~g}$; docosahexaenoic acid $0.45 \mathrm{~g}$ daily) was administered to patients with UC for 12 months in an attempt to increase the synthesis of less inflammatory eicosanoids. Disease activity was assessed at 3-monthly intervals using standard clinical sigmoidoscopic and histological features. In addition, assessments of secondary parameters; quality of life, weight, diet, adverse events. hemato stratitied for extent of disease 58 patients with quiescent UC were randomised to receive HGA ( $n=29$, mean age $41 \pm 9$ yrs), or placebo ( $n=29$, mean age $43 \pm 12 y r s)$. 20 patients with poorly controlled UC were randomised to $\mathrm{HGA}$ ( $\mathrm{n}=9$, mean age $44 \pm 11 \mathrm{yrs}$ ) or placebo ( $\mathrm{n}=11$, mean age $43 \pm 8 y r s)$. Secondary parameters such as sex, smoking, allergies and treatment were matched. HGA treatment did not benefit either group of patients (Table).

\begin{tabular}{|c|c|c|c|c|}
\hline 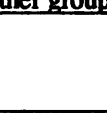 & \multicolumn{2}{|c|}{$\begin{array}{c}\text { Active UC } \\
\text { \% of patients in relapse } \\
\text { (95\% confidence } \\
\text { intervals) }\end{array}$} & \multicolumn{2}{|c|}{$\begin{array}{l}\text { Quiescent UC } \\
\text { \% patients in remission } \\
\text { (95\% confidence intervals) }\end{array}$} \\
\hline Months & $\begin{array}{c}\text { Placebo } \\
(n=11)\end{array}$ & $\underset{(n=9}{\text { HGA }}$ & $\begin{array}{c}\text { Placebo } \\
(\mathrm{n}=29)\end{array}$ & $\begin{array}{c}\text { HGA } \\
(\mathrm{n}=29)\end{array}$ \\
\hline 3 & 9174 & $71(36)$ & 9079 & 7538 \\
\hline 6 & 9174 & 7136 & 8660 & $48(36)$ \\
\hline 12 & $\begin{array}{ll}6836 \\
98\end{array}$ & $\pi\left(\begin{array}{c}36 \\
(100)\end{array}\right)$ & 7660 & $\begin{array}{r}55(36) \\
(74)\end{array}$ \\
\hline
\end{tabular}

The time (days) for $25 \%$ (lower quartile) of patients with active colitis to enter remission was 275 in placebo and 92 in HGA groups (NS), and that for $25 \%$ of patients in remission to relapse was 365 in placebo and 83 in HGA group (NS). There were no differences in secondary parameters. HGA treatment had no clinical benefit in either active or quiescent UC. 
A RANDOMISED CONTROLLED TRIAL OF ESSENTIAL FATTY ACIDS (EFA) IN ACUTE ULCERATIVE COLITIS(UC). Stack WA. Cole AT, Makhdoom Z*, Murray FE, Cullen DE, Stewart JCMI, Everitt SE, Holmes $G^{*}$ and Hawkey CJ. Divisions of Gastroenterology, University Hospital, Queen's Medical Centre, Nottingham, and Derby Royal Infirmary*, Scotia Pharmaceuticals GuilfordI.

Background: Omega-3 EFA (fish oil) has recently been shown to be beneficial in decreasing relapse rates in Crohn's disease (Beluzzi NEJM 1996; 334:1557). Omega-3 EFA appear to be of more limited benefit in acute ulcerative colitis and possible synergy with omega-6(plant oil) EFA has been suggested. We therefore carried out a randomised double blind controlled trial of omega- 3 and omega-6 EFA supplementation in acute UC to determine if they reduced steroid requirement and to investigate if synergism existed between them.

Methods: Patients with acute relapse of colitis were randomised to receive omega-3 EFA (eicosapentaenoic acid 1.5g), omega-6 EFA (gamma linolenic acid $2.1 \mathrm{~g}$ ), both or placebo daily for four months. Prednisolone use was systematically reduced using a standard withdrawal protocol. As the trial was exploratory, the main analysis was of steroid use in patients treated per protocol by logistic regression analysis.

Results: 66 (36F) patients were randomised to treatment and 53 completed the study. 6 patients withdrew due to severe exacerbations of UC ( 2 placebo, 2 omega-3, and 1 each omega- 6 and both groups), 4 withdrew because of side effects ( 1 each group), and 3 defaulted from follow up. Daily mean prednisolone $( \pm S D)$ for all groups was 19.8 9.6. $11.4 \pm 9.1,8.9 \pm 9.3$ and $7.2 \pm 8.1 \mathrm{mg} / \mathrm{d}$ for months 1 to 4 respectively $(p<0.001$; month 1 to 4 ). There was no significant difference in mean daily prednisolone requirement in patients treated with omega-3 and omega-6 EFA either alone or together compared with placebo (Table).

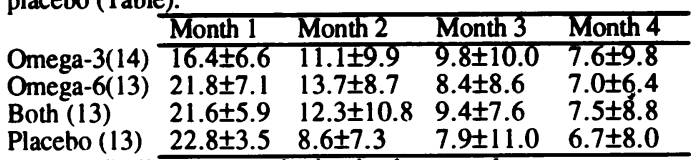

$\begin{array}{lllll}\text { Placebo (13) } & 22.8 \pm 3.5 & 8.6 \pm 7.3 & 7.9 \pm 11.0 & 6.7 \pm 8.0\end{array}$

Similar findings were obtained when results were compared on an intention to treat analysis.

Conclusion: In acute UC we could find no steroid sparing effect with omega-3 or omega- 6 EFA supplementation compared with placebo whether given alone or in combination.
MACROSCOPIC AND HISTOLOGICAL INACTIVITY IN ULCERATIVE COLITIS (UC) SURVEILLANCE: A GOOD PROGNOSTIC SIGN?

E Chiotakakou-Faliakou, S Ganesh, K Wilkinson, A Forbes. St Mark's Hospital, Watford Road, Harrow, HA1 3UJ.

Surveillance colonoscopy in UC is imperfect and expensive. Better targeting of especially high and relatively low risk patients would improve its costeffectiveness. A clinical impression that the risk of neoplasia is lower in those with persistently inactive disease has been tested. Thirteen cases of confirmed dysplasia or carcinoma (n=3) docurrented between 1/1/93 and 31/12/95 in a major surveillance program, which currently includes more than 400 patients with macroscopically extensive colitis of $>10$ years duration, were reviewed. For each case, 2 unresected UC controls matched for age, sex, and disease duration were selected from the database. Contemporary records of biennial colonoscopic appearances and the degree of histological activity were compared with those for the patients with neoplasia. At the first occasion of dysplasia/malignancy the cases had had a mean of 23.1 years extensive UC (controls 23.5y), and had undergone 6.8 surveillance colonoscopies (4.9). $58 \%$ of colonoscopies in the cases had been reported to show normal appearances or quiescent disease, compared to $78 \%$ in the controls $\left(x^{2}: p<0.05\right)$. $48 \%$ of histological reports in patients with subsequent neoplasia indicated inactive disease, compared to $58 \%$ in the controls (not significant). Although persistent macroscopic and histological quiescence of extensive UC may be associated with a lower risk of progression to early dysplasia/malignancy, the magnitude of this effect is unlikely to be sufficient to support a reduced frequency of surveillance colonoscopy.
MUCOSAL AMINOSALICYLATE LEVELS CORRELATE WITH CLINICAL ACTIVITY IN PATIENTS WITH ULCERATIVE COLITIS. F.Hussain. R. Ajjan. M.Grundman. R. Bolton, S. Riley. Chesterfield, Doncaster and Northern General Hospital, Shefficld. UK.

Introduction Despite maintanance mesalazinc treatment some patients with ulcerative colitis relapse frequently. Systemic drug levels do not relate to clinical activity and correlate poorly with tissue levels. We have therefore studied the relationship between rectal tissue drug levels and clinical outcome. Methods 20 patients (10 male, age 19-75 years) taking delayedrelease mesalazinc $2.4 \mathrm{~g} /$ day were recruited. Each underwent clinical assessment and sigmoidoscopy at 0, 3. and 6 months or at relapse. At each timepoint 24 hour urine collections and rectal biopsies were taken for drug analysis. 9 patients relapsed during the study (reported compliance was good)

\begin{tabular}{|c|c|c|c|}
\hline Results: mean (sem ) & $\begin{array}{l}\text { Quiescent } \\
\text { throughout } \\
n=11\end{array}$ & $\begin{array}{l}\text { Quiescent } \\
\text { but } \\
\text { subsequenthy } \\
\text { relapse } n=9\end{array}$ & $\begin{array}{l}\text { During } \\
\text { relapse } \\
n=9\end{array}$ \\
\hline Mucosal ac5ASA ng/mg & $8.2(2.7)$ & $6.2(1.2)$ & $2.3(0.7)$ \\
\hline Mucosal SASA ng/mg & $6.2(1.6)$ & $3.6(1.6)$ & $0.3(0.18)$ \\
\hline Urine ac5ASA mg & $483(40)$ & $854(178)$ & $557.5(46)$ \\
\hline Urine SASAmg & $79.5(15)$ & $152.7(43)$ & $70.9(15)$ \\
\hline
\end{tabular}

Mucosal drug levels were significantly lower at relapse than during quiescent disease (5ASA $p=0.02$, ac5ASA: $p=0.008$ ). Urinary drug levels were lower but this did not achieve statistical significance. Mucosal 5ASA drug levels were also reduced in patients who were quiescent at entry but who subsequently relapsed $(p=0.02)$ whereas total urinary drug levels and ac-5ASA were significantly increased $(p=0.04)$.compared to patients who were quiescent throughout. Conchusion Mucosal aminosalicylate levels in patients with ulcerative colitis fall appreciably at times of relapse. Patients who subscquently relapse have lower rectal mucosal 5ASA levels and higher urinary drug excretion. This may reflect differences in pharmacokinetics and may predispose to relapse. Rectal mucosal drug analysis is a useful tool in the study of patients with ulcerative colitis.

( Rescarch part funded by Smith Kline Beecham Pharmaceuticals, U.K )
CROHW'S DISEASE PATENTS IN CLIUCAL REMSSHON SHOW EVDENCE OF ONGONG IUCOSAL INFLAMMATION. IAmott, S Ghosh, H Drummond, A Ferguson. GI Unit, Depertment of Medicine, University of Edinburgh, Westem General Hospitd, Edinburgh, Scolland.

Background: Clinical remission in Crohn's Disease is generally defined as a CDAl < 150. Endoscopic and histologic disease activites may not correlate. Inflammaivory markers in Whole gut lavage livid (WGLF) such as granulocyte clastase (GE) and IL-1B have been used as objective measures of both small bowel and colonic mucosal inflammation. We aimed to study whether clinical remission is associated with normalisation of WGLF inflammatory markers. methods: In a prospective study, CDA wes recorded in well characterised CD paients undergoing whole gut lavage with polyethylene dycol electrolyte solution (Klean-Prepo, Norgine), generally as a bovel preperation prior to colonoscopy or barium enema. The first cleer livid passed per rectum was collected, processed by addition of proteese inhibitors and stored at $-70^{\circ} \mathrm{C}$. IL$1 \beta$ (normal < 4pg/mL) and IL-8 (normal concentration <20pg/mL) concentrations were measured by ELSA and GE concentration (normal <39nkath) was measured by an enzyme-substate reaction as described previousty.

Results: 24 patients with $C D$ were in clinical remission with $C D A \mid<150$. 15/24 (62\%) of these patients had raised WGLF IL-1 $1 \beta$ concentrations, 16/24 (67\%) had raised IL-8 concentations and 7/24 (30\%) has raised GE concentrations. Overall,

$67 \%$ of patients in clinical remission had one or more abnormal WGLF inflammatory parameters.

Conclusion: A significant proportion of CD patients in clinical remission have WGLF features suggesfive of ongoing mucosal intarmation. We have previously shown that $C D$ patients with abnorma WGLF infarnmeitory markers relapse more often than those with normal WGLF perameters. Further research is needed to ascertain whether medical therapy to induce mucosal remission will produce longer relapse free periods 
FURTHER VERIFICATION OF THE REALLY USEFUL SIMPLE COLITIS ACTIVITY INDEX.

\section{RS Walmsley, "RCS Ayres, RE Pounder, "RN Allan.}

Inflammatory Bowel Disease Study Group, Department of Medicine,

Royal Free Hoepital School of Medicine, London, "Department of

Gastroenterology, Queen Elizabeth University Hospital, Edgbaston,

Birmingham.

Backgrenand \& Aims: We have devised a clinical scoring system of five simple questions to assess the activity of ulcerative colitis (UC) which correlates significantly with the Powell-Tuck score (1). We have now evaluated the simple clinical score against a complex score devised from clinical and laboratory data (2) as well as biochemical and haematological results relevant to UC (3).

Methods: 60 patients with UC underwent 110 assessments. They completed a questionnaire concerning: bowel frequency (day \& night); presence of blood in stool; urgency of defecation; general well being and extracolonic manifestations. Laboratory tests included:

haemoglobin; platelet count; haematocrit; erythrocyte sedimentation rate and serum albumin. Scores were calculated as published $(1,2)$ and compared using Pearson correlation.

\begin{tabular}{|c|c|c|c|}
\hline \multirow[t]{7}{*}{ Results: } & $\begin{array}{l}\text { Simple Index } \\
\text { Correlation with; }\end{array}$ & r value & p value \\
\hline & Complex score & 0.838 & $<0.0001$ \\
\hline & Albumin & -0.5 & $<0.0001$ \\
\hline & Hacmorjobin & -0.322 & 0.0006 \\
\hline & Platelet count & 0.323 & 0.0006 \\
\hline & Haematocrit & -0.325 & 0.0005 \\
\hline & ESR & 0.321 & 0.0015 \\
\hline
\end{tabular}

For 8 patients assessed during an exacerbation of their disease the simple score correlated well with the complex score and laboratory parameters.

Conclualon: This simple clinical colitis activity index is a robust tool for assessing the activity of ulcerative colitis.

Ref. (1).RS Walmsley et al.Gut. 1994:35; supl 5: S29. (2). M Seo et al Am J Gastro. 1992:87:8; 971. (3).W Cooke, P Prior. J Clin Gastorenterol 1984: 6; 17.
PERIPHERAL BLOOD PRO-INFLAMMATORY CYTOKINE PROFILE IN ACTIVE INFLAMMATORY BOWEL DISEASE (IBD) DIFTER BETWEEN SMOKERS AND NON-SMOKERS. Bhatti MA, Hodgson HJF.

Royal Postgraduate Medical School, Hammersmith Hospital, London.

Strong evidence exists that patients with Crohn's disease (CD) are more likely to be smokers than control population whilst, on the other hand, nicotine improves the condition of patients with active ulcerative colitis (UC). However the mechanism(s) of the effects of nicotine remains elusive. We have investigated whether there are differences in proinflammatory cytokines $\mathbb{I}-1 \beta$, $\mathbb{L}-6, \mathbb{L}-\mathbf{B}$ between smokers and nonsmokers in ex-vivo LPS stimulated blood.

METHODS: $6 \mathrm{ml}$ blood were taken from each patient with both active and inactive UC and CD (12 in each group; total $n=48)$ and 12 healthy volunteers ( 7 patients with $\mathrm{UC}, 11$ with $\mathrm{CD}$ and 5 healthy volunteers were smokers). Plasma was separated from $3 \mathrm{ml}$ of each blood sample and other $3 \mathrm{ml}$ were incubated for $24 \mathrm{~h}$ with $20 \mathrm{ng} / \mathrm{ml}$ LPS before isolating cell free plasma. All cytokines were measured by sandwich ELISA (lower detection limit $15 \mathrm{pg} / \mathrm{ml}$ ). Disease activity was measured by Crohn's disease activity index in CD and Truelove and Witts criteria in UC.

RESUTS: Among patient with IBD LPS stimulated IL-1B and IL-8 levels among non-smokers were significantly higher than smokers $(\mathrm{p}<0.05 \& \mathrm{P}<0.01$ respectively). This effect was more pronounced for II-8 levels particularly among active UC and CD patients (Non-smokers : Smokers; UC(median) $1143: 684$ pg/ml. p $<0.001$ \& CD $954: 630$ $\mathrm{pg} / \mathrm{ml}: \mathrm{p}<0.01)$. IL-6 levels were not significantly different between smokers and non-smokers. IL-1B and $\mathbb{L}-8$ levels also correlated well with disease activity ( $r=0.543 \& \mathrm{r}=0.64$ respectively). In spite of lower cytokine levels, number of monocytes, a primary source of proinflammatory cytokines, was higher among smokers $(p<0.001)$.

CONCLUSIONS: 1. Non-smokers tend to have higher levels of proinflammatory cytokines than smokers.

2. These results indicate one possible way (probably a cytostatic activity) by which nicotine is effective among active UC patients.
MESENTERIC MARGINAL ULCERATION IN CROHN'S DISEASE: CORRELATION WITH VASCULAR ANATOMY AND CRITICALLY-PERFUSED SITES. A Anthony, RE Pounder, AJ Wakefield, AP Dhillon. Inflammatory Bowel Disease Study Group, Depts of Histopathology/Medicine, Royal Free Hospital, London, UK

Backsround/Aim. In Crohn's disease (CD) of the ileum, ulcers lie along the same side of the bowel as the mesenteric attachment (ie. mesenteric margin), while the anti-mesenteric mucosa is often spared. The mesenteric and anti-mesenteric borders of the human small intestine are supplied respectively by vasa brevia (VB) and vasa recta (VR) feeding vessels. CD affects the terminal ileum more often than the jejunum. It has been proposed that mucosal infarction, as a consequence of primary granulomatous vasculitis, contributes to $\mathrm{CD}$. We tested the hypothesis that $\mathrm{CD}$ ulcers along the ileal mesenteric margin are explained by the existence of VB end arteries within the human ileum but not the jejunum. Methods. Post mortem specimens of normal terminal ileum and jejunum were dissected from adult cadavers $(n=8)$. Mesenteric arcade arteries were cannulated and perfused with carbon (India) ink with or without prior ligation of single isolated VR or VB. Specimens were fixed and cleared by Spalteholtz's method. The blood supply of the bowel wall and the submucosal plexus was examined by dissection microscopy. Tissues were also examined histologically. Results. The submucosal vascular plexus of the jejunum was more extensive than that of the terminal ileum. The submucosal vascular plexus derived from ileal VB were noted to be end-arteries with little or no communication with the submucosal plexus formed from VR. Ligation of both isolated ileal and jejunal VR prior to carbon ink perfusion did not affect filling of the submucosal plexus. Prior ligation of ileal, but not jejunal, VB revealed filling defects of the submucosal plexus along the mesenteric margin. Conclusion. In the ileum, VB do not communicate with the main submucosal plexus, (ie. they are end arteries) suggesting that pathological occlusion of ileal VB would preferentially render ischaemic, areas of the ileum along the mesenteric margin. These findings support a vascular hypothesis for CD and may explain the ileal and mesenteric distribution of CD ulcers.
DFFERENTIL EFFECT OF STERODS ON NITRIC OXDE (NO) PRODUCTION BY CYTOKNE STMULATED HT-29 CEUS. Dr D Linehen Dr GKolios, Dr DAF Robertson, Professor J Westwick Dept of Phermeocology \& Phermagy University of Beth

Buckeround Sudies in coltis have shown increases in NO production and increesed inducblo NO spthese activity in the infermed mucoee expecialy in

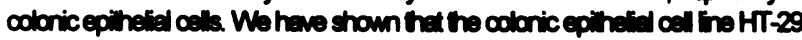

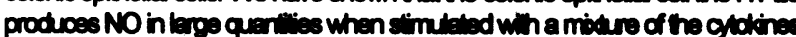
TNF-a (100notm), L-1a (10notml) and FNog (300/m)and this is intibled by protreatment wh L-13. Siroids are ueed to reat IBD petients and in reepiritory epthelial cells are lnown to reduce NO production.

Ain To evenine the eflect of wo stercids, prectrisotone and budescride on the production of NO in a colonic epithelits cell tine.

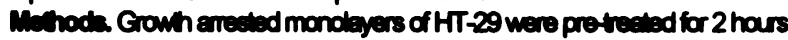

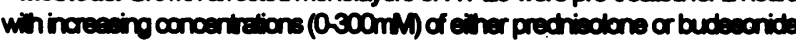
diseoved in MoCoys 54 medum The cells were hen stimulated with the cbove glokino mix Moda wes collected at both 24 ( $n=4)$ \& 48 ( $n=4$ ) hours. NO

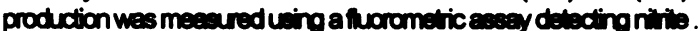

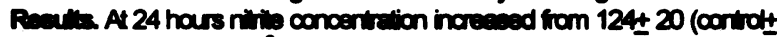
SEM) to 309+ 67nM per $10^{\circ}$ cells with ordine stimultion. Protrectment with prechisolone concentrations up to $300 \mathrm{mM}$ made no efistence to nitits production. Protrecitment with budesonide decreesed nitits production at concentrations of $10 \mathrm{mM} \mathrm{to} 182+55,30 \mathrm{mM}$ to $196 \pm 36,100 \mathrm{mM}$ b $190 \pm 28$ and $300 \mathrm{mM}$ b203 $+34 \mathrm{nMper} 10^{\circ} \mathrm{cells}$.

At 48 hours nitite concentretion increesed from $211 \pm 28$ (controlt SEM) to $534+121$ MM per $10^{8}$ oels with ojoline stimulation. Protreatiment with prectrisolone concentrations up to $300 \mathrm{mM}$ mede no cillerence to nitite production Pretreatment with budesonide decreased nitite production a concentrations of $30 \mathrm{mM}$ to $370 \pm 81,100 \mathrm{mM}$ to $347 \pm 89$ and $300 \mathrm{mM}$ to $273 \pm$ 24 rMper $10^{\circ}$ cells.

Concivion Protreetment with budesonide but not prechisotone a comperatively high concentrations decreeses the production of nititio by HT-29 cells at both 24 \& 48 hours. The beneficial eflact of prectivotone in collis is unilkely to be die to a direct eflect on NO production by colonic eplineliel cells. 
EXPRESSION OF INTEGRIN $\alpha 4 \beta 7$ ON CIRCULATING LYMPHOCYTES IN INFLAMMATORY BOWEL DISEASE. Arun Dhiman, Mike J. Weldon, Douglas J. Ringler", Jennifer A. Tooze" \& J.D. Maxwell. Divisions of Gastroenterology and "Haematology, St. George's Hospital Medical School, London SW17 ORE and. "LeukoSite Inc., Cambridge, MA 02142 USA

Backeround: The cell adhesion molecule integrin $\alpha 4 \beta 7$ is involved in the migration of $B$ and $T$ tymphocytes to the gut. Anti- $\alpha 4$ integrin antibodies reduce colonic inflammation in the Cotton-top tamarin.

Aim: To determine if there is any change in the expreseion of integrin $\alpha 4 \beta 7$ on circulating lymphocytes in inflammatory bowel disease patients.

Methods: Peripheral venous lymphocytes from 7 normal controls, 16 Crohn's disease (CD) and 9 ulcerative colitis (UC) patients (both active and inactive disease) were studied using flow cytometry. The percentage of hymphocytes expressing intergin $\alpha 4 \beta 7$ was determined using monoclonal antibody Act-1 and an indirect immmoftuorescence technique. The relative number of $\alpha 4 \beta 7$ receptors per lymphocyte was compared by calibrating the mean fluorescence intensity (MFI) in fluorescnce (MEF) units for each population of $\alpha \mathbf{4} \beta 7^{+}$lymphocytes.

\begin{tabular}{|r|c|c|}
\cline { 2 - 3 } \multicolumn{1}{c|}{ Results } & $\begin{array}{c}\text { Mean percent } \alpha 4 \beta 7^{+} \\
\text {lymphocytes } \pm \text { SEM }\end{array}$ & $\begin{array}{c}\text { MFI of } \alpha 4 \beta 7^{+} \\
\text {lymphocytes } \pm \text { SEM }\end{array}$ \\
\hline Controls & $71.9 \pm 5.3$ & $2816 \pm 419$ \\
\hline CD Active & $69.1 \pm 3.5$ & $3614 \pm 313$ \\
\cline { 2 - 3 } Inactive & $77.3 \pm 3.8$ & $2810 \pm 524$ \\
\hline $\begin{array}{r}\text { UC Active } \\
\text { Inactive }\end{array}$ & $68.2 \pm 5.8$ & $2624 \pm 234$ \\
\cline { 2 - 3 } & $82.0 \pm 2.3$ & $2799 \pm 441$ \\
\hline
\end{tabular}

No significant difference in values ( $p>0.084)$ between any disease group and control group, or between any two disease groups.

Conclusion: In inflammatory bowel disease, mucosal accumulation of lymphocytes is not associated with a change in the proportion of circulating lymphocytes expressing the gut homing integrin $\alpha 4 \beta 7$, or in the relative density of lymphocyte $\alpha 4 \beta 7$ receptors. However, anti- $\alpha 4 \beta 7$ therapy may be beneficial in treating inflammation by reducing the proportion of lymphocytes recirculating through the gut.
ABSENCE OF E.COLI, LISTERLA AND RLEBSIELLA PNEUMONIA ANTIGENS WITHIN INFLAMMATORY BOWEL DISEASE TISSUES.

RS Walmsley, R Sim, A Anthony, RE Pounder, AJ Wakefield. Inflammatory Bowel Disease Study Group, Department of Medicine, Royal Free Hospital School of Medicine, London.

Background \& Aims: Colonic bacteria may have a major role in the pathology of inflammatory bowel disease (IBD). E.coli, Listeria and Streptococcal antigens have been found in the inflamed bowel wall of French families with IBD (Yui et al, Gastroenterology 1995;108:1396) and serum antibodies to a number of organisms including Klebsiella pneumoniae and $E$. coli occur in IBD. We therefore undertook an investigation for persistent microbial antigens within IBD affected tissues.

Methods: Formalin-fixed and paraffin-processed sections from resected bowel specimens of 53 patients (19 ulcerative colitis [UC], one with AS; 23 Crohn's disease [CD]; 11 normal tissues from cancer resections) were investigated. Control tissue consisted of normal human small bowel injected submucosally with E.coli, Listeria Monocytogenes NCTC 7973, Proteus mirabilis and Klebsiella pneumoniae serotypes $\mathrm{K} 2,3,17,21,26,36$ and 50 , along with colonic biopsies from a child with E.coli 0114 infection. Sections underwent Gram-Twort and specific immunohistochemical staining with antibodies for $E$. coli (DAKO B357), L. Monocytogenes (DIFCO 230250) and $K$. pneumoniae (Biogenesis 5580-5208 and Sanbio-Monosan 2006), using an immuno-peroxidase technique (DAKO Duet).

Results: E.coli; positive staining on luminal surface, including ulcers in $41 \%$ of UC, CD and normals. Listeria Monocytogenes; two cases (both Crohn's disease) showed positive staining confined to mucus layer. Klebsiella Pneumoniae; superficial staining in 14\% (4 CD, 2 UC, 2 normal) of patients.

Conclusion; Microbial antigens of E.coli, Listeria monocytogenes and Klebsiella pneumoniae are found only on the epithelial surface and not within the affected tissues in inflammatory bowel disease.
THE IMMUNE RESPONSE TO KLEBSIELLA PNEUMONLAE IN INFLAMMATORY BOWEL DISEASE AND ANKYLOSING SPONDYLITIS.

RS Walmsley, H Tiwana*, C Wilson*, MJ Hudson **,A Ebringer*, RE Pounder, AJ Wakefield. Inflammatory Bowel Disease Stuay Group, Royal Free Hospital School of Medicine, London. *Division of Life Sciences, King's College, London. ${ }^{* *}$ Department of Microbial Pathogenicity, Centre for Applied Microbiology and Research, Porton Down. UK.

Background: Occult bowel inflammation is found in up to two thirds of ankylosing spondylitis (AS) patients. IgA antibodies to Klebsiella pneumoniae (Kleb.p) are implicated in the pathogenesis of AS in HLA-B27 positive patients and have been found in inflammatory bowel disease (IBD). It has been suggested that the important serotypes of Kleb.p in AS are K26, 36 and 50. The serotypes involved in IBD are unknown. Aims: To define the antibody subclass response and Kleb.p serotypes involved in IBD and AS. Methods: Sera was studied from HLA-B27 positive AS patients (40), Crohn's disease [CD] (46), ulcerative colitis [UC] (38), coeliac disease (50) and normal blood donors (40). Direct, Ig subclass-specific ELISAs were performed using whole bacterial and capsular extacts of Kleb.p serotypes $K 2,3,17,21,26,36$ and 50. Mean ODs were compared using Student's ttest, significance was taken as $p<0.02$. Results: Significantly raised antibodies compared with normal controls were found in: $A S$; IgG to capsular extracts of $\mathrm{K} 2,3,21,36,50$ and whole bacterial preps. of $\mathrm{K} 36,50$; IgA to capsular $\mathrm{K} 2,3,17,21,26,36,50$ and whole bacteria $\mathrm{K} 21,26,36,50$. CD: IgG and IgA to capsular extracts of all serotypes; IgG to whole bacteria $\mathrm{K} 17$; IgA to whole bacteria $\mathrm{K} 17,21,26,36,50$. IgM to capsular and whole bacteria of all serotypes: $U C$; IgG to capsular K17,36,50 and whole bacteria K3,50; IgA to capsular extracts K2,3: Coeliac disease; no elevation.

Conclusion; A broad range of Kleb.p capsular serotypes are involved in the immune response to Kleb.p in AS, CD and UC. The similarity of immune response between IBD and AS is further evidence of the common association of gut and joint inflammation.
SMOKING AND APPENDICECTOMY IN TWINS DISCORDANT FOR INFLAMMATORY BOWEL DISEASE (IBD).

LSubhani, S Montgomery, S Ebrahim, R Pounder, A Wakefield IBD Study Group, Royal Free Hospital, London, NW3 2QG, UK

These factors have been shown to either be protective (e.g. smoking \& appendicetomy in ulcerative colitis (UC)), or a risk (e.g. smoking in Crohn's disease (CD)), for the development of IBD. Potential confounders include material and cultural circumstances in childhood. An unaffected co-twin provides an ideal control minimizing mandom and "ffalse" systematic differences in these confounders. In addition a twin also controls for genetic susceptibility. Finally the timing of the exposures, in relationship to the disease onset, is critical to their assessment as "true" risk factors. A twin case-control method was used to study these factors. Method: A UK repistry of 175 twins-pairs, at least one of which had IBD, was validated for disease status and zygosity. Each member was sent, sequentially, questionnaires asking about childhood events and smoking (Q1) and other life events including appendicetomy (Q2). Results:

Of the 110 same-sex discordant pairs in the registry both twins in 88 pairs replied to Q1 (80\%), and in 67 pairs to Q2 (79\%).

\begin{tabular}{|c|c|c|c|c|}
\hline Risk factors & Case & Control & Odds Ratio & Significance \\
\hline $\begin{array}{l}\text { Smoking ever } \\
\text { Crohn's disease } \\
\text { ulcerntive colitis }\end{array}$ & $\begin{array}{l}24 \\
18\end{array}$ & $\begin{array}{l}17 \\
19\end{array}$ & $\begin{array}{l}2.5 \\
0.8\end{array}$ & $\begin{array}{l}p=0.18 \\
p=1.00\end{array}$ \\
\hline $\begin{array}{c}\text { Smoking before Diagnosis } \\
\text { Crohn's disease } \\
\text { ulcerative colitis }\end{array}$ & $\begin{array}{l}21 \\
17\end{array}$ & $\begin{array}{l}14 \\
18\end{array}$ & $\begin{array}{l}2.5 \\
0.6\end{array}$ & $\begin{array}{l}\mathrm{p}=0.18 \\
\mathrm{p}=0.72\end{array}$ \\
\hline $\begin{array}{l}\text { Appendicectomy } \\
\text { ever } \\
\text { before dingnosis }\end{array}$ & $\begin{array}{l}9 \\
3\end{array}$ & $\begin{array}{l}6 \\
6\end{array}$ & $\begin{array}{l}1.6 \\
0.5\end{array}$ & $\begin{array}{l}p=0.57 \\
p=0.48\end{array}$ \\
\hline Appendicitis & 0 & 5 & & $p=0.057$ \\
\hline
\end{tabular}

Though no exposure achieved significance, the trend in smoking was simila to that previously reported for the UC and $C D$. There were no cases of appendicitis among the twins with IBD, this despite very similar environmental exposures (assessed by sharing a bedroom, classes, hobbies and time together) to their twins who developed appendicitis.

Conclusion: Differences in exposures in twin studies are more noteworthy because of the very close matching of case and control. Though no factor achieved significance, the relationship of appendicitis to IBD seems worthy of further study. 
INVESTIGATION OF PLATELET-ACTIVATING FACTOR-INDUCED SECRETION IN HUMAN COLON. R.A. Borman, R. Jewell, K. Hillier, Clinical Pharmacology Group, Biomedical Sciences, University of Southampton, Southampton SO16 7PX, UK

Platelet-activating factor (PAF) has been implicated as a putative mediator of the diarrhoea associated with inflammatory bowel disease (IBD), endotoxic shock, and cholera. Increased levels of PAF have been found in specimens of human colon taken from patients with IBD, and when culture medium bathing such specimens is applied to rat colon, there is a significant increase in fluid secretion across the mucosa In addition, it has been shown that exogenously-applied PAF enhances fluid secretion in rat colon. The aim of the present study was to determine whether PAF exerts pro-secretory actions in human colon, and to investigate the mechanism of action.

Segments of human sigmoid colon were obtained from specimens removed at operations for carcinoma. After removal of smooth muscle, sheets of mucosa complete with submucosa were mounted in Ussing chambers for measurement of short-circuit current $\left(\mathrm{I}_{\mathrm{sc}}\right.$; an indicator of electrogenic fluid secretion). Tissues were exposed to varying concentrations of PAF, and responses modified by a selection of inhibitors

Serosal application of PAF $\left(10^{-9}\right.$ to $\left.10^{-5} \mathrm{M}\right)$ induced a significant increase in $\mathrm{I}_{\mathrm{sc}}$ across human sigmoid colonic mucosa, with a maximum response of $74.3 \pm 9.5 \mu \mathrm{Acm}^{-2}$ at $10^{-5} \mathrm{M}$ and an $\mathrm{EC}_{50}$ of $18.2 \mathrm{nM}(\mathrm{n}=6)$. Mucosal application of PAF $\left(10^{-6} \mathrm{M}\right)$ had no effect on $\mathrm{I}_{\mathrm{sc}}(\mathrm{n}=6)$. Prior treatment of tissues with indomethacin $(1 \mu \mathrm{M}, n=4)$ or WEB 2170 (a PAF receptor antagonist, $10 \mu \mathrm{M}, \mathrm{n}=4$ ) significantly reduced the secretory response to PAF, signifying the response is mediated via a specific PAF receptor and dependent on a product of cyclo-oxygenase enzymes. In addition, application of the loop diuretic bumetanide $\left(10^{-8}\right.$ to $10^{-5} \mathrm{M}$, an inhibitor of chloride ion secretion) caused a concentration-dependent inhibition of the secretory response to PAF $(n=3)$

In conclusion, application of PAF induces significant fluid secretion across human colonic mucosa. The response is dependent on a specific PAF receptor and cyclo-oxygenase products. The rise in $\mathrm{I}_{\mathrm{sc}}$ can be accounted for by an increase in chloride ion secretion.

This study was supported by MRC RQOPA award G9507991
W103

LOW TISSUE ENDOTHELIN LEVELS IN INFLAMIMATORY BOWEL DISEASE, DESPITE ENHANCED ET-2 GENE EXPRESSION S.A.McCartney, ${ }^{*} T$ T.D.Warner, ${ }^{*} \mathrm{M}$ Woods, P.D.Fairclough, M.J.G.Farthing. Digestive Diseases Research Centre and *The William Harvey Research Institute, St Bartholomew's and the Royal London School of Medicine and Dentistry. London U.K.

Endothelins (ETs) are implicated in the pathophysiology of inflammatory bowel disease (IBD). ETs are produced by inflammatory, endothelial and epithelial cells in response to stimulation from cytokines (eg TNF- $\alpha$, IL-1 and IL-2). ETs stimulate further cytokine and prostanoid production and cause local ischaemia and increased vascular permeability. We have assessed the tissue content of ETs by sandwich ELISA and expression of mRNA for the preproendothelins 1,2 and $3, E_{A}$ and $E_{B}$ endothelin receptors in patients with active, treated and quiescent IBD. Biopsy or resection material was obtained from 55 patients: 21 with Crohn's disease, 18 with ulcerative colitis and 16 controls. Samples were snap frozen and stored at $-70^{\circ} \mathrm{C}$. ET1/2 was measured in 45 samples and RT-PCR for mRNA for preproET - 1,2 and 3, ET $A$ and $\mathrm{ET}_{\mathrm{B}}$ receptors and GAPDH was performed on 54 samples.

There was significantly less ET-1/2 in UC and Crohn's vs. controls: UC $15.3 \pm 4 \mathrm{pg} / \mathrm{mg}$ vs. $25.4 \pm 2.8(\mathrm{P}<0.03$, Mann Whitney); $\mathrm{CD} 13.4 \pm 2.2(\mathrm{P}=$ $0.0035)$. No significant differences were seen between subgroups on of off therapy, quiescent or active. RT-PCR for preproET-2 showed that message was present in $40 \%$ of control specimens, $81 \%$ of $C D$ samples $(P<0.02)$ and $72 \%$ of UC samples $(\mathrm{P}<0.06)$. PreproET-1 was present in $<15 \%$ of all samples and preproET -3 was virtually absent in all. All patients with active $\mathrm{CD}$ were positive for preproET-2 $(n=17)$. ET $A$ receptors were upregulated in association with preproET-2, and mRNA was present in $43 \%$ of controls, $79 \%$ with $C D(P<0.03)$ and $71 \%$ of $U C$ samples $(P<0.12)$. mRNA for $\mathrm{ET}_{\mathrm{B}}$ receptors was less prevalent than that for $\mathrm{ET}_{\mathrm{A}}$ but in similar proportions.

Conclusions: Colonic mucosa from patients with IBD contains a reduced quantity of ETs, contrary to previous evidence. This is in contrast to increased mRNA for preproET-2 and $\mathrm{ET}_{\mathrm{A}}$ receptors. This disparity may be due to enhanced gene expression matched by increased protease activity in inflamed tissue degrading unbound ET. Interestingly it appears that ET2 , not ET-1, is the physiologically significant isopeptide within the human colon
STONE INHIBITOR/PROMOTOR RATIO, A RISK FACTOR FOR RENAL CALCIUM OXALATE CALCUL FORMATON IN INFLAMMMATORY BOWEL DISEASE - N. MCConnell, S. Campbell, I. Gillanders, H. Rolton and B.J. Danesh. Biochemistry and Gastroenterology Departments, Stobhill NHS Trust, Glasgow, G21 3UW, U.K.

INTRODUCTION: Enteric hyperoxaluria has traditionally been seen as the cause of the higher incidence of calcium oxalate renal stones in inflammatory bowel disease and malabsorption syndromes compared to the general population. This study was undertaken to examine urinary factors contributing to this increased risk.

METHODS: Forty patients with inflammatory bowel disease (IBD) were studied along with 17 healthy controls. Two of 25 patients with Crohn's disease had stones confirmed (8\%), a further $5(20 \%)$ had a history of renal stone symptoms. None of the 15 patients with ulcera tive collitis (UC) had either stones present or a history of renal stone symptoms. Levels of oxalate and calcium (known stone promoters) and citate and magnesium (known stone inhibitors) were measured in 24 hour urine collections.

RESULTS: Hyperoxaluria was present in $36 \%$ of Crohn's patients but none of the UC group. Renal calculi or history of stone symptoms were no more common in hyperoxaluric Crohn's patients than in those with normal urinary oxalate output indicating urinary oxalate lovels are less important in stone development than previously suggested. Crohn's patients had significantly lower urinary magnesium and citrate outputs compared to both the control and UC groups. In this study a combined deficiency of urinary magnesium and citrate relative to urinary calcium, as expressed in a Cit x Mg/Ca index (CMC), correlated well with apparent risk of renal calculi. Risk of developing nephrolithiasis was higher in Crohn's disease compared to UC and was highest in Crohn's patients following gastrointestinal surgery.

CONCLUSION: In Crohn's disease a low stone inhibitor/promoter ratio seems to be a precondition of stone formation, whereas hyperoxaluria is not, and urinary magnesium depletion may be the critical abnormality in these patients. Avoiding magnesium depletion and correcting inhibitor status by citate replacement may be a more successful strabgy for stone prevention in IBD, using the CMC index.
W104

LOW BONE MINERAL DENSITY IS RELATED TO DISEASE DURATION IN CROHN'S DISEASE AND TO GLUCOCORTICOID TREATMENT AND MALE GENDER IN ULCERATIVE COLITIIS. S. Ardizzone, S. Bollani, P. Bettica* P. Molteni, M. and "Endocrinology, University-Hospital "L. Sacco", Milan. Italy.

Low bone mineral density has been shown in inflammatory bowe disease (IBD), but it is not clear, whether, this bone complication is the same in Crohn's disease (CD) and in ulcerative colitis (UC). In this cross sectional study we evaluated spine and femoral neck bone mineral density (BMD) (expressed as $t$ score), calciotropic hormones. (PTH, 25: OH) D, $1,25(\mathrm{OH}) 2 \mathrm{D})$ and biochemical markers of bone turnover lostecalcin, OC; total alkaline phosphatase, ALP; type I
collagen C-terminal telopeptide, ICTP) in 51 CD (30 women, 21 men) and 40 UC (15 women, 25 men) patients. Inirty healthy subjects were selected as age-matched controls (C). The twu IBD groups were similar for: age $(C D=38.7 \pm 13.2$ years, $\mathrm{JC}=34.4 \pm 12.5)$, disease duration $(\mathrm{CD}=83.5 \pm 67.7$ months, $\mathrm{JC}=70.9 \pm 44.0$ ) and cumulative prednisolone dose (CPD) $(C D=6.16 \pm 5.54 \mathrm{~g}$, $U C=6.87 \pm 5.84)$. Spine and femur $t s c o r e s$ were similar in the two groups (spine: $C D=1.49 \pm 1.46 ; \quad U C=1.67 \pm 1.13$; femur: $C D=1.89 \pm 1.36 ; \quad U C=1.60 \pm 1.03)$. Based upon the wHO guidelines, only 88 of CD patients and 15 of of UC patients had a normal BMD, $55 \&$ (CD) and 67 \& (UC) were osteopenic, and $37 \&$ (CD) and 18 \& (UC) were osteoporotic. The distribution among the 3 different diagnostic groups was not significantly different between $C D$ and UC groups $(p=0.11)$. PTH and $25(\mathrm{OH}) 2 \mathrm{D}$ concentrations were not significantly different among IBD patients and controls. However, $1,25(\mathrm{OH}) \mathrm{D}$ concentrations were significanly lower in $C D$ and UC patients compared to controls $(C D=28.7 \pm 8.6, \quad C U=28.7 \pm 9.4, \quad C=34.6 \pm 11.4, \quad P<0.05)$. Bone turnover was increased in UC patients, but not in CD patients, as shown by significantly increased concentrations in UC patients of both $O C$ ( $C D=7.77 \pm 5.06, \quad U C=10.03 \pm 6.24, C=$
$6.58 \pm 2.87$

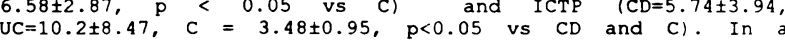
stepwise regression that included age, sex, disease duration and CPD as independent variables, the femur $t$ score was significantly inversely related to disease duration $(\mathrm{r} 2=$ $0.125, F=6.06$ ) in $C D$ patients. In UC patients, the spine $t$ score was inversely related to age ( $120.107, F=5.49)$, and was significantly related to sex, and was more negative in males $(r 2=0.3, F=16.1)$; the femur $t$ score was significantly related to sex (more negative in males) and inversely related to the CPD $\left(\mathrm{I}_{2}=0.283, F=7.3\right)$. In conclusion, our data show that IBD Fatients have a diffuse osteopenia whose degree is not different $\mathrm{A}$ CD and $U C$; however, bone turnover is significantly higher in UC. Finally, osteopenia is related to 


\section{Inflammatory bowel disease TH105-TH112}

INDUCIBLE NOS (iNOS) IS EXPRESSED IN THE NORMAL HUMAN COLON

P.J. Roberts, K. Morgan*, M. Shorthouse, J.O. Hunter, S.J. Middleton, R. Miller. Department of Gastroenterology, Addenbrooke's Hospital, Cambridge CB2 2QQ and *Department of Biochemistry, University of Cambridge.

\section{Background}

It is suggested that the expression of inducible Nitric Oxide Synthase (iNOS) is inflammation-dependent in the human colon. Hitherto, the expression of iNOS has only been demonstrated in the inflamed human colon. We investigated iNOS expression in both acutely inflamed and normal colonic tissue.

\section{Materials and Methods}

Colectomy specimens from patients with active ulcerative colitis $(n=8)$ and histologically normal tissue from patients undergoing resection for colorectal carcinoma $(n=8)$ were studied. Tissue was immediately frozen in liquid nitrogen and post-fixed as required. RTPCR using specific iNOS primers giving a 423bp product and standard western blotting were performed on fresh, frozen tissue to evaluate expression of iNOS. Cellular localisation of iNOS protein was established using $\mathrm{ABC}$ immunohistochemistry with a monospecific iNOS antibody (Santa Cruz). Paraffin-embedded, diseased $(n=6)$ and normal $(n=6)$ colonoscopic and sigmoidoscopic biopsies were evaluated for iNOS localisation to exclude the possibility that iNOS expression was secondary to surgical manipulation.

\section{Results}

iNOS mRNA and protein was expressed in all specimens. Irrespective of the means by which tissue was obtained, labelling of iNOS was seen not only in diseased but also in normal tissue in both epithelial and inflammatory cells of the lamina propria. This staining was neutralised when the antibody was pre-absorbed with iNOS peptide illustrating specific iNOS localisation.

\section{Conclusion}

These results suggest that iNOS is expressed in the epithelium of normal colon in addition to that of ulcerative colitis. It may have an, as yet, undetermined physiological role.
TH107

THE CONTRIBUTION OF DIETARY PROTEIN FROM MEAT TO FAECAL SULPHIDE EXCRETION.

E.A.M.Magee and J.H. Cummings. Dunn Clinical Nutrition Centre, Hills Road, Cambridge, UK.

Aim: To determine the effect of consuming diets differing in meat content on concentration of faecal sulphide ( $\mathrm{mmoV} / \mathbf{g}$ wet weight ).

Background: The dissimilation of inorganic sulphur compounds Background: The dissimilation of inorganic sulphur compoun
(SO4, $\mathrm{SO}_{3}$ etc.) by sulphate-reducing bacteria (SRB) and by the fermentation of sulphur amino acids produces hydrogen sulphide (HS) within the colonic lumen. HS $^{-}$is a cell poison and is toxic to the colonic epithelium by inhibition of B-oxidation of butyrate. In a study of the effect of dietary sulphwe on SRB activity in ulcerative colitis (UC) patients, alterations in dietary sulphate intake affected sulphide production in the colon (Pitcher of al., 1996). This study investigates the contribution of sulphur amino acids in the diet to generation of sulphide in the colon.

Methods: Six healthy, male volunteers were maintained in a metabolic Methods: Six healthy, male volunteers were maintained in a meth
suite and fed a sequence of five randomised diets, varying in meat content only $(0 \mathrm{~g}, 60 \mathrm{~g}, 240 \mathrm{~g}, 420 \mathrm{~g}$ and $600 \mathrm{~g} / \mathrm{day})$. The duration of each test period was ten days. On days 9 and 10 of each period, faecal and urine samples were collected for the measurement of sulphide and sulphate respectively. Faecal HS $^{-}$concentrations were measured by the adapted methylene blue method (Florin, 1991) and total urinary sulphate was measured by ion exchange chromatography (Florin et al., 1991).

Results : Mean faecal sulphide concentrations for the diets containing $0 \mathrm{~g} / \mathrm{day}, 60 \mathrm{~g} / \mathrm{day}, 240 \mathrm{~g} / \mathrm{day}, 420 \mathrm{~g} / \mathrm{day}$ and $600 \mathrm{~g} / \mathrm{day}$ respectively were as follows: $0.216 \mathrm{mmol} / \mathrm{g}$ wet weight $(+/-0.13) ; 0.268 \mathrm{mmol} / \mathrm{g}$ wet weight $(+/-0.17) ; 1.09 \mathrm{mmol} / \mathrm{g}$ wet weight $(+/-0.83) ; 0.72 \mathrm{mmol} / \mathrm{g}$ wet weight
$(+/-0.54)$ and $2.78 \mathrm{mmol} / \mathrm{g}$ wet weight $(+/-1.63)$. Mean total urinary $(+/-0.54)$ and $2.78 \mathrm{mmol} / \mathrm{g}$ wet weight $(+/-1.63)$. Mean total urinary
sulphates increased from $21.5 \mathrm{mmol} /$ day on the $0 \mathrm{~g} /$ day diet to 45.8 mmol/day on the $600 \mathrm{~g} /$ day diet $(60 \mathrm{~g} / \mathrm{day}-22.5 \mathrm{mmol} / \mathrm{day} ; 240 \mathrm{~g} / \mathrm{day}-$ $26.5 \mathrm{mmol} / \mathrm{day} ; 420 \mathrm{~g} / \mathrm{day}-41.8 \mathrm{mmol} / \mathrm{day})$.

Conclusions: Faecal sulphide excretion increased with increased meat consumption, in a dose response manner except for the $420 \mathrm{~g} /$ day period. Intake of meat provides an important source of sulphur containing amino acids and may have implications for HS $^{-}$production in UC. Further work is being carried out to investigate the effects of other Further work is being carried out to investigate the effects of sulphur compounds on HS $^{-}$production in the human colon. Pitcher, M.C.L., Magee, E.A.M., Beatty,
(1996), Gastroenterology, 110: A992.

Florin, T.H.J., (1991), Clin. Chim. Acta., 196: 127-134.

Florin, T.H.J., Neale, G., Gibson, G.R., Christl, S.U. and Cummings, J.H., (1991), Gut, 32: 766-773.
MECHANISMS FOR DETOXIFYING HYDROGEN SULPHIDE IN THE GASTROINTESTINAL TRACT

S Singh, R Picton \& MJS Langman. Dept. of Medicine, Queen Elizabeth Hospital, Birmingham B15 2TH.

Hydrogen sulphide $\left(\mathrm{H}_{2} \mathrm{~S}\right)$ is synthesised mainly by sulphate reducing bacteria in the large bowel. The mechanisms by which this highly toxic gas is detoxicated thus preventing mucosal injury are poorly understood. The microsomal enzyme thiol methyltransferase (TMT) is able to detoxify $\mathrm{H}_{2} \mathrm{~S}$ by methylation. The mitochondrial enzyme rhodanese is also able to detoxify $\mathrm{H}_{2} \mathrm{~S}$ by conversion to thiocyanate. We have sought activity for TMT and rhodanese in the human gastrointestinal tract. In addition, as a control, we have determined activity of the cytosolic enzyme thiol purine methyltransferase (TPMT). This enzyme methylates sulphydryl groups on aromatic compounds e.g. 6-mercaptopurine, but is not able to detoxify $\mathrm{H}_{2} \mathrm{~S}$.

Mucosa was obtained from surgery. TMT assay was performed using $B$ mercaptoethanol as the methyl acceptor and co-factor, tritium labelled S-adenosyl methionine. TPMT assay was performed using 6-mercaptopurine as the methyl acceptor. Rhodanese activity was determined by measuring thiocyanate production from thiosulphate and cyanide

$$
\begin{array}{llll}
\text { Oesop Stomach } & \text { Small } & \text { Right Left Rectum } \\
\text { hagus } & \text { intest. Colon Colon } &
\end{array}
$$

$\begin{array}{lll}n & 4 & 5 \\ \text { TMT } \times 10^{-3} & 4(1) & 43(13) \\ \text { Rhodanese } & 16(6) & 34(11)\end{array}$

$\begin{array}{lll}\text { Rhodanese } & 16(6) & 34(11) \\ \text { TPMT } \times 10^{-3} & 12(3) & 26(9)\end{array}$

$$
\begin{array}{llll}
2 & 5 & 12 & 7 \\
91(12) & 87(11) & 50(9) & 51(6) \\
68(32) & 129(38) & 112(19) & 110(18) \\
36(4) & 33(6) & 28(4) & 30(3)
\end{array}
$$

The Table shows mean(SEM) pmol/min/ug enzyme activity. Activity of TMT and rhodanese was highest in the large bowel, with lowest levels in oesophagus. in contrast TPMT activity was highest in the stomach. The distribution and activity of enzymes detoxifying $\mathrm{H}_{2} \mathrm{~S}$ may be important in ulcerative colitis or large bowel cancer, where chronic mucosal injury by $\mathrm{H}_{2} \mathrm{~S}$ may play a pathogenic role.
GROWTH FAILURE IN INFLAMMATORY BOWEL DISEASE. S.A.McCartney, E.M.Hallyburton, S.E.Patchett, M.J.G.Farthing Digestive Diseases Research Centre. St Bartholomew's and the Royal London School of Medicine and Dentistry. London U.K.

Growth failure is the most common extraintestinal complication of Crohn's disease (CD) and ulcerative colitis (UC) in children and adolescents. Here we present interim data (at age $18 \mathrm{yrs}$ ) from a prospective study of growth in 67 children and adolescents with IBD (52 $\mathrm{CD}$ and $15 \mathrm{UC}$ ). The difference between observed and expected midparental height (MPH) was related to diagnosis, duration of disease and site of disease.

\begin{tabular}{lllll}
$\begin{array}{l}\text { Results } \\
\text { Crohn's disease }\end{array}$ & $\begin{array}{l}\text { Colonic } \\
\text { disease only }\end{array}$ & $\begin{array}{l}\text { Large }+ \\
\text { small bowel }\end{array}$ & $\begin{array}{l}\text { Small bowel } \\
\text { only }\end{array}$ & lleocaecal \\
Height - MPH/cm & -0.35 & -5.8 & -7.1 & -5.2 \\
Mean $(95 \% \mathrm{Cl})$ & $(-5.6 / 4.9)$ & $(-9.9 /-2.5)$ & $(-11.9 /-2.5)$ & $(-10.1 /-0.3)$ \\
Mean age at & 12.2 & 9.8 & 13 & 11.5 \\
diagnosis (Range) & $(7-15)$ & $(4-13)$ & $(11-17)$ & $(7-16)$ \\
$\mathrm{n}$ & 13 & 19 & 9 & 11 \\
\hline Ulcerative colitis & Pancolitis & Distal & & \\
Height - MPH/cm & -4.5 & -0.06 & & \\
Mean $(95 \% \mathrm{Cl})$ & $(-10.7 / 1.7)$ & $(-14.2 / 14.0)$ & \\
Mean age at & 10.8 & 10.2 & & \\
diagnosis (Range) & $(7-13)$ & $(2.5 /-18)$ & & \\
$\mathrm{n}$ & 12 & 3 & &
\end{tabular}

$71 \%$ of patients with early onset CD and $60 \%$ with UC fail to meet their expected heights by 18 yrs, except for $C D$ patients with disease restricted to the colon. Patients with small bowel disease alone were most severely affected, despite having a shorter duration of disease than those with combined small bowel and colonic disease. There was a trend for disease duration to relate positively to growth deficit $(<5$ yrs of disease: mean deficit $-2.5 \mathrm{~cm}$ vs. $>8$ yrs of disease $-6.8 \mathrm{~cm}$ ).

Failure to achieve optimal linear growth in IBD is common and is related to site of disease and probably age of onset. 
LOSS OF BONE MASS IN INFLAMMATORY BOWEL DISEASE (IBD) PATIENTS ON LONG TERM STEROIDS, IS THERE A SAFE LIMIT? M.F.M. Santoe ${ }^{1,2}$, R.J. Erdtsieck', M.van Blankenstein'. Dept. of Internal Medicine III' and Gastroenterology ${ }^{2}$, University Hospital, Rotterdam, The Netherlands.

The aim of this study was to establish the effect of total life time steroid dosage (TLSD) on bone mass in IBD patients on ongoing or previous steroid treatment. The TSLD was calculated for each patient at their first bone mass measurement, performed to monitor the effects of steroid treatment.

Bone mass was measured by means of dual energy x-ray absorptiometry (DXA) in the lumbar spine and the femoral neck and with single photon absorptiometry in the proximal and distal forearm. The obtained data were compared with a normative Dutch population and transformed into Z-scores (number of S.D. from zero), corrected for age, sex and menopausal state.

128 patients were assessed, 118 of whom had received long term steroids without prophylactic supplements. 92 had Crohn's disease, 36 ulcerative colitis. The mean duration of steroid therapy was 102 months ( \pm 6 months SEM), and the mean daily prednisone dose was $13 \mathrm{mg}$ ( $\pm 0,7 \mathrm{mg})$. Bone mineral densities (BMD), measured at the spine $\left(\mathrm{L}_{2}-\mathrm{L}_{4}\right)$, the femoral neck, the trochanteric region, the proximal and distal forearm were -.84, $.75,-.83,-.31$ and -.61 respectively. Except for the BMD in the proximal forearm, all sites were significantly reduced $(\mathbf{P}<.01)$. A significant negative correlation was observed between BMD at the various sites, the TLSD and the duration of steroid treatment, especially when exceeding 100 months. A decrease of BMD >1 SD was only found in patients with a TLSD > 7.5 gram prednisone. BMD was not influenced by the type of IBD, the duration of the disease and the number or nature of resections.

Conclusions: 1.Bone mass loss in IBD is related to TLSD and the duration of steroid treatment. 2.The upper limit of a relatively safe TLS $\Gamma$ seems to be about 7.5 gram prednisone. 3.Above this limit patients should be monitored by regular BMD measurements.
HYBRID CAPTURE FOLLOWED BY RT-PCR DOES NOT DETECT MEASLES RNA IN INTESTINAL TISSUE

Chadwiot. N., Bruca I., Davies. M., Pounder. R., Wakefield. A

IBD Study Group, Dept. of Histopethology, Royal Free Hoepital, London NW3 20 .

Aims. The aim of this study wes to use a sensitive and robust method of messles RNA detection to search for moseles RNA in infermmetory boowd discease (IBD) and intertinal control tisenes. Recent epidemiobsejeal and immunohistochemical studies have indicatod a poseible lint between meases virus and IBD.

Methods. Two measles nucleoprovin (N) geos RNA tranecripts, derived from a recombinant plasmid vector and a modifiod version of the same, were used to spite tiveve homogenates. The first tranecript was ued to determine the devection limit sensitivity for the method to be employed, and the second. modified tranecript wes used as an invernal positive control. This second, modified tranecript yielded a product, anter roverse tranecription followed by the polymerase chain resction (RT-PCR), which was hreor than the wildtype, non-modified form to allow its diecriminetion after agurose of doctrophoresis. In experiments to determine the precence of measles virus in IBD, frech frozen resection tissuve from petionts with Crohn's disense $(n=10)$, ulcerative colitis $(n=3)$ and non-IBD control petients $(n=7)$ were homogenised in 2ml of total RNA isolation reagent (Advanced Biotechnologies Ltd.). Duplicate homogenates were spited with $10^{7}$ copies of the internal control transeript prior to RNA extrection. Hybrid capture, using meessees-specific oligonucleotides linked to paramagnetic supports was performed on extracted RNA. Sul of hybrid capture cluant was used for measles RT-PCR using rTh DNA polymernse and EZ buffer (Perkin Elmer). Products were electrophoresed and analysed by Southerm hybridisation using an internal probe. Extracted RNA was also used for RTPCR of a housekecping mRNA species (mRNA of the splisosome UIA subunit) to assess RNA quality.

Results. Hybrid capture increased the detection sensitivity by 100 -fold over RT-PCR. As few as $10^{4}$ transcripts in a tissue homogenate could be detected using this method. All but one sample were UIA mRNA positive and all samples were positive for the internal control transcript after RTPCR. None of the samples analysed were positive for measles RNA.

Conclusion. No measles RNA could be detected in intestinal tissue, either IBD or control, using the methods described in this experiment.
CYTOKINE EXPRESSION AND RELAPSE OF ULCERATIVE COLITIS: A PROSPECTIVE STUDY.

F. Hussain, R.Ajian, M. Grundman, R. Bolton, S.Riley. Doncaster, Chesterfield and Northern General Hospital, Sheffield, UK

In patients with ulcerative colitis the relationship between cytokine expression and clinical activity remains unclear. We have therefore undertaken a prospective study of 12 patients with ulcerative colitis (8 females, aged 19-76 years). Clinical assessments, sigmoidoscopy and rectal biopsies were undertaken at 0,3 , and 6 months or at relapse and biopsies analysed for cytokine expression. IL-1B, IL-1receptor antagonist (IL-1RA), IL-2, IL-4, IL-6, IL-8, IL-10, IL-12, IL-13, IL-15, IFN-y and TNF-0. mRNA were analysed using RT-PCR followed by Southern blotting of the PCR products. IL-1 $\beta$ and IL-IRA protein was measured by ELISA. 6 petients relapsed during the course of the study. Reanlts:

\begin{tabular}{|c|c|c|c|c|}
\hline mRNA & $\begin{array}{l}\text { Quiescent } \\
\text { throughout } \\
n=18\end{array}$ & $\begin{array}{l}\text { Quiescent but } \\
\text { subsequently } \\
\text { relapse } n=12\end{array}$ & $\begin{array}{l}\text { Prior } \\
\text { to relapse }\end{array}$ & $\begin{array}{l}\text { During } \\
\text { relapse } \\
n=6\end{array}$ \\
\hline IL-8 & $7 / 14$ & $7 / 7$ & $5 / 5$ & $5 / 5$ \\
\hline IL-2 & $2 / 14$ & $1 / 7$ & $5 / 5$ & $1 / 5$ \\
\hline IL-6 & $5 / 14$ & $3 / 7$ & $4 / 5$ & $5 / 5$ \\
\hline IL-15 & $4 / 14$ & $1 / 7$ & $3 / 5$ & $3 / 5$ \\
\hline IFN-y & $5 / 14$ & $3 / 7$ & 2/5 & $4 / 5$ \\
\hline IL-10 & $4 / 14$ & $2 / 7$ & $4 / 5$ & $3 / 5$ \\
\hline \multicolumn{5}{|c|}{ ELISA mean (scm) pg/mg } \\
\hline IL-1及 & $2.9(1.6)$ & $3(0.7)$ & $31(20)$ & $7(1)$ \\
\hline IL-IRA & $1160(160)$ & $1100(200)$ & $740(160)$ & $1280(400)$ \\
\hline RAN1B ratio & $460(90)$ & $586(176)$ & $80(24)$ & $214(60)$ \\
\hline
\end{tabular}

petionts in Paticats who subsequently relapsed were more likety to express II-8 at times of quiescence $(p<0.05)$. IL-2 expresecion was increaned prior to but not during relapece episodes $(\mathrm{p}<0.05)$ suepecting a porsible role in inieting but not perpetuating relepse. IL-1B protein was incressed during relapece $(p<0.05)$ compared to quivecent disense. IL-1 RA did not increase during relapse. This imbalmonce between IL-1B and IL-1RA may be important in the pathogenesis of relapse.
LIMITED EXPOSURE OF LEFT COLON TO DAOCY DOSED ORAL FORMULATION IN ACTIVE DISTAL ULCERATIVE COLITIS: EXPLANATION OF POOR RESPONSE TO TREATMENT?

JM Hebden, *AC Perkins, *M Frier, †CG Wilson, RC Spiller. Dept of Medicine \& *Dept of Medical Physics, University Hospital, Nottingham. †Dept of Pharmaceutical Sciences, Strathclyde University, Strathclyde.

Patients with active left-sided ulcerative colitis (UC) often fail to respond to topically active oral agents such as 5ASA's. We have previously shown by daily dosing of a radiolabelled resin that the distal colon behaves like a conduit in healthy volunteers, containing less material compared to the proximal

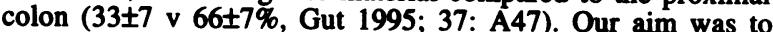
examine the relative distribution in distal UC. Methods: On 4 consecutive mornings 10 patients (age 33-67; 6M:4F) with active UC extending to the splenic flexure ingested a Eudragitcoated gelatin capsule containing In 111 labelled amberlite resin. Patients were scanned on the 4th morning immediately prior to dosing with $X$ counts, and at $4,8 \& 12 \mathrm{~h}$ later. The distribution of label in ascending (AC), transverse (TC), descending (DC) and rectosigmoid colon (RS) was expressed as \% of total colonic activity. Transit time (TT) through each region was calculated as regional counts $+X$ counts $\times 24 \mathrm{~h}$. Similarly, \% daily dose (DD) in each region was regional counts $+X$ counts. Results: (meantSEM). Averaging the 4 scans, percentage activity was distributed as follows: AC $54 \pm 4$, TC $37 \pm 3$, DC $7 \pm 2$ \& RS $3 \pm 1 \%$. The mean $\%$ in the distal colon (DC+RS) was significantly less than in healthy controls [n=10] $(9 \pm 3 \%$ v $33 \pm 7 \%, \mathrm{p}<0.002)$. Distal colonic TT was shorter in colitics $(3.9 \pm 2.1 \mathrm{v} 19.3 \pm 3.5 \mathrm{~h})$, and resulted in a smaller \%DD resident within this area $(0.16 \pm 0.09$ × $0.81 \pm 0.15 \times D D, p<0.002)$. Conclusions: Following daily dosing of an enteric coated formulation, only $1 / 10$ th of the total activity within the colon lay in the distal segment (DC+RS) in patients with distal colitis. Limited exposure of the inflammed distal colon to topically active oral agents may explain the poor response to treatment. 


\section{Liver TH113-TH119}

SAPHENO-PERITONEAL SHUNTING FOR DIURETIC RESISTANT ASCITES. S Ryder, J Doran and R Charnley, Departments of Medicine and Surgery, Queen's Medical Centre, Notingham, NH7 2UH.

Background. Treatment of diuretic resistant ascites is usually by repeated large volume paracentesis, although this is effective, it does involve repeated hospitalisations and has a significant risk of complications. We have used a surgical anastamosis of the saphenous vein to the peritoneal cavity to provide internal drainage.

Patients and Mothod. Surgery was undertaken in 8 patients, 6 under GA and 2 under LA. Saphenous vein patency was assessed by doppler ultrasound. A groin incision was made, the saphenous vein isolated and a reversed segment anastamosed to the reflection of the peritoneal cavity below the inguinal ligament. All 8 patients had diuretic resistant ascites and had been treated with at least 4 paracenteses prior to surgery. 5 had alcoholic liver disease, 1 hepatitis B, 1 hepatitis C and 1 BuddChiari syndrome. Median follow-up was 15 months.

Results. Successful shunt formation was achieved in 7/8 patients (88\%). Frequency of paracentesis was markedly reduced following surgery (mean 1.7 per month to 0.1 per month, $p=0.001$ ). Diuretic dose was reduced in 7 out of 8 patients and discontinued in 5 patients. Surgery failed in one patient due to infection of the wound site. Two further patients developed wound infections which required antibiotic therapy. No thrombotic or other septic complications occurred. Median hospital stay after shunt formation was 6 days (range 2 to 18). One patient later underwent liver transplantation, three further patients died at 7,12 and 14 months following shunt creation.

Conclusion. Sapheno-peritoneal shunting is an effective means of treating diuretic resistant ascites. It does not involve insertion of foreign material into the vasculature and may represent an alternative to repeated paracentesis without the risks of thrombosis and infection seen with Le Veen shunts.
HIGH DOSE URSODEOXYCHOLIC ACID (UDCA) IN PRIMARY SCLEROSING CHOLANGITIS (PSC): RESULTS AFTER TWO YEARS OF A RANDOMISED DOUBLE-BLIND, PLACEBO-CONTROLLED TRIAL. SA Mitchell, D Bansi, N Hunt ${ }^{*}$, J Christie, K Fleming * and R Chapman. Department of Gastroenterology and Nuffield Department of Pathology ${ }^{*}$, Oxford Radcliffe Hospital, Oxford, UK.

Aim: Previous trials of UDCA therapy in PSC have shown improvements in liver biochemistry but varying changes in liver histology. We report the results after 2 years of a double-blind placebo controlled trial of high dose $(20 \mathrm{mg} / \mathrm{kg} /$ day $)$ UDCA in PSC.

Methods: 24 patients (17 male, mean age 54, range 24-81) were randomised to UDCA $(n-12)$ or placebo $(n-12)$. All patients had a pre-trial liver biopsy and cholangiography. 20 patients had repeat liver biopsy and cholangiography at 2 years. 2 patients were withdrawn from the study, the first after 6 months from the UDCA group due to a dominant stricture which required stenting and the second after 15 months from the placebo group due to recurrent variceal haemorrhage. One patient from the placebo group died from an unrelated cause. Preand post- trial liver biopsies were staged and graded using a modified histological activity index (HAI) by two histopathologists.

Results: The two groups did not differ significantly on entry. No improvement in symptoms was recorded. Despite the high dose of UDCA used there were no reported side effects. Significant improvement $(p<0.05)$ was observed in the serum levels of ALP (mean 455 vs $779 \mathrm{iu} / \mathrm{l}$ ) and $\gamma \mathrm{GT}$ (mean 157 vs $377 \mathrm{iu} / \mathrm{l}$ ) in the UDCA group at 2 years compared with entry levels but changes in the bilirubin and AST were not significant. In the placebo group no significant changes were noted. Liver histology revealed an unchanged or improved $\mathrm{HAI}$ score in $9 / 10$ of the UDCA group but a worse score in $5 / 9$ of the placebo group. Disease stage remained unchanged or decreased in $8 / 10$ of the UDCA group but progressed in $5 / 9$ of the placebo group.

Conclusion: High dose UDCA treatment of patients with PSC is well tolerated and associated with a significant improvement in both ALP and $\gamma \mathrm{GT}$ after 2 years. In contrast to our previous trial (Hepatology 1992; 16:92A.) using lower doses of UDCA, the majority of the group treated with high dose UDCA had unchanged or improved inflammation (HAl) scores on liver histology and 4/10 showed regression of the disease stage.
MATERNAL AND PERINATAL OUTCOME IN SEVERE PREGNANCY-RELATED LIVER DISEASE. SP Pereira J O'Donohue, J Wendon, Roger Williams. Institute of Liver Studies, King's College Hospital, London SE5 9RS.

Acute fatty liver of pregnancy (AFLP) and the syndrome of haemolysis, elevated liver enzymes and low platelets (HELLP), are rare but major complications of the third trimester of pregnancy, with published maternal and perinatal mortality rates of approximately $20 \%$. Aims: To review the outcome of a large group of patients with severe liver dysfunction in late pregnancy, treated according to a standard protocol for acute liver failure. Methods: Over a 10 year period, 46 women (median age $30 \mathrm{yr}$, range 17 . 4 I yr) with a provisional diagnosis of severe AFLP or HELLP syndrome (median gestational age $35 \mathrm{wk}$, range 24-40 wk), were transferred to our Liver Failure Unit. Results: At admission, 32 patients $(73 \%)$ were preeclamptic, and 21 (46\%) were encephalopathic and/or ventilated. The median INR was 1.6 (range 0.9-3.4) and platelet count $107\left(19-409 \times 10^{9} n\right)$. 40 patients $(87 \%)$ had a raised serum creatinine (median $210 \mu \mathrm{M}$, range 63-758 $\mu \mathrm{M}$ ). The median serum bilirubin concentration was $113 \mu \mathrm{M}(17-$ $646 \mu \mathrm{M})$, rising to a peak value within $48 \mathrm{~h}$ of $153 \mu \mathrm{M}(19-646 \mu \mathrm{M}) .32$ patients $(70 \%)$ had clinical features and laboratory values consistent with AFLP, while seven (15\%) had HELLP syndrome. In seven other patients, causes of severe liver dysfunction unrelated to AFLP or HELLP syndrome, were found. Infectious complications occurred in 19 of the 39 patients (49\%) with AFLP or HELLP syndrome - 17 of whom were in the AFLP group. Major bleeding complications occurred in 12 women (10 with AFLP). Nine required laparotomies for clot evacuation, while one with preeclamptic liver rupture underwent liver transplantation. None of the eight patients who delivered vaginally had bleeding complications. Four of the 32 patients with AFLP (12.5\%) had a fatal outcome, with a corresponding perinatal mortality rate of $9 \%$. There were no maternal or perinatal deaths associated with HELLP syndrome. Conclusions: In contrast to many previous studies, the results of this large series suggest a relatively favourable maternal and perinatal outcome in severe AFLP and HELLP syndrome.

SK Hep 47.9+7.7, $n=8$ ) and MIP1 $\alpha$ (HepG2 $0.40+0.03$, SK Hep $0.30 \pm 0.06, n=8$ )

CONCLUSIONS. Production of IL8 and MIP1 occurs during monocyte adhesion with hepatoma cells in an adhesion dependant manner. This may enhance the recruitment of other inflammatory cells to the site of a hepatoma, but may also enhance the growth and metastatic potential of the tumor by promoting angiogenesis. 
PROLIFERATING HEPATOCYTE CELL LINES CONDITION THEIR EXTRACELLULAR ENVIRONMENT WHILST DEVELOPING THREE DIMENSIONAL CONFIGURATION IN A HOLLOW FIBRE CARTRIDGE.

D Floyd', P McCloskey', C Selden', E Roberts ${ }^{2}$ and H Hodgson' 'Dept. of Medicine, RPMS, London. ${ }^{2}$ Gastro Dept, Toronto, Canada.

Introduction: Bioartificial liver support devices must both nourish and detoxify the blood of liver-failure patients. Synthesis and transport of proteins are essential.

Methods: A human hepatocyte cell line, HHY41 (1.5 $\times 10^{7}$ cells) was cultured in the extracapillary space (ECS; $1.4 \mathrm{mls}$ ) of a hollow fibre cartridge (HFC). Culture medium was recirculated $(50 \mathrm{mls} / \mathrm{min}$ ) through the intracapillary space (ICS) of hollow fibres with $0.5 \mu \mathrm{m}$ pores. HFCs with polypropylene (pp) fibres were inoculated with cells attached to microcarriers. HFCs with fibronectin (fn)-coated fibres were inoculated with freshly trypsinised cells. Samples were taken from the medium reservoir for ELISAs to determine albumin, $\alpha 1$-antitrypsin and fibrinogen. Cultures were terminated after 30-35 days

Results: Data were similar for cells grown either in the presence of fn-fibres or pp-fibres and microcarriers. Albumin (170-200 $\mu \mathrm{g} / \mathrm{day})$ and $\alpha 1$-antitrypsin (210-280 $\mu \mathrm{g} /$ day) increased continuously during culture. Fibrinogen appeared in the reservoir within 3 days $(20-50 \mu \mathrm{g})$ but did not increase until after 16-20 days (60-100 $\mu \mathrm{g} / \mathrm{day})$.

Cells initially adhered to microcarriers were found to have left the carriers and formed 3-dimensional structures of cells around and between the fibres. Cells grown on fn-fibres had grown around the fibres in multi-layered sheets.

Conclusions: Production of proteins such as albumin and $\alpha \mathrm{l}-$ antitrypsin increased continuously throughout the experiment. Fibrinogen was detectable but did not increase until 16-20 days of culture presumably reflecting fibrin deposition as cells condition their environment. During this time cells adopted multicellular threedimensional structures whether initially adhered to microcarriers or grown in the presence of fibres coated with fibronectin.

\section{TH118}

PROGNOSTIC SIGNIFICANCE OF HEPATIC VENOUS PRESSURE MEASUREMIENTS IN CIRRHOSIS.

Armonis A, Patch D, McCormick PA, Christopoulou K, Greenslade L, Dick R, Sabin C, Burroughs AK. Liver Transplantation and Hepatobiliary Medicine, Royal Free Hospital, London, NW3 2QG

Introduction: We wished to examine whether portal pressure measurements were predictive of survival in cirrhotic patients, and if there was a height of portal pressure that had prognostic significance. Method: 132 (81 male, 51 female) cirrhotic patients (Childs A:35, B:5, C:46) who consecutively underwent hepatic venous pressure gradient (HVPG) measurement were investigated. Median age was 52 years. (range 21-79) $63 \%$ had alcoholic cirrhosis. Prior to admission, 112 patients had bled from oesophageal varices and 40 patients (30.7\%) were on long term treatment for the prevention of rebleeding. Differences in survival curves using an HVPG of $16 \mathrm{mmHg}$ were tested using the log-rank test.

Results: 41 patients died during the follow up period (median 550 days). Using multivariate analysis, previous long term endoscopic or surgical treatment $(p=0.03)$, prothrombin time $(p=0.005)$, ascites $(p=0.0001)$ and HVPG $(p=0.001)$ were found to be the only significant predictors of survival. Dividing the patients into three groups according to the time of HVPG measurement in 1slation to a variceal bleeding episode $(0-7,8-14,>15$ days) the predictive value of HVPG was found to be much higher if the measurement was taken within the first $(p=0.03)$ or second $(p=0.004)$ week from bleeding.

Concluaion: HVPG measurement provides further prognostic information in addition to that obtained from the Child-Pugh classification. In patients with a previous variceal bleed, this predictive value is higher if the measurement is taken within two weeks of bleeding. We advocate the routine use of HVPG measurement, not only in the management of bleeding, but also in the general work up of cirrhotic patients.
BENEFICIAL IN VITRO EFFECTS OF TUCARESOL ON THE IMMUNE RESPONSE TO HEPATITIS C VIRUS

M.E.Cramp*, S.Chokshi, N.Tzampouras, F.Torre, Roger Williams and N.V.Naoumov. "Institute of Liver Studies, King's College Hospital, London and Institute of Hepatology, University College London Medical School, London.

A strong $T$ helper lymphocyte $\left(T_{H}\right)$ response to hepatitis $C$ virus is important for viral clearance, while viral persistence is associated with a weak $T_{H}$ response. The orally bioavailable drug tucaresol selectively enhances $T_{H}$ response and to assess its therapeutic potential in HCV infection we investigated the in vitro effects of tucaresol on $T_{H}$ response to HCV proteins.

Method: Peripheral blood mononuclear cells from 18 patients with chronic HCV infection were cultured in the presence or absence of both tucaresol and HCV proteins - NS3 and core. Proliferative response was measured using ${ }^{3} \mathrm{H}$-thymidine uptake and cytokine production (IL-2, IL-4 and IFNY) was measured in the culture supernatants using standard ELISA.

Results: Tucaresol enhanced $T_{H}$ proliferation in 17 of the 18 patients in response to HCV core (mean increase 94\%) and in 10 of the 18 to NS3 (mean increase 56\%). Tucaresol increased mean IL-2 production in response to HCV core and NS3 $(45$ to $96 \mathrm{pg} / \mathrm{ml}$, and 42 to $71 \mathrm{pg} / \mathrm{ml}$, respectively). Detectable $\mathbb{I L}-2$ was found in the lymphocyte culture supernatants of all 18 patients in response to NS3 and core whereas IL-4 was found in only 2 . In 4 patients background IL-4 production by lymphocytes in the absence of any antigen was found and tucaresol reduced the mean $\mathbb{L}-4$ in these cases from 46 to $5.8 \mathrm{pg} / \mathrm{ml}$. Low levels of IFN $\gamma$ were found in response to NS3 and core in 10 of the 18 patients with a rise in mean values from 12-36 $\mathrm{pg} / \mathrm{ml}$ and $14.37 \mathrm{pg} / \mathrm{ml}$ respectively with tucaresol.

Conclusions: Tucaresol favours production of a $T_{H} 1$ cytokine profile and enhances lymphocyte response to viral proteins in patients with chronic HCV infection. These results suggest that tucaresol has potential as a new treatment for $\mathrm{HCV}$ infection.

\section{Oesophagus TH120-TH150}

TH120

PSEUDOMEMBRANOUS ESOPHAGITIS (PME). A K Nayyar, C Royston, KD Bardhan, Rotherham General Hospitals NHS Trust, Rotherham, UK.

Introduction and Aim PME is an uncommon condition of striking endoscopic appearance. Here we describe it's features, associated conditions \& outcome. Endoscopic enearno Concentric stough or membrane covers much of the lower half or the whole of the esophagus, ending abruptly at a normal squamocolumnar junction. Yellow, or black with digested blood, the membrane can be peeled away to reveal fragile esophageal mucosa. These appearances differ markodly from erosive esophagitis. Histology The pseudomembrane shows fibrinous exudate, inflammatory cells but no besement membrane (hence "pseudomembranous") and esophagus severe inflammation, granulation \& loss of epithelium. Bacteria, fungi \& viral inclusions are not identifiod. Results Ratient numbers From 1982-May $1996 \mathrm{n}=42$. The setting $36(86 \%$ ) were in-petients, many already seriousty ill. 10 had gastrointestinal (GI) disorders (eg intractsble vomiting, diarthea, malignancy) 9 non-GI (eg stroke, respiratory failure, other malignant disease) and 17 were admittod with GI bleoding. Indicotion sor endoscopy GI hemorrtage $n=27(64 \%)$, dysphagia $n=5$, pain and/or vomiting $n=7$, anemia $n=2$, peptic uloer follow-up $n=1$. Other endoscopic findenger Peptic ulcer $n=12$; outlet stenosis $n=4$; dileted stomach but without obstruction $n=3$. Demography Male $26(62 \%)$. Age $>65$ $n=30$ (71\%); 35-64 $n=11(26 \%)$. Histork of neflur/duapensia Nil $n=15(36 \%)$; उwk $n=9(21 \%)$. Recent doug usoge $13 / 42(31 \%)$ had antibiotics and $7 / 42$ (17\%) had NSAIDs. Early ontcome 7 died shortly after diagnosis \& 5 were still on healing trestment when the study ended. Most of the other 30 were re-endoscoped after 3 months treatment with cimetidine $1.6 \mathrm{~g}$ or omeprazole $20 \mathrm{mg}$. The pseudomembrane had clearod in all and the esophagus lookeod normal. Long-term outcome After healing 30 petients were followed (mean 39 months, range 1-139), 22 on maintenance treatment (MT) with cimetidine (mainty $1.6 \mathrm{~g}$ ) or omeprazole (20mg). 26 continue in remission including 8 pettients off MT. Despite this treatment 4/22 relapsed, 3 with PME, again associated with serious illness as at presentation. Only one patient developod erosive esophagitis . Disconesion PME is different from erosive esophagitis and it's causo(s) unknown. A poesibility is unusual tissue response in the elderty, with underlying serious illnesees, resulting in diffuse esophageal inflammation and sloughing of squamous cpithelium Infectious agents have not been identified. Peptic uleer, vomiting, antibiotics \& NSAIDs may contribute. The role of gastroesophageal reflux in PME is not known. Conchusion This probably is the first description of idiopathic PME. The condition is uncommon, of unknown cause, with distinct appear ance, associated with severe illness, responds well to treatment, and rarely recurs. 
ALGNATES ALTER OESOPHAGEAL GELL FUNCTION IN AN ANIMAL MODEL. W. Hall, P. E. Ross, D. Hopwood. Dept of Molecular and Cellular Pathology, Ninewells Hospital and Medical School, University of Dundee, Dundee, DD1 9SY.

Background / Aims: Alginates are used to alleviate symptoms of reflux in oesophagus. It has been proposed that they act by forming a barrier to refluxed material. We aimed to develop an animal model to determine whether alginates also play a more complex role by altering cell function.

Methods: Pig oesophageal epithelium was mounted in four Ussing chambers. Fluid phase endocytosis was used as a marker of cell function, therefore the mucosal surface was exposed to a solution containing FITC labelled $0.02 \mu \mathrm{m}$ latex microspheres. In addition 0 , $0.001,0.01$ or $0.1 \mu \mathrm{M}$ of alginate $\mathrm{A}$ (high $\mathrm{m}$. wt. Laminaria hyperborea stem) $\mathrm{n}=6, \mathrm{~B}$ (Lessonia nigrescens) $\mathrm{n}=5$, or $\mathrm{C}$ (low $\mathrm{m}$. wt. Laminaria hyperborea stem) $\mathrm{n}=5$, were added to the four chambers. Tissue was incubated for $1 \mathrm{hr}$ then disaggregated to form single cell suspensions which were examined using flow cytometry. Measurements were made before and after the addition of the quenching agent trypan blue to obtain total and endocytosed fluorescence readings.

Results: Values are \% differences compared to no added alginate. EFFECT ON TOTAL

\begin{tabular}{|l|l|l|l|}
\hline$[A L G] \mu \mathrm{M}$ & A & B & C \\
\hline 0.001 & $+22 \%(p<0.05)$ & none & none \\
\hline 0.01 & $-23 \%(p<0.05)$ & none & none \\
\hline 0.1 & $-23 \%(p<0.05)$ & $-12 \%(p<0.1)$ & $+63 \%(p<0.05)$ \\
\hline
\end{tabular}

Conclusions: Depending on their source and structure, alginates are capable of upregulating total or endocytosed fluorescence, indicating changes in cell physiology. At different concentrations the same alginates may also downregulate these.
CONCENTRATED (80\%) ACETIC ACID INGESTION: SYSTEMIC AND GASTROINTESTINAL EFFECTS P.D.Siersems, W.R.Hartmans, J.Dees, and M.van Blankenstein. Department of Gastroenterology, University Hospital Dijkzigt, Rotterdam, The Netherlands.

Ingestion of concentrated ( $80 \%$ ) acetic acid (CAA) is a form of suicide practiced by immigrants from Surinam. To compare the effects of CAA ingestion to other caustic agents and to determine if early endoscopy is predictive, data on 132 adult patients ( $44 \%$ M/ $56 \%$ F), admitted between 1980 and 1994 for ingestion of a caustic agent, were reviewed. All patients were endoscoped within 24 hours to grade the gastrointestinal lesions (grade 0: none - grade 3: severe). Clinical severity was judged by duration of admission, ICU admission, systemic and local complications.

\section{Results:}

Agent (n) Endosc. grade (\%) Hospitalisation Systemic Stricture Mortality

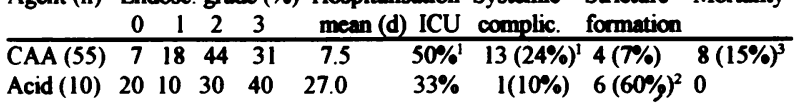

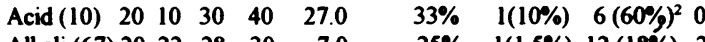

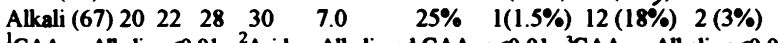

${ }^{1}$ CAA vs Alkoli: $p<0.01$; ${ }^{2}$ Acid vs Alkali and CAA: $p<0.01$; ${ }^{3}$ CAA vs Alkoli: $p<0.05$

Systemic complications were only seen in grade $2+3$ lesions and included renal damage in 8 , liver damage in 9 , diffuse intravascular coagulation in 7 , and hemolysis in 10 patients. Ten patients died from systemic (CAA: $8 / 55$ (15\%) and alkali: $1 / 67(1.5 \%) ; p<0.05$ ) or local (alkait?. $1 / 67(1.5 \%)$ ) complications. More strictures (mainly oesophageal) developed in grade $3(32 \%)$ than in grade $2(7 \%)$ and grade $1(8 \%)(p<0.05)$. Fifteen of 22 patients with a stricture underwent 190 endoscopic dilatations (median: 6, range: 1-84), which were succesful in only 6 . Nine patients needed surgery for perforation $(N=5)$ or failure $(N=4)$. Six stricture patients underwent direct surgical reconstruction.

In conclusion: (1) CAA ingestion has a far higher incidence of systemic complications and mortality than other caustic agents. (2) Early endoscopy is safe and gives prognostic information. (3) Endoscopic dilatation for strictures is often unsuccesful and surgery should be considered at an early stage.
FURTHER EVIDENCE THAT SUMATRIPTAN INDUCED CHEST PAIN

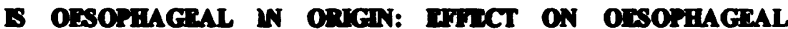
VISCTRAL SENSATION. M Fo.t. LA Howediven, PJ Whorwoll. Dept of

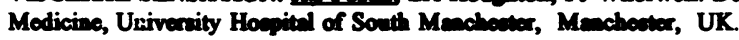

We have recenthy menented the the cheat pain experienced by moet of the

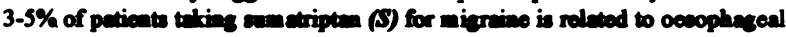
dyenotility rater the centiec ischecinin. This is beed on our observations

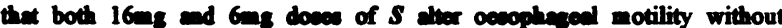
chmenging the ECG. Furthernore, thewe chenges in notility tended to be greatent in those subjects who experience $S$-indsced cheat discomfort comperod with those who did not. However, we were unsble to show a diroct correlation between the tine of ocenresce of chent disconfort and chmenges in motility. This conld be explaisod by $S$ afioctins the viscerd sensitivity of the oesopheress, and it wes tho parpose of this study to enower this quection. Serial belloon dimtencion of the oesophnzus we therefore cerried out both

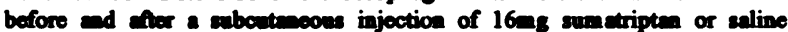
control in 30 acred bellity volunteen (aged 18-34 ym; 15 male). Treatments were randomised and donble bliad, and ECG wa monitored throughout the studies.

Peil.

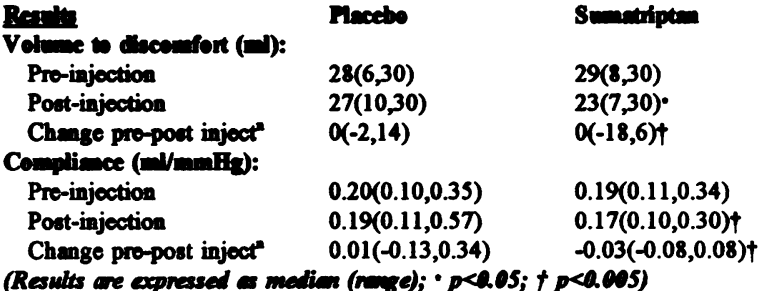

3 subjects experienced $S$-induced chest discomfort, but no subject exhibited any ECG abnormalities.

Conclusion Our observation that $S$ increases visceral sensitivity of the oesophagus and reduces its compliance provides further evidence that $S$ induced chest pain is in most instances oesophageal in origin. Furthermore, it strongly suggests that the role of SHT, receptors should be evaluated in relation to the visceral sensitivity of the gut. "This research was partially funded by GlaxoWellcome, UK."
OESOPHAGEAL MOTOR DYSFUNCTION IN PATIENTS WIT H THE INDETERMINATE FORM OF CHAGAS' DISEASE SM Almeida, P Martins, DF Evans*, M Sanchez \& DL Wingate*. GEN-CAD Service, Dept of Surgery, UFMG, Belo Horizonte, Brazil, and *GI Science Research Unit, St Bartholomew's and the Royal London School of Medicine and Dentristry, London, UK.

Patients with the indeterminate form of Chagas' Disease (CD) are seropositive, without megaoesophagus and asymptomatic. Small intestinal dysmotility has previously been found in CD patients without pseudo-obstruction (GE, 1995, 108: A592). Oesophageal dysmotility may also be present without dysphagia or dilatation. We used prolonged, ambulant, oesophageal manometry to test the hypothesis that motor abnormalities precede clinical manifestations of $\mathrm{CD}$ in the oesophagus. We studied 19 patients (12M, 7F, age 24-62) seropositive for $C D$; all were symptom-free. Recordings were performed for $24 \mathrm{hrs}$ from a manometry catheter incorporating 3 micro strain gauges $7.5 \mathrm{~cm}$ apart positioned in the oesophagus and connected to a digital datalogger; patients were studied in hospital but were freely mobile. Data were downloaded for computer analysis of the incidence, amplitude and type (peristaltic, simultaneous, incomplete, and retrograde) of oesophageal contractions and compared with published data on healthy controls (GE, 1996, 110: A624).

$74 \%$ patients had evidence of impaired oesophageal peristalsis (Median of abnormal v normal contractions) $(33.75 \% \mathrm{v} 64.6 \%, \mathrm{p}<0.001)$ and incomplete propagation $(49 \% \mathrm{v} 23.5 \%, \mathrm{p}<0.002)$, but no increase in simultaneous contractions $(13.3 \%$ v $7.6 \%, p=0.07)$ or retrograde contractions which were rarely seen ( $0-3 \%$ both groups). Contractile amplitude, duration and propagation velocity were similar for all patients and within normal limits and there was no manometric evidence of dilatation.

The data confirm that impaired peristalsis precedes the clinical manifestations of oesophageal involvement in Chagas' disease. This is a useful model for the study of the evolution of oesophageal denervation, and of the factors that determine progression of oesophageal neuropathy that has an outcome similar to achalasia. Long term surveillance of progression of 'non-specific motility disorders' may be desirable in the light of these findings. 
LOXIGLUMIDE INHIBITS POST-PRANDIAL TRANSIENT LOWER OESOPHAGBAL SPHINCTER RELAXATIONS IN PATIENTS WITH GASTRO-OESOPHAGEAL REFLUX DISEASE

Nigel Tnudrill, Massimo D'Amato, Stuart Riley. Northern General Hospital, Sheffield and Rotta Research Laboratorium, Monza, Italy.

Transient lower cesophageal sphincter relaxation (TLOSR) frequency increases and lower oesophageal sphincter (LOS) pressure falls following a fat meal. We have previously shown that these effects are attenuated in healthy volunteers by the cholecystokinin $\left(\mathrm{CCK}_{\mathrm{A}}\right)$ antagonist loxiglumide. We have therefore studied the effects of loxiglumide on postprandial LOS function in patients with reflux disease.

Nine patients (3M, 33-66 years), with symptomatic reflux disease and excess acid exposure, were studied on two separate occasions. After a four hour fast, each patient was intubated with a manometric assembly, incorporating a Dent sleeve, and a $\mathrm{pH}$ probe and studied supine. Following a 60 minute basal period, petients were randomly assigned to receive intravenous loxiglumide $(30 \mathrm{mg} / \mathrm{kg} / \mathrm{hour}$ for 10 minutes and then $10 \mathrm{mg} / \mathrm{kg} / \mathrm{hour}$ ) or placebo. After 20 minutes, a $300 \mathrm{ml}, 200 \mathrm{kcal}$, long chain triglyceride meal (Calogen) was infused into the stomach. Manometric and pH data were recorded for a further two hours.

TLOSRs occurred more frequently in the post-prandial period during placebo (median 0 (range $0-3)$ to $1(0-15)(p=0.03$, Wilcoxon signed rank test)), but not during loxiglumide $(0$ to $O(0-7)$ ). Post-prandial TLOSR frequency was significantly reduced during loxiglumide ( $p=0.04$ cf. placebo). Basal LOS pressure fell during the placebo postprandial period from 11(6-27) $\mathrm{mmHg}_{\mathrm{g}}$ to $9(2-29)$, but not during loxiglumide $(14(4-23)$ to $14(2-50))(p-0.05$ cf. placebo). Fewer reflux episodes occurred during loxiglumide infusion (1(0-8)) than during placebo infusion (2(0-19)), but this difference failed to reach statistical significance.

Loxiglumide inhibits TLOSRs and attenuates the fall in basal LOS pressure following a fat meal in patients with reflux disease. CCK may play an important role in mediating the post-prandial increase in TLOSRs and fall in basal LOS pressure, suggesting a therapeutic role for loxiglumide in the management of reflux disease.

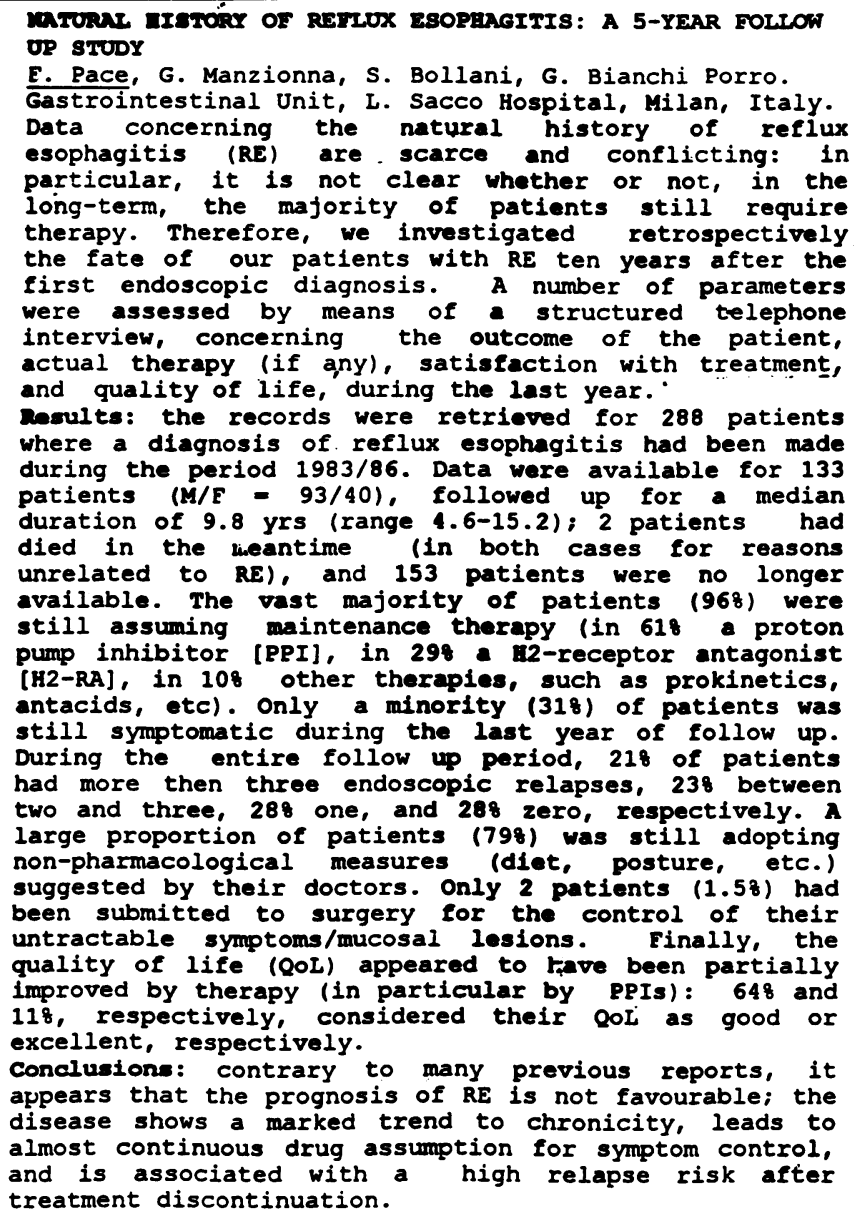
treatment discontinuation.
SLMULTANEOUS AMBULATORY OESOPHAGEAL MOTILITY AND DUODENOGASTRO-OESOPHAGEAL REFLUX MEASUREMENT . Ame Smythe, Nigel Bird, Sarah Labem and Alm Johnson. University Department of Surgical and Anaesthetic Sciences, Royal Hallameshire Hospital, Sheffield.

Athough ambuilatory methods for duodenogastro-oesophageal reflux (DGOR) and oesophageal motility are available, simultaneous measurement has not been reported. The aim of this work was to carry out these measurements on a group of volunteers during finsting, fed, supine and upright conditions to obtrin a detailed picture of oesophageal motiky during DGOR episodes.

8 volunteers were studied, asymptomatic for oesophageal reftux but who in previous invertigations had demonstrated periods of DGOR. Using a 3 preacure transtucer asecembly attached to a Gastroscan 11 data lozger ( MIC, Solothum, Switzerland) the position of the gastrooesophageal junction (GOJ) was obtrined. A sodium ion selective eloctrode attached to a Nymph data logger (Albyn Medical, Scotind) was placed $5 \mathrm{~cm}$ above the GOJ, alongeide the distal preseure transtucer, the two other preseure transtucers being positioned at 10 and $15 \mathrm{~cm}$ above the GOJ, and sodium ion measurement was carried out to assess DGOR together with wave propagation characteristics.

Sodium ion concentration could be mensured during fasting, fod and ambulatory periods, and interference from meals was short lived. (Range 4-17 minutes from onset of meal). During periods of DGOR, motility pattems showed a reduction in the rate of propagated peristaltic waves compared to the preceding 5 minutes $(1.5 \pm 0.3 \mathrm{v} 2.2 \pm 0.3, p=0.018)$ Simultsmeous waves occured in only 1 out of 17 pre-DGOR 5 minute periods but were seen in 5 out of 17 DGOR episodes, but there was no evidence of retrograde peristalsis.

Simultaneous ambulatory oesophageal motility and sodium ion measurement gives a detailed study of events during reflux of duodenal contents into the oesophagus. The diminished activity during DGOR may lead to delayed clearance and increased oesophageal damage.
TH128

DBPRESSION AND IIFE EVEITS TA PAFTENATS RBFBRRED WITH GASTRO-OBSOPBAGEAL REFLUX SYMPTOMS

$M$ C Allison, M Fouweather, P Clarke, I Jones, ED Srivastava. Gastroenterology Unit, Royal Gwent Bospital, Newport, South Wales.

Background: Anxiety and depression are thought to be more common in patients with reflux than control subjects. We examined whether recent unpleasant life events could be contributing to excess psychological morbidity in such patients.

Hethods: We studied 165 patients referred by general practitioners to our endoscopy service for investigation of reflux symptoms. Inclusion criteria were primary symptoms of heartburn, acid regurgitation and/or burning retrosternal pain. A control group comprised 79 patients having minor operations under local anaesthesia. All patients completed selfreport hospital anxiety and depression (HAD) questionnaires and Brugha threatening life experience checklists.

Results: Among the reflux group 57 patients had hiatus hernia only at endoscopy. 37 had oesophagitis only, 38 patients had both, 8 had gastritis/erosions/duodenitis and 40 had normal findings. The reflux patients gave higher BAD scores than the control group (mean 27.8 vs 24.1, $p<0.001)$. Life events during the preceding year had been no more common among the refiux group than the controls (median of one event per person in each group), and life event severity scores were no different (median 5 per person in each group). There was a weak but significant correlation between HAD and life event severity scores in the reflux group $(r=0.097, p<0.001)$

Conclusions: This large study confirms that anxiety and depression scores are higher in patients with reflux symptoms than controls. Personality traits, and indeed perhaps reflux itself, probably contribute more to the excess psychological morbidity than life events. 
PATHOLOGICAL GaSTROESOPHACF.AL, RF.FI.UX (GER) IN PATIENTS WITH A GAI.L.BLADDER (GB) IN SITL: ANI: SMALL GALLSTONES

$P$ Poitincasa'? A Di Ciaula'. GP vanBcige-Henegouwen', C: Palasciano' Semeintica Medica. Dept. Internal \& Occupationa Medicine (IJIMIL), University Medical Scilcoul. Bant. Ilaly Gastrucntcrulogy Dept.. Univcrsity Hospital ( 'trecht. The Netherlands"

('holecystecinmy inay enhance patholongical (iT:R in symplumulid gallstunc patients (Br J Surg 1493. $x(1) 50-3)$. Lillle is known. houce:e on gastro-csuphageal $\mathrm{nH}$ profiles in gullstence paticnts with a $\mathrm{GB}$ in stru. patent cystic duct and small stonc burden.

Mechods: ambulatory $24-h$ gastroesnphageal pll munitoring wats done in 2.3 patients with symptomatic gallstones (8M!1.5F. medn dge 45 yrs (range 21-74]. BMI 24-1 $\mathrm{ky} \mathrm{m}^{-2}$ ), an opacitied (in (ura cholecystogram) and a gallstonc burden < $2 U^{\prime !}$ : of fasting (ill volun:e (ultrasonography) and 21 controls (IIM/|OF: 44 yrs [range 25-87]. B:1!

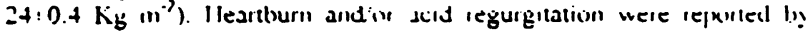
$75 \%$ of patients. Data of pll weri cxamuncd in the fasting period and afte: a standardized dict.

Results: 80\% of patients had abnurmal gastric and/or esophaged $\mathrm{pH}$ in the festing state (GF:R in $69 \%$ of patients) In the fasting pertiex vallstune patients had higher \% esophlageal time at pll $1 \cdot 4$ (median(Iange])

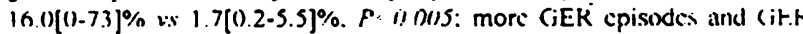

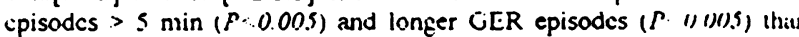
controls. GER cpisudes were synuptumatic (i.e. heartburn within 2 min. 0 esophageal fll decrease) in $34 ": 0$ of patients. Postprandially, gallstonc patients had sigmificantly mute $G E R$ than controls $(P \cdot(1) 5)$. The prevalence of eastric alkaline shift in the lasting statc (i.c. proportion of time at $\mathrm{plI}=4)$ tended to he higher in patients than controls $(3.5 \% \mathrm{~W} 19 \%$ $P$ Nis). Postprandial gastric pH was comparable betwecn paticits ant. cuntrols.

Conclusions: The presence of symploms crocutive of GER shouk: be investigaled in gallstune patients with a functioning (ill and smal: gallstunes since they have stgniticant (iT:R which might henefit from i: diagnostic/therapeutic approach.
THE IMPACT OF BREAST FEEDING, ATOPY AND OTHER FACTORS ON THE PREVALENCE OF GASTRO-OESOPHAGEAL REFLUX AlAtia R, Golding J and Sandhu BK

Institute of Child Health,Royal Hospital for Sick Children,Bristol BS2 8BJ

Gastro-oesophageal reflux (GOR) is the involuntary passage of gastric contents into the oesophagus. It becomes pathological if its frequency and intensity is increased or if complications arise. A few studies elude to epidemiology of GOR (Carré 1959) but there are no paediatric population based studies in this field.

Aims: We have attempted to look at the prevalence of GOR in children aged 6 months and 18 months and its association with factors such as breast feeding, social background, atopy, other symptoms and hospital admissions.

Methods: The study is based on the Avon Longitudinal Study of Pregnancy and Childhood (ALSPAC), a longitudinal population-based study starting in pregnancy and following all children to the age of 7 years. A series of self-completion questionnaires have been distributed to mothers and partners at various set times. For the purposes of this study GOR was defined as being present if a child "often vomited". Vomiting was defined as "bringing up most or all of the feed". The data for this study is based on questionnaires completed at 6 and 18 months.

Results: The prevalence of GOR in children aged 6 months is $4.3 \%$. By 18 months the prevalence is reduced to $1.5 \%$. At 6 months breastfed infants have a lower prevalence of GOR (4.0\%) compared to their non breast-fed counterparts $(5.3 \%)(p<0.001)$. Serum IgE is not associated with GOR but wheezing and family history of atopy are. Eczema is associated with GOR at 6 months but not at 18 months. Of children with GOR at 6 months $26.3 \%$ were adrnitted to hospital, the figure for 18 months is $25.3 \%$.

Conclusions: In this large prospective population based longitudinal study the prevalence of GOR is $4.3 \%$ at 6 months and $1.5 \%$ by 18 months. Breast feeding reduces the possibility of GOR. Wheezing and family history of atopy are associated with GOR. Children with symptoms of GOR have a high risk ( 1 in 4$)$ of being admitted to hospital.
IS H PYLORI PROTECTIVE AGAINST GASTROOESOPHAGEAL REFLUX DISEASE?

H Curtis. I Coutts, B McKaig, A Lloyd, P Hill,

G K T Holmes, B Norton.

Derbyshire Royal Infirmary, London Road, Derby.

$\mathrm{H}$ pylori colonisation of the stomach has been incriminated in a wide variety of upper GI and non-GI disorders. So far, there is little evidence to link the presence of $\mathrm{H}$ pylori with gastro-oesophageal reflux disease. Symptoms of gastro-oesophageal reflux (GOR) are extremely common and this study was designed to explore any association between GOR and infection with $\mathrm{H}$ pylori.

Method: Patients with long-standing symptoms of GOR were recruited. Symptoms of GOR were scored using the DeMeester questionnaire. All patients underwent upper GI endoscopy and the presence of $H$ pylori was determined using antral biopsy and rapid urease test. Patients with either a normal upper GI endoscopy or oesophagitis were included in the study. Patients with additional upper GI pathology or who had received antibiotics and or proton pump inhibitors within the previous six weeks were excluded. A control group of 196 patients matched for sex and age were tested serologically using a Helico $\mathrm{G} 2$ kit to determine $\mathrm{H}$ pylori status.

Results: 45 patients were studied ( 24 male, 21 female, mean age 49.6 years). The mean DeMeester reflux score was 5.1 (range 3 to 9) and symptoms of reflux had been present for a mean of 3 years (range 2 months to 20 years). 32 patients had a normal upper GI endoscopy, 13 patients had evidence of oesophagitis and/or hiatus hernia. Only 3 patients were positive for $H$ pylori and 42 patients were negative. This gave a prevalence of $6.7 \%$ for the presence of $\mathrm{H}$ pylori in the study population. This was significantly $(p<0.01)$ less than in the control group ( $37.5 \%$ positive).

Conclusions: Routine testing for $\mathrm{H}$ pylori in patients with symptoms of GOR is inappropriate and is likely to lead to a positive result in less that $10 \%$ of cases. This study has shown, for the first time, a very low prevalence of $H$ pylori in patients with GOR. Could the presence of $\mathrm{H}$ pylori in some way protect against symptoms of GOR?

\section{FORCES EXERTED DURING OESOPHAGEAL DILATATION} C A Mosse, T N Mills, D G Bell, C P Swain. Departments of Medical Physics, University College, Ipswich General and Royal London Hospitals.

Aim: An electronic device was designed and built for use during oesophageal dilatation to allow measurement of the forces exerted on a bougie dilator during dilatation. Methods: The device featured a handle designed in the shape of hinged split cylinder which could be locked around the dilator but could be readily moved up and down the shaft as the dilatation proceeded if necessary. The handle consisted of two parts, one that gripped the dilator and the other that was gripped by the clinician. One of the members that joined these parts together contained strain gauges arranged as a Wheatstone bridge so that the forces transmitted by the clinician's hand could be measured accurately. The device was designed to measure and also record the push and pull forces exerted during the examination. The force measurements were recorded using a computer which stored the data on disk while in real time it displayed the data graphically as a chart recorder style trace on the screen. The device was calibrated against a range of weights exerting force on a bougie dilator using a pulley system and was shown to give reproducible linear measurements of force over the range of interest. A series of interchangeable split cylinders allowed it to be used with different sizes of dilator. The device was electronically isolated from the patient. Resulks: This device was used to measure the forces at dilatation in 10 patients using 2 thermoelastic esophageal dilators of 13 and $18 \mathrm{~mm}$ diameter (Savary, Celestin). Peak forces varied from 0.4 to $3.8 \mathrm{Kg}$ force for the large 18 $\mathrm{mm}$ dilator and 1 to $2.2 \mathrm{Kg}$ for the small $13 \mathrm{~mm}$ dilator. The mean peak force for the $18 \mathrm{~mm}$ dilator was $2.3 \mathrm{Kg}$ and the mean peak force for the $13 \mathrm{~mm}$ dilator was $1.5 \mathrm{Kg}$. The force exerted in order to pass the cricopharyngeus was $0.25-1.3 \mathrm{Kg}$. The length of time that forward thrust was transmitted to the patient's esophagus was 10-21 sec. Peak retrograde force on removing the dilator was $-0.4 \mathrm{Kg}_{\mathbf{g}}$. In all these cases the clinician felt he was applying only low or moderate force. Conclusion: These measurements represent the first accurate measurements of the forces exerted during oesophageal bouginage. 
Gastrocesophageal reflux as a complication of achalasia therapy.

M Dalkals JGC Cox, JR Benneth, Hull Royal Infirmary, Hull.

Gastrooesophageal reflux is a recognised complication of achalasia therapy, whether by cardiomyotomy or by balloon dilatation.

Reflux is often disregarded by the petient or the doctor unless it is very troublesome.

Our series consists of 176 patients, 38 cases were treated surgically while 138 were treated with balloon dilatation. The patients were followed up carefully in one centre over 27 years.

There were 47 cases of reflux. 27 of these cases were recognised by symptoms, by endoscopy or by $24 \mathrm{~h}$ pH monitoring and were satisfactorily treated with medical therapy.

There were 20 other cases in which peptic strictures developed and required stricture dilatation. There were 10 cases of strictures among the patients who were treated by balloon dilatation and a similar number of patients developed stricture among the patients who had cardiomyotomy. The mean period between achalasia therapy and the diagnosis of stricture was $6.0+5.14$ years in the dilatation group and $16.2 \pm 9.07$ years in the surgical group.

The diameter of the balloon used did not appear to influence the likelihood of subsequent reflux or stricture. None of the patients in the surgical group who had an anti-reflux procedure performed at the time of cardiomyotomy developed a peptic stricture.

Conclusions:

1. A high proportion of patients treated for achalasia develop reflux complications.

2. Anti-reflux procedure at the time of cardiomyotomy may prevent the development of a peptic stricture.
EKTDOSCGPICGASTROPLASTYYORGASTRO-OESOP IAGEAI REFLUX DISEASE. C. P.Smin, SS Kadairkamanathan, F Gong, D Evans. Roynl London Hospital, Whitechapel, London E1 1BB, UK

Alm: The aim of this study was to perform and record the results of endoscopic gastroplasty in a series of patients. Methods: Endoscopic Gastroplasty was performed at flexible endoscopy in 28 patients with gastro-oesophageal reflux disease uncontrolled by longterm medical therapy and who were offered and declined anti-reflux surgery (open or laparoscopic) or were deemed unfit for general anesthesia due to concurrent illness. GORD was confirmed by preoperative manometry and 24 hour ambulatory pH studies. Using a $9 \mathrm{~mm}$ diameter endoscopic sewing machine a neo-oesophagus of 1-2 $\mathrm{cm}$ was created below the cardio-oesophageal junction by placing nylon sutures and securing the tissue with 4 half-hitches tied extracorporeally. Results: The operation was performed as a daycase procedure under sedation (usually diazemuls $20 \mathrm{mg}$ and pethidine $50 \mathrm{mg}$ IV) and the median duration of the procedure was 35 minutes. Post-operative assessment was made at a median of 12 weeks (8-52) with respect to symptoms, manometry and 24 hour ambulatory pH studies. Symptoms assessed by DeMcester symptom score improved from a median of 5 to 1 [p $<0.05]$. Median lower oesophageal sphincter length increased from 1.9 to $2.9 \mathrm{~cm}[\mathrm{p}<0.05]$ and pressure increased from 5.25 to $8.25 \mathrm{~mm} \mathrm{Hg}[\mathrm{p}<0.05]$. The median (range) \% time $\mathrm{pH}<4$ decreased from 8.4 (0.5-16.4) to 2.7 $(0-8.1)[p<0.05]$. Complications included minor haematemesis in one patient, transient dysphagia in 3 , in one patient with thoracogastric adhesions following thoracoplasty the endoscopic stitches cut out and a surgical Nissen fundoplication was performed. Repeat $\mathrm{pH}$ measurments at 1 year post procedure in 2 patients showed no reflux. Conchusion: In this series, endoscopic gastroplasty significantly improved symptoms reduced acid reflux., and increased sphincter length and pressure. Potential advantages of this procedures include casy. repeatability, reversibility, short operation time, lack of need for general anaesthesia. Endoscopic gastroplasty has a short term efficacy comparable to operative fundoplication, but with a much lower utilization of health care resources.

Ten-year follow up after forceful balloon dilatation of achalasia. M Dalkak, JR Bennett. Hull Royal Infirmary, Hull.

Achalasia is a condition which occurs infrequently resulting in relatively small numbers in many series and the tendency to provide data on short or medium term follow up. 66 new cases of achalasia were diagnosed and treated with forceful balloon dilatation in one centre between 1971 and 1986. Contrast radiological examinations were performed following each dilatation. Careful clinical and radiological follow up for more than 10 years has been carried out (699 patient-year)

Contrast radiological studies revealed 3 cases of perforation. 2 were treated conservatively and recovered well, while one patient was treated surgically and subsequently died.

The long term outcome has been satisfactory in the majority, with 45 (68\%) having an excellent result, $13(20 \%)$ with a modest result and $8(12 \%)$ whose results were less satisfactory.

In most cases one dilatation was sufficient, but $18(27 \%)$ required further balloon dilatation.

Long term follow up revealed 18 patients (27\%) with symptomatic gastrooesophageal reflux, $8(12 \%)$ of these developed peptic strictures. Only 3 of these patients with reflux had more than one balloon dilatation.

12 patients died during the follow up from unrelated causes.

Conclusion:

Forceful balloon dilatation remains a simple, safe and satisfactory form of treatment for achalasia, but long term follow up reveals that a third of the patients suffer from subsequent reflux. 
LONG TERM OBJECTIVE FOLLOW UP AFTER LAPAROSCOPIC FUNDOPLICATION IN PATIENTS WITH REFRACTORY GASTROOESOPHAGEAL REFLUX DISEASE. LRogers, S.S.Kadirkamanathan, D.F.Evans, S.M.Scott. Academic Surgical Unit and Gastrointestinal Science Unit, The Royal London Hospital Medical College, London, UK

Laparoscopic fundoplication (LF) was performed on 166 consecutive patients (male 100, female 66) with gastro-oesophageal reflux disease (GORD) who were refractory to medical treatment. Diagnosis of GORD was confirmed by 24 hour ambulatory $\mathrm{pH}$ studies. Ninety six patients continued to take proton pump inhibitors and these underwent an additional $\mathrm{pH}$ study on therapy. Median age of patient group was 42 years (range 16-82) and median symptom duration was 48 months (3-600). LF was performed using 3 to 4 sutures to create a 2 to $3 \mathrm{~cm}$ floppy wrap. There were no conversions. Median operating time was 68 minutes (33-330) and the median hospital stay was 2 days (0-5). Post-operative assessment was made at a median of 47 days (2676) with respect to symptoms, lower oesophageal sphincter (LOS) function on manometry and 24 hour ambulatory $\mathrm{pH}$ studies. To date 52 patients have been followed up for over 12 months, 14 over 24 months and two up to 36 months. Symptoms assessed independently using DeMeester symptom score improved significantly from a pre-treatment median score of $5(2-8)$ to $4(2-9)[p=0.02]$ while on anti reflux medication but, LF markedly reduced the symptom score to $1(0-6)$ which was significantly better than both $\mathrm{ON}$ and OFF treatment [ $<<0.0001 \& 0.0001]$. The symptom improvement was maintained at 1,2 and 3 year follow up (median symptom score 1). Acid exposure of distal oesophagus ON medication was no different to that OFF medication. [\% time $\mathrm{pH}<4$ ON was $4.8(0.5-58.8)$ and OFF was $7.6(1.3-25.1) \mathrm{p}=0.06]$. LF produced effective control of acid reflux which was significantly better than both $\mathrm{ON}$ and OFF medication: $\{\%$ time $\mathrm{pH}<4 ; 0.4(0-11.5)[\mathrm{p}<0.0001 \&$ $\mathrm{p}<0.0001]\}$. The median $\%$ time $<4$ was 0.6 at one year, 0.3 at two years after LF confirming that effective control of acid reflux was maintained. LF also prociuced significant increases in median LOS pressure from $6(0-25)$ to 13.5 $(5.5-27.75) \mathrm{mmHg}[\mathrm{p}<0.0001])$ and length from $2(1-4)$ to $3.5(2-5) \mathrm{cm}$ [p<0.0001]). These data shows that LF is effective in controlling the symptoms and distal oesophageal acid exposure in patients with refractory GORD for at least 36 months.
H139

\section{THORASCOPIC ASSISTED TRANSHIATAL OESOPHAGECTOMY- NEW LAMPS FOR OLD?} MK Lingam, LY Hiew, B Bartley, D Byrne, G Bell (introduced by Mr G Fullerton), Department of Surgery, Inverclyde Royal Hospital, Greenock

Surgical excision remains the best chance of long term survival for patients with oesophageal carcinoma. The advent of minimal access surgery allows accurate dissection and thorascopic mobilisation of the oesophagus without the need for thoracotomy and its associated complications. We report our experience of thorascopic-assisted transhiatal oesophagectomy (TATH) between December 1993 and June 1996. Forty-two consecutive patients underwent TATH. Twelve patients required conversion to thoracotomy because of pulmonary adhesions, size of tumour, tracheal injuries or ventilation difficulties. The mean age of the patients was 65.7 (45-80) years. The stricture length was between $3-11 \mathrm{~cm}$ in the TATH and $5-12 \mathrm{~cm}$ in the conversion group. average total operation time was 308 minutes (235-400) in the TATH, thoracoscopic dissection taking 83 minutes (50-120). One death occurred in each group. The mean post operative hospital stay was 14 days in both groups. The 1 and 2 year survival rates were $71 \%$ (30 of 42 ) and $60 \%$ ( 25 of 42 ) respectively. The results of TATH are very similar to those of conventional surgery. We propose that TATH may offer an advantage in terms of visualisation of mediastinal structures during dissection, thus minimising operative complications.
ANOTHER VEW ON LAPAROSCOPIC ANTI- REFLUX SURGERY S El Hasani PM Murchan I Chetter B Khan SS Somers ACJ Windsor PJ Guillou

Professorial Surgical Unit, St James's University Hospital, Leeds

Aims: Measurement of outcome for laparoscopic antireflux surgery (LARS) has to date been confined to the technical feasibility, its impact on symptomatology and the financial implication of its introduction. As no data are available from the patients' perspective about the quality of life (QOL) following its introduction, this study was designed to obtain preliminary information in such petionts.

Mothods: All petients selected for LARS were requested to complete QOL questionnaires (SF36, Euroqual) both prior to and 6 months following surgery. Twenty-six patients have been studied. All patients had manometric evidence of gross incompetence at the lower cosophageal sphincter, with deranged pH profiles (mean De Moester score $58 \pm 18$ SEM).

Results are shown in table

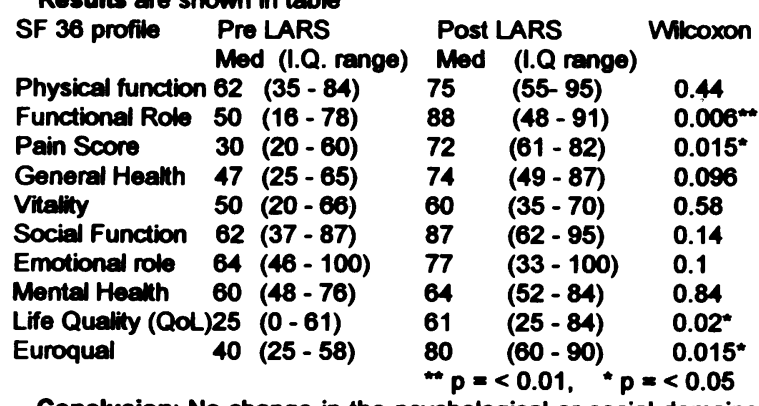

Conclusion: No change in the psychological or social domains was noted following surgery, although significant improvements were noted in the physical role, pain scores and overall healthrelated QOL. Further evaluation of both surgical and medical therapies of gastro-oesophageal reflux is needed to establish the long term benefits as perceived by the patient, rather than by the clinician in order to compare the value of these two treatments.
THE UK NATIONAL BARRETT'S OESOPHAGUS REGISTRY CPJ Caygill, PI Reed, MJ Hill, A Watson. UK National Barrett's Oesophagus Registry, Lady Sobell Gastrointestinal Unit, Wexham Park Hospital, Slough, Berkshire, SL2 4HL.

A UK National Registry of Barrett's Oesophagus (BO) patients was established in June 1996 as a joint initiative between the Oesophageal Section of the BSG and the European Cancer Prevention Organisation (ECP). Since then over 500 patients have been registered from the first 3 centres and this communication reports the results of a pilot study of data from two of these centres in adjoining health districts. The hospitals were Wexham Park Hospital, Slough (WPH), catchment population 360,000 , and Wycombe General Hospital, High Wycombe (WGH), catchment population 220,000. At WPH the visual diagnosis of $\mathrm{BO}$ was initially made at endoscopy irrespective of length of involved segment and confirmed histologically in at least $76 \%$. At WGH the diagnosis was only considered in segments of approximately $4 \mathrm{~cm}$ or more, but all of these had histological confirmation of $\mathrm{BO}$.

Between January 1991 and August 1996, 424 BO cases were registered at WPH. There was a male preponderance of $1.5: 1$, the mean age being 65 years for males and 70 years for females. In the period July 1995 to June 1996197 BO patients were endoscoped at WPH (M:F 1.7, mean ages 62 and 71 years respectively) and 71 BO patients at WGH (M:F 1.7, mean ages 62 and 69 years respectively).

Adenocarcinoma of the oesophagus was diagnosed at WPH in $5 / 424$ ( 1 in 85) patients between January 1991 - June 1996, of whom 2 were diagnosed in the period July 1995 - June 1996 and in 1 patient ( 1 in 71 ) at WGH in the latter period.

These data confirm the practicality of running a multicentre BO Registry, establishing comparisons of diagnostic criteria of $\mathrm{BO}$ in different departments and variations with time. The Registry is now being extended first to the Anglia/Oxford Region and then to the whole of the United Kingdom. 
INCREASING INCIDENCE OF BARRETT'S OESOPHAGUS DIAGNOSTIC ZEAL OR GENUINE OBSERVATION? A T Prach, T M MacDonald, D Hopwood, D A Johnston. Departments of Digestive Diseases, Clinical Pharmacology and Pathology, Ninewells Hospital and Medical School, Dundee, DD1 9SY, Scotland, UK.

Barrett's cesophagus is the major recognised risk factor for the development of oesophageal adenocarcinoma. It is well documented that the incidence of oesophageal adenocarcinoma is rising, and one might suspect that this is paralleled by an increase in the incidence of Barrett's oesophagus. We have studied the incidence of Barrett's oesophagus in Tayside to determine whether there is an increasing incidence in the diagnosis of Barrett's oesophagus.

The incidence of endoscopically diagnosed Barrett's oesophagus was determined by searching the endoscopy database for years 1980-1993. This represented 53,433 endoscopies performed in our population of 384,000 . 961 new cases of endoscopically diagnosed Barrett's oesophagus were identified representing 18 new cases $/ 100,000 /$ year (18 cases/1,000 endoscopies). The incidence was not constant throughout, but showed a dramatic rise from $1 / 100,000 /$ year $(1.4 / 1,000$ endoscopies) in 1980/81 to $48 / 100,000 /$ year (42.7/1,000 endoscopies) in 1992/93. When only cases with histological confirmation were considered, the incidence for $1992 / 93$ was $18 / 100,000 /$ year (16.5/1,000 endoscopies).

We have demonstrated a significant rise in the incidence of Barrett's oesophagus. This may be partially explained by an initial low incidence, possibly due to a failure to recognise Barrett's oesophagus endoscopically, combined with a change in endoscopic referral patterns (possibly more reflux disease) and/or an overzealous attitude to the endoscopic diagnosis of Barrett's oesophagus. However, we believe there is a true increase in the incidence of Barrett's oesophagus in our population. The cause of this increasing incidence is unknown, but it may be related to the increasing incidence of oesophageal adenocarcinoma.

\section{PREVALENCE OF SPECIALISED COLUMNAR EPITHELIUM AT THE CARDIA OF PATIENTS WITH GASTRO-OESOPHAGEAL REFLUX WITHOUT OBVIOUS BARRETT'S OESOPHAGUS; COMPARISON WITH NORMAL CONTROLS. B.T.Cooper, M.A.Cox, J.C.Gearty, Gastroenterology Unit, City Hospital, Dudley Road, Birmingham, B18 7QH, UK}

Previously unsuspected specialised columnar epithelium (SCE) has been reported in biopsies of the cardia from $18 \%$ of unselected patients undergoing endoscopy (1). This may be relevant in the increasing prevalence of adenocarcinoma in the distal oesophagus and at the cardia and raises the question whether Barrett's oesophagus is much commoner than previously thought. In this study, we have looked at the prevalence of SCE at the cardia of 54 consecutive patients with symptoms of gastro-oesophageal reflux (GOR). 15 of the 54 had mild erosive reflux oesophagitis (Savary Miller grades 1\&2) and 13 of the 54 had erythema of the distal oesophagus without erosions. The results were compared with 18 normal controls who had neither symptoms of GOR nor any endoscopic abnormality of the upper GI tract. Patients with more severe endoscopic GORD including Barrett's oesophagus were excluded. The 54 GOR patients (33 females) were aged 23-83 mean 56 years and the 18 controls (11 females) were aged 22-75 mean 45 years. At least 3 large endoscopic biopsies were taken from below the squamo-columnar junction at the cardia in each patient, stained with haematoxylin/eosin and alcian blue/PAS diastase and assessed histologically for the presence of SCE by one pathologist (JCG) who was unaware of the clinical or endoscopic features. $29(53.7 \%)$ of the patients with GOR had SCE at the cardia compared to $4(22.2 \%)$ of the controls $\left(\chi^{2}=5.38 ; P<0.02\right)$. There was no correlation between SCE at the cardia and age, sex and the presence of reflux oesophagitis at endoscopy. We conclude that SCE is relatively common in both groups but is commoner in patients with GOR than controls. However it must be doubtful whether SCE at the cardia has the same significance as Barrett's oesophagus.

1. Spechler et al. Lancet $1994 ; 344: 1533-6$.
ACID AND BILE REFLUX IN SHORT SEGMENT BARRETT'S OESOPHAGUS

CK MacKay, H Ihmaidat, J Going*, CR Carter, MR Ward, JF MacKenzie**, RC Stuart

Departments of Surgery, Pathology* and Gastroenterology**, Glasgow Royal Infirmary, Glasgow.

Barrett's oesophagus (BO) is a consequence of oesophageal exposure to severe acid and bile reflux. It has been suggested that Short Segment Barrett's oesophagus (SSBO) represents an early, metaplastic phase in the transition from normal to BO. If this is the case, oesophageal acid and bile exposure in SSBO should be greater than normal. To examine this hypothesis the aim of this study is to compare oesophageal acid and bile exposure in normal, SSBO and BO patients. Methods: BO is defined as $\geq 3 \mathrm{~cm}$ columnarisation of the distal tubular esophagus $n=21$; SSBO is defined as intestinal metaplasia at an otherwise normal squamocolumnar junction, $\mathrm{n}=19$; and normal is defined as no BO or SSBO, $\mathrm{n}=43$. Normal and SSBO patients were all symptomatic patients attending for diagnostic endoscopy. Ambulatory 24 hour oesophageal $\mathrm{pH}$ and bile studies were performed using a Synectics mark III Digitrapper and Bilitec 2000 system 10 days after stopping acid suppression therapy. When possible both studies were performed simultaneously and the probes were positioned $5 \mathrm{cms}$ above the lower oesophageal sphincter. A positive $\mathrm{pH}$ study is defined as a DeMeester score $>15$ and a positive bile study is defined as a bilirubin exposure $>5 \%$ of the supine period.

Results:

No. of + ve pH studies

Median DeMeester score

No. of +ve bile studies

Barrett's

$18 / 21^{*}$

SSBO Normals

Median bilirubin exposure $\quad 9.45 \%$

$11 / 16$

17.9

$2 / 10$

25.6

$9 / 18$

$* p<0.03$ by $\chi^{2}$ test. $\quad * * p<0.01$ by Mann- Whitney U test

Conclusion: Oesophageal acid and bile exposure in SSBO does not differ from normal but is significantly less than in BO. These results do not support the hypothesis that SSBO is an early step in the progression to BO. It is suggested that gastroesophageal reflux is not an aetiological factor for SSBO
TH144

PATTERN OF EARLY CHROMOSOMAL ALTERATIONS IN BARRETT'S OESOPHAGUS.

CK MacKay, RC Stuart , J Going**, JN Baxter , WN Keith* (introduced by JF MacKenzie)

Department of Medical Oncology*, University of Glasgow. Depts. of Surgery and Pathology**, Glasgow Royal Infirmary, Glasgow

Barrett's oesophagus is the major risk factor for oesophageal adenocarcinoma. The progression to malignancy involves several genetic events. but little is known about early changes occurring in the metaplastic epithelium before dysplasia develops. Aim: to identify chromosomal alterations, consistent with malignant potential in nondysplastic Barrett's mucosa. Method: Multiple endoscopic biopsies were taken from 17 patients with uncomplicated Barrett's oesophagus, including normal oesophagus and stomach as controls. The frozen biopsies were sectioned, clustered on slides and subjected to interphase cytogenetics. Fluorescent In-Situ Hybridisation (FISH) was performed with probes specific to chromosomes $1,8,9,12,17$ \& 18 . Signals per nucleus were counted on 200 cells per biopsy, using fluorescent microscopy. The chromosome index $(\mathrm{Cl})$ was calculated (No. of signals (No. of nuclei). The mean $\mathrm{CI}$ for controls $(\mathrm{n}=77)$ was $1.58 \pm 0.1$ and a value $>3$ standard deviations from the mean was regarded as abnormal Results: Chromosome No. biopsies No. patients Chromosomal Changes

\begin{tabular}{lrrl}
\hline 1 & 24 & 8 & No abnormality \\
8 & 9 & 4 & 1 gain (Patient 2) \\
9 & 31 & 9 & 2 gains (Patients 2 \& 5) \\
12 & 15 & 6 & 1 loss (Patient 3) \\
17 & 16 & 5 & No abnormality \\
18 & 33 & 13 & No abnormality \\
Total & 128 & 17 & 4 alterations
\end{tabular}

Conclusion: Chromosomal changes occur in uncomplicated Barrett's oesophagus, at a low frequency, consistent with the hypothesis that genetic alterations are rare in non-dysplastic disease. Clonal divergence, reflecting the histological heterogeneity of Barrett's mucosa is suggested, as changes do not occur at all biopsy sites in each patient. 


\section{AMPLIFICATION AND OVEREXPRESSION OF CYCLIN D1} IN OESOPHAGEAL CARCINOMA

R. Morran, P. Newcomb, H. Barker, R. Hardwick, D. Alderson. University Department of Surgery, Bristol Royal Infirmary, Bristo BS2 8HW

The cyclin D1 gene encodes a protein which controts the passage of the cell through the G1/S checkpoint in the cell cycle. Cyclin D1 is a proto-oncogene, since its aberrant expression could contribute to uncontrolled cell proliferation. This study investigated amplification and overexpression of cyclin D1 in oesophageal carcinoma.

Twenty-six oesophageal adenocarcinomas and 19 squamous cell carcinomas were studied. Paired tumour and normal DNA samples were analysed by Southem blotting with specific DNA probes for cyclin D1 and for a control gene ( $\alpha$-lactalbumin) which is present in a single copy. The cyclin D1 gene copy number was calculated for each tumour. Expression of the cyclin Dl gene was assessed by immunohistochemical analysis of its protein product, which is usually undetectable by this method in normal tissues.

Cyclin D1 gene amplification (by a factor of between 2 and 6) was identified in 7 tumours (16\%); 5 were squamous cell carcinomas, 2 were adenocarcinomas. No significant association was identified between amplification and tumour $\mathrm{T}$ stage, $\mathrm{N}$ stage, or patient survival.

Overexpression of cyclin D1 protein was identified in 8 tumours (6 squamous cell carcinomas and 2 adenocarcinomas) and was significantly associated with gene amplification ( $p=0.04$, Fisher's Exact test). Overexpression was also significantly associated with earty $\mathrm{T}$ stage (T1 or T2; $\mathrm{p}=0.01$, Fisher's Exact test). No significant association was identified between overexpression and $\mathrm{N}$ stage or patient survival

There was a trend (non-significant) towards a predominance of both amplification and overexpression of cyclin D1 in squamous cell carcinomas over adenocarcinomas.

These results indicate that cyclin D1 amplification and overexpression occur commonly in oesophageal carcinoma, particularty squamous cell carcinoma. Cyclin D1 overexpression may influence tumour behaviour, causing the disease to present at an earlier $T$ stage. The mechanism for this effect is unclear, and warrants further investigation.

\section{RISING INCIDENCE OF OESOPHAGEAL ADENOCARCINOMA} A 20 YEAR RETROSPECTIVE REVIEW FROM A SINGLE UNIT BJ Johnston, PI Reed, MS Carpani de Kaski, S Levi. Lady Sobell GI Unit, Wexham Park Hospital, Slough, Berkshire, SL2 4HL

It is now recognised that the pattern of oesophageal cancer has changed dramatically. A previous report from our unit in 1991 revealed that during 1976-1990 49\% of all oesophageal cancers were adenocarcinomas (AC). The review of endoscopy records has now been extended to include the next 5 year cohort, 1991-1995 inclusive. A total of 37,992 consecutive endoscopy records for the period 1976-1995 were studied retrospectively for mention of oesophageal cancer, 289 cases were identified. They were subdivided by histological type, oesophageal location, sex, age and into four cohorts of five years by year of presentation to the unit. The oesophagus was divided into two segments, above and below $32 \mathrm{~cm}$, by adapting the criteria suggested by the US National Cancer Institute (1989).

The mean age at diagnosis of both male and female patients with squamous cell carcinoma (SCC) had increased during the 20 years study period; in males from 67.4 years in the first, to 74.2 years in the last quartile and in females from 66.4 to 72.8 years during the same period. In contrast, whereas the age of males with $\mathrm{AC}$ had remained virtually unchanged (66.7 to 68.3) in females with AC the age had dropped from 74.2 to 69.9 years between the first and last quartiles. AC were located predominantly in the lower oesophagus, $132(83 \%)$ below $32 \mathrm{~cm}$ and $28(17 \%)$ above $32 \mathrm{~cm}$. SCC were more evenly distributed; $48(43 \%)$ below and $62(57 \%)$ above $32 \mathrm{~cm}$. In line with other published series the numbers of AC had risen from $21(45 \%)$ in the first quartile to $63(70 \%)$ in the fourth quartile. Overall the male:female sex ratio for $A C$ was $3: 1$ (M120: F40 cases) and 0.7:1 for SCC (M46 : F64).

AC now represents the majority of all oesophageal cancers diagnosed in our unit, especially in males. These findings confirm a continuing rise in incidence of oesophageal $\mathrm{AC}$ to $70 \%$, the highest incidence reported to date.

Eur J Cancer Prev 1991; 1: 23-25; Cancer 1989; 64: 526-30
ADENOCARCINOMA OF THE LOWER OESOPHAGLIS AND CARDIA ARE SIMILAR BOTH EPIDEMIOLOGICALLY AND CLINICALLY : A POPLLATION BASED STUDY FROM 1974 TO 1993.

I) olan k. Walker SJ. Sutton R. *Williams EMI

Departments of Surgery and *Public Health, Royal Liverpool University Hospital. Liverpool L8 7XP. England.

There were 5,322 cases of primary cesophageal carcinoma and 10,573 cases of primary gastric carcinoma reported to the Merseyside and ('heshire ('ancer Registry ipopulation 25 million) hetween 1974 and 1993 The ratio of oesophageal to gastric carcinoma was $1: 2$ Calculation of the cumulative incidence rates revealed a significant increase in oesophageal carcinoma in males over the study period this was found to be entirely due to a rapid rise in adenocarcinoma of the oesophagus, the incidence of which trebled in males and doubled in females. Eighty-six percent of these adenocarcinomas occurred in the lower cesophagus

The incidence of gastric carcinoma decreased in both sexes between 1974 and 1993 . However analysis of the subsite-specific incidence rates indicated that carcinoma of the cardia more than doubled in males, and almost doubled in females. whereas carcinoma at all other sites of the stomach decreased. Twenty percent of all gastric carcinoma occurred in the cardia

The similar trends in incidence of adenocarcinoma of the oesuphagus and ol the cardia prompted a comparison of the epidemiological and clinica parameters of adenocarcinoma occurring in the middle oesophagus, lower oesophagus, cardia and subcardia. Adenocarcinoma of the lower oesophagus and cardia were very similar in their changing incidence, age at diagnosis. male : female ratio. percentage of patients who smoked and in their survival. Both carcinoma of the lower oesophagus and the cardia differed signiticantly from tumours of the subcardia. This suggests that adenocarcinoma of the lower oesuphagus and gastric cardia may be the same disease, and this has important consequences for the surgical treatment of carcinoma of the cardia.
PET SCANNING FOR ASSESSING RESECTABILITY OF OESOPHAGEAL CANCER - Preliminary results

AUTHORS: R.MASON, D.GOLD, N.MAYNARD, D. MANIFOLD, N.BOYLE, H.TAYLOR, M.MAISEY, AND S.RANKIN.

INSTITUTION: DEPARTMENTS OF SURGERY AND RADIOLOGY, GUY'S AND ST THOMAS'S HOSPITALS, LONDON

Ain: To determine whether PET scanning improves the accuracy of pre-operative staging with spiral CT scanning of patients with primary oesophageal carcinoma. METHODS: 14 consecutive patients with oesophageal (10 ade no, 4 squamous) were studied. 3 were excluded due to distant metastases detected by PET and CT scans. 11 patients with operable disease were scanned preoperatively by spiral CT and PET scan, using the positron emitter 18F fluoro-2-deoxy-D-glucose. The findings of spiral CT and PET were assessed independently of the findings at operation and pathological examination of the resected specimen.

RESULTS: The primary tumour was visualised in 10 cases by spiral CT and in all 11 cases by PET. CT gave anatomic information of the extent of local spread which would not by expected from PET scans. Positive left gastric/ coellac lymph nodes were found in 7 cases. These were detected in 4 cases on CT (with 1 false positive) and in only 1 case by PET because of the lack of anatomical detail required to separate them from the primary. Positive mediastinal nodes were found in 5 cases. These were detected in 3 cases by CT and in 2 of these by PET. One patient had $4 \times 0.5 \mathrm{~cm}$ subcapsular liver metastases. These were detected by PET but not by CT. CONCLUSIONS: The ability of PET scans to detect disease distant to the operative fleld suggests its main role may be in patients with large tumours and borderline operability. In addition PET may have a role in predicting response to neo adjuvant chemotherapy. 
DOES PRIOR RADIO- AND/OR CHEMOTHERAPY PREDISPOSE TO COMPLICATIONS AFTER INTUBATION FOR MALIGNANT OESOPHAGO-GASTRIC OBSTRUCTION R.A. Reuters, M. van Blankenstein, J.Dees and P.D.Siersema. Department of Gastroenterology, University Hospital Dijkzigt, Rotterdam, The Netherlands.

Endoscopic intubation is an effective procedure for palliation of dysphagia in patients with malignant oesophago-gastric obstruction. Prior radio- and/or chemotherapy may entail an increased risk of complications following intubation with a rigid prosthesis.

The aim of the study was: (1) to assess efficacy, complications, recurrent dysphagia and survival after intubation for palliation of dysphagia, and (2) to evaluate the relationship between prior radioand/or chemotherapy and the occurrence of complications.

From 1988 to 1995, a consecutive series of 307 patients underwent intubation with a Celestin prosthesis under general anaesthesia for palliation of dysphagia, caused by a malignant stricture of oesophagus and cardia. Of these 307 patients, 111 (36.2\%) patients had undergone prior radio- and/or chemotherapy. In $306(99.7 \%)$ patients, a rigid prosthesis was succesfully placed. The dysphagia score improved from $2.7 \pm 0.6$ (grading from 0 to 4 ) at baseline to $0.6 \pm 0.8$ at 4 weeks after intubation. Major complications were registered in 97 (31.7\%) patients and included: perforation (22), fistula (5), haemorrhage (9), severe pain (10), aspiration (8), erosion/ulcer at the end of prosthesis (7), fever (4), migration (22), malposition (7), and fracture of prosthesis (3). Sixtynine $(22.6 \%)$ patients had recurrent dysphagia. Median survival was 67 days and hospital stay after placement was $6.6 \pm 5.5$ days. Prior radioand/or chemotherapy increased the risk of perforation, fistula, haemorrhage and severe pain following intubation $(26 / 111$ vs $20 / 195$; $p=0.0026$ ). Median survival was not different between patients with or without prior radio- and/or chemotherapy.

In conclusion: 1. Celestin prostheses are an effective palliative treatment for malignant dysphagia, however they carry a relatively high risk of complications and recurrent dysphagia. 2. Prior radio- and/or chemotherapy predisposes to prosthesis-related complications

TH151

PATIENTS' OWN PERCEPTIOUS OF ENDOSCOPY UNDER THROAT SPRAY. M Welch, OD 8 mm 8 Choeh, KR Palmer.

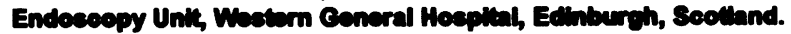

Backeround: Dimonoetic endoscopy is commonly carried out in UK under N sedetion, but B.S.G guidelines supoest then this prectice is not alweys required. Unsedated endoscopy offers edventages of quick tumover and few sedetion related complications, but pationts own perceptions of such a practice has not been widely studied. A nurse led study performed immedietely after completion of ondoscopy wes used to assess petients' perceptions hollitically. Aim: To determine the acceptebiliny of dinonoetic endoscopy to petionts performed under locel aneosthetic sprey.

Mothod: 76 petionts who chose to undergo endoscopy affer throet sprey (M=38, F=40, modian age 42, age renge 18-70 yeers) wore studiod using a nurse administered questionneire, explained to them prior to the procedure. The endoscopy kself was expleined in detail by a nurso. Comploted questionnaires were collocted prior to discheree on the seme dey. The response rele was $100 \%$.

Results: 71 petients (95\%) considered that they had received sufficiont informetion about the procedure. 69 petionts $(91 \%)$ fell that 4 matched their expectations. 58 petionts $(78 \%)$ wore prepered to undergo a repeet procedure if necessary under throet spray. Abdominal pein and bloeting were reletively uncommon following endoscopy (8\% and 17\% repectively), but, despile anaesthetic throet spray (Xylocaine spray, Astra) 38 petients (50\%) complained of a sore throet within 30 minutes of the procedure. 19 (25\%) petients received regular orel suction during the procedure to avoid the uncomfortable feeling of drowning in their own seliva, and described it as holpful.

Conclusion: Endoscopy under throet spray was well accepted in a selected group of petionts who chose to have the procedure done unsedeted. Petients generally foll well post-procedure but sore throet was a common problem despilte local anaesthetic spray. The effectiveness and dose of throeat spray may need further study. Proprocedure detailed explanation helps to alleviate anxiety and match the expectations with the actual procodure.

\section{TH150}

QUALITY OF LIFE FOLLOWING STENT INSERTION IN MALIGNANT OESOPHAGEAL STENOSIS: A RANDOMISED TRIAL COMPARING METAL AND PLASTIC STENTS C Roseveare, P Patel, P Goggin, N Simmonds, J Kimble, H Shepherd Royal Hampshire County Hospital, Romsey Road, Winchester.

Background: Metal stents are widely used in palliation of oesophageal carcinoma but their advantage over plastic tubes has yet to be proven. Aim: To compare the effect of Gianturco metal stents with Atkinson tubes on quality of life in malignant oesophageal obstruction.

Methods: Thirty one consecutive patients with inoperable malignant oesophageal obstruction were randomised, patient single blind, to receive either a modified Gianturco silicone-covered metal $Z$ stent $(n=15)$ or a plastic Atkinson tube $(n=16)$. Sedation was similar in each group and patients were given identical dietary advice. Data were collected by a specialist nurse before insertion, one week after and thereafter 6 weekly until the patient's death. Quality of life at each time point was assessed using the Nottingham Health Profile (NHP)

Results: Three stent-related deaths occurred in the first week following insertion of an Atkinson tube with only one in the Gianturco group. Complication rates were otherwise similar in the two groups. The table shows outcome variables between the groups after insertion.

\begin{tabular}{|l||l|l|l|l|}
\hline & wkss & Gianturco & Atkinson & P \\
\hline \hline $\begin{array}{l}\text { \% change in weight } \\
\text { (from original wt) }\end{array}$ & 1 & $-0.6(-2.9-+0.8)$ & $-4.5(-7.1-0.5)$ & 0.05 \\
\hline $\begin{array}{l}\text { \% of patients with } \\
\text { no dysphagia }\end{array}$ & 1 & $0.8(-3.1-+1.9)^{*}$ & $-7.3(-11.1-+2.5)^{\circ}$ & 0.13 \\
\hline $\begin{array}{l}\text { \% of patients with } \\
\text { improved appetite }\end{array}$ & 7 & $50 \%$ & $38 \%$ & 0.55 \\
\cline { 2 - 5 } & 1 & $57 \%$ & $50 \%$ & 0.09 \\
\hline
\end{tabular}

* Median (inter-quartile range)

Patients in the Gianturco group showed greater improvements in NHP parameters following insertion of the stent than those in the Atkinson group. (Energy: $p=0.04$; emotion: $p=0.06$; social isolation: $p=0.05$ )

Conclusion: Patients treated with Gianturco stents maintain their weight for longer, with improved swallowing, appetite and quality of life when compared to those with Atkinson tubes.
TH152

THE COLORECTAL NURSE ENDOSCOPIST - INITLAL RESULTS Moshakis V., RubenR.C.

George Eliot Hoeplal NHS Trust, Nuneaton

Introduction - Over a one year period a Nurse Endoscopist was trained in flexible sigmoidoscopy and clinical coloproctology. Following assessment the Nurse Endoscopist was able to practice sigmoidoscopy as part of the colorectal endoscopy service.

Method - Sigmoidoscopy was performed in petients referred directly to the one-stop clinic, from the outpatients department and general surgical wards. Comprehensive Practice Protocols were followed. Informed consent was obtained. A video recording of every procedure was taken. A "Sigmoidoscopy Report" was issued to the referring doctor on completion of each procedure.

Sigmoidoscopy results were then audited.

Result - 400 procedures were performed over an 8 month period. $81 \%$ of patients were referred to the one-stop clinic. $50-60 \mathrm{~cm}$ insertion depth was echieved in $70 \%$ of patients. The descending colon/splenic floxure was reached in $70.5 \%$ of cases. Principle clinical findings were:- carcinoma (4.75\%); polyp (17\%); inmammatory bowel diseese (12.75\%); haemorrhoids (31.75\%); diverticuli (7.25\%) and normal findings (23\%). ("Some patients had > 1 diagnosie/finding). Biopsy and injection sclerotherapy was indicated in $38 \%$ and $35.75 \%$ of cases respectively. Follow-up included outpatients clinic (40.25\%); discharge (38\%) and colonoscopy/barium enema (17\%). There was no morbidity or mortality.

Discussion - Audit shows that, following a period of intensive training and assessment, a Nurse Endoecopist is able to perform independent fiexible sigmoidoscopy competently and safely. 
COMMUNITY BASED OPEN ACCESS NURSE LED FLEXIBLE SIGMOIDOSCOPY FOR RECTAL BLEEDING

A. Betts, K.P. Nugent, P. Daniels, S. Griffin , H. Smith, D. Mant, J.N. Primrose.

University Units of Surgery and Primary Care Medicine, F Level, Centre Block, Southampton General Hospital, Tremona Road, Southampton. SO16 6YD

A direct access nurse led endoscopy service based at 6 community sites was launched following a 6 month nurse training period. Patients with rectal bleeding are referred directly to the nurse by general practioners and an appointment sent by return of post. Clinics are staffed by a nurse endoscopist and nursing auxillary.

79 patients were endoscoped by the nurse endoscopist ( 48 female, median age 63 years [range $23-89$ ]). 67 patients complained of rectal bleeding ( $81 \%$ bright red bood, $19 \%$ dark, $48 \%$ mixed in with motions). Other symptoms included abdominal pain (30\%), change in bowel habit (38\%) amd weight loss (13\%).

One patient had two cancers at endoscopy, $8 \%$ had polyps, $8 \%$ diverticular disease and $20 \%$ had significant haemorrhoids. $60 \%$ were normal. Median depth of endoscopy $55 \mathrm{~cm}$ (range $10-60 \mathrm{~cm}$ ).

Patient satisfaction was recorded using a postal questionnaire. $96 \%$ felt the examination was worthwhile, the staff helpful and that a full explanation of the procedure had been given. $27 \%$ found the examination embarassing and $53 \%$ painful, of these $8 \%$ required analgesia and $21 \%$ sought medical advice. $94 \%$ would be prepared to undergo the examination again.

In conclusion, a nurse led open access flexible sigmoidoscopy service is feasible. acceptable to patients and yields pathology in up to $40 \%$ of patients.

APHTHOUS ULCERATION IN THE TERMINAL ILEUM : WHAT IS THE SIGNIFICANCE ? D.Suri, B.P. Saunders, J.D. Sanderson. Dept. of Gastroenterology, Guy's and St. Thomas' Hospitals, London SE1 9RT.

Aphthous ulceration is a well-recognised feature of number of inflammatory bowel diseases but a particular hallmark of Crohn's disease (CD). At ileocolonoscopy, the finding of ileal aphthous ulcers is not infrequent. In a previous study, ileal aphthae were demonstrated as the sole finding in $11 \%$ of patients of patients undergoing ileocolonoscopy for chronic diarthoea or abdominal pain. The significance of these lesions is, however, uncertain.

We have therefore studied the characteristics of 30 consecutive patients in whom ileal aphthae were demonstrated at ileocolonoscopy. Patients were aged 23-66 yrs. (median 32.5 yrs.). 19 patients were female. The indication for ileocolonoscopy was assessment of known inflammatory bowel disease (UC $n=3, C D n=8)$, chronic diarthoea $(n=10)$, abdominal pain $(n=6)$ and rectal bleeding ( $n=3$ ). 2 patients were taking non-steroidal anti-inflammatory drugs (NSAID).

Of the 19 patients without known inflammatory bowel disease, 17 had normal inflammatory parameters (haemoglobin, platelets, ESR and C-reactive protein). 2 patients had a mild rise in ESR, 1 patient had a borderline low B12 level. 4 patients had undergone small bowel barium studies and 2 had had labelled white cell scans. These tests were all normal

No obvious morphological differences were noted in aphthous ulcers detected in patients with or without IBD or those on NSAID's. Histology of ileal biopsies showed an inflammatory infiltrate in $13 / 19$ patients. Further sectioning revealed inflammation in 2 additional cases. Granulomas were absent in all cases.

Ileal aphthous ulceration may be the only abnormality detected in patients undergoing ileocolonoscopy for the investigation of gut symptoms. Morphology, histology, and additional standard investigations offer no apparent clues as to the significance of such lesions. Though a small number may be due to the use of NSAID's, the majority appear likely to represent a form of Crohn's disease. Prospective follow-up studies by ileo-colonoscopy and immuno-pathology are essential to determine the significance and natural history of these lesions.
Prospective audit of Thoracoscopic Splanchniceetomy in the management of intractable upper abdominal pain. Meneres.N. Carter.R, Imrie.C.W. Royal Infirmary, Glasgow, G31 2ER

AIMS: Methods used for the relief of intractable upper abdominal pain have variable success. Anecdotal reports have suggested that Thoracoscopic Splanchnicectomy (TS) may be associated with improved response rates. The aim of this study was to prospectively evaluate the short and medium term response in a consecutive series of patients undergoing this procedure.

METHODS: All patients presented with a clinical syndrome of intractable upper abdominal pain, most frequently from chronic pancreatitis refractory to standard treatment. Assessment was performed by analog pain scores and analgesic requirements with a minimum follow up of six months. RESULTS: Six males and five females (median age 41, range(34-69)) underwent TS between June 95 and April 96. Procedure related morbidity was mild. At one month, a good response (pain score reduction of $>4$ and reduction in analgesia) was achieved in 8 out of 11 patients $(73 \%)$ and a moderate response (pain score reduction of $>2<4$ and reduction in analgesia) in 1 out of 11 patients ( $9 \%)$. At six months, a good response was sustained in 6 out of 10 patients $(60 \%)$, and a moderate response was seen in one patient $(10 \%)$, one patient having died from disease progression prior to the six month follow up.

CONCLUSION: Thoracoscopic Splanchnicectomy would appear to be an effective alternative in patients with upper abdominal pain refractory to standard treatment modalities. Further prospective evaluation of this technique are ongoing.
COLONOSCOPIC ARGON PLASMA COAGULATION FOR BENIGN AND MALIGNANT RECTAL TUMOURS

JP Watson, S Jowett, K Oppong, CO Record, K Matthewson. Gastroenterology Unit, Royal Victoria Infirmary, Newcastle upon Tyne, NE2 4HH

Endoscopic Nd YAG laser therapy for gastrointestinal tumours requires large capital expenditure, class 4 containment and carries a risk of perforation. Endoscopic Argon Plasma Coagulation (EAPC) is a diathermy based non-contact technique which may be as effective as laser therapy with fewer side effects.

Methods: All patients with colonic tumours treated by EAPC between July and Decenber 1996 were studied. After initial endoscopic and histological diagnosis, patients received EAPC until satisfactory debulking of the tumour was achieved. The duration of each treatment, power used and patient tolerance were recorded for each session. Symptoms were assessed at each endoscopy session.

Results: 5 males and 3 females (mean age $79.1 \pm 7.4$ years) with rectal adenocarcinoma (5) or rectal villous adenoma (3) were treated. Reasons for non-operability were advanced age, coexistent medical problems or metastatic disease. The power used was 50-99W, with each session lasting a mean of $13.6 \pm 6.1$ minutes. Mean sedation requirements were diazemols $10.0 \pm 4.6$ $\mathrm{mg}$, in addition to pethidine $50 \mathrm{mg}$ given in 10/15 treatment sessions. Patient tolerance of the procedure was reported as good or excellent in all cases. Patients required 1-3 treatment sessions during the study period, with a mean of $4.3 \pm 3.1$ weeks between sessions. The symptoms of rectal bleeding and passage of mucous improved or resolved in 7 of the 8 cases. 1 patient died from metastatic disease during the study. No complications were observed.

Conclusions: EAPC in this group of patients was well tolerated, safe and resulted in useful symptomatic improvement. 
TECHNIQUE, AND LONG TERM OUTCOME OF ENDOSCOPIC BALLOON DILATATION FOR PYLORIC STENOSIS.

C P Swnin. Royal London Hospital, Whitechapel, London E1 1BB.

Aim: The aim of this study was to review the technique, results and long term outcome of patients with benign pyloric stenosis treated with balloon dilatation. Patients and Methods: Sixteen patients were treated over a 7 year period. 15/16 were of Asian origin. The mean age was 31 (range 20-49). 9/16 were Clo test positive, 10/16 were taking omeprazole at presentation and 6/16 had been treated with triple therapy prior to initial endoscopy. Mean follow up of patients was 36 months (range 7-84). 4/16 had inpatient stays ranging from 2-8 days. 16/16 had oesophagitis and 10/16 had evidence of active duodenal ulceration at initial endoscopy. All had food in stomach, 3/16 had gastric dilatation at endoscopy. All had mid-bulbar stenosis and none had true endoscopic pyloric stenosis. The exit was found at 7 o'clock in 7/16. Technique: An $18 \mathrm{~mm}$ through the scope (TTS) balloon was used to dilate the duodenal stricture. A variety of techniques were needed to open the stenosis sufficiently to pass the TTS balloon which is poorly designed for this application. For 14/16 screening was needed. An overtube was passed and a peediatric endoscope used to place a guide-wire into the 2nd part of the duodenum. Tapered and balloon ERCP dilators were used over the wire to predilate the stricture prior to the passage of an $18 \mathrm{~mm}$ balloon. A large channel endoscope was used to pass the balloon. In 10 cases the balloon was inflated distal to the stricture an then pulled through and in 6 it was possible to inflate the balloon inside the stricture. Results: Eight patients required a single dilatation session, four needed two, three needed three and one patient needed four dilatation sessions before an endoscope could reach the second part of the duodenum. There were no perforations or deaths and no patient required surgery. Yearly endoscopic follow up indicated that the dilated stenosis could be crossed with an endoscope, that $\mathrm{H}$ Pylori was eradicated in all, and the symptoms of stenosis were abolished and none had recurrent ulceration at endoscopy. Conclusion: Although endoscopic balloon dilatation of pyloric stenosis can be technically demanding the long-term results are excellent.
FORCES EXERTED BY THE ENDOSCOPIST ON THE COLONOSCOPE DURING COLONOSCOPY. C A Mosse, T N Mills, DG Bell, C P Swnin. Departments of Medical Physics, University College, Ipowich General and Royal London Hospitals.

Aim: An electronic device was designed and built for use at colonoscopy to allow measurement of the forces exerted by the clinician on the endoscope during colonoscopy. Methods: The device featured a handle designed in the shape of hinged split cylinder which could be locked around the endoscope but could be readily moved up and down the shaft as the colonoscopy proceeded. The handle consisted of two parts, one that gripped the scope and one that was gripped by the colonoscopist. One of the members that joined these parts together contained strain gauges arranged as a Wheatstone bridge so that the forces transmitted could be measured accurately. The device measured and recorded the twisting forces exerted during the examination as well as the push and pull applied. A computer stored the data on disk while in real time it displayed the forces graphically as two chart recorder style traces. The device was calibrated against a range of weights exerting force on a colonoscope using a pulley system and was shown to give reproducible linear measurements over the range of interest. A series of interchangeable split cylinders allowed it to be used with any size of colonoscope. It was electronically isolated from the patient. The width of the colonoscopes used varied from 11 - $16 \mathrm{~mm}$ diameter. Results: This device was used to measure the forces at colonoscopy in preliminary studies in 10 patients. Results: Peak forward force $=4.4 \mathrm{Kg}$, backward force $=$ $1.2 \mathrm{Kg}$, left torque $=0.35 \mathrm{Kg}$ meters, right torque $=0.9 \mathrm{Kg}$ meters. Percentage time force greater than $1 \mathbf{K g}=5 \%$. Peak anal insertion force $=270 \mathrm{~g}$.

Conclusions: These measurements represent the first accurate measurements of the forces exerted during colonoscopy. Methods and developments which reduce the force exerted during successful colonoscopy are likely to diminish pain and reduce the risk of perforation. A knowledge of these forces may also help with the design of new instruments and models for teaching or research.
RANDOMIZED TRIAL OF ORAL SODIUM PHOSPHATE COMPARED WITH ORAL SODIUM PICOSULPHATE PREPARATION OF THE COLON FOR COLONOSCOPY. $\mathrm{S}$ Yoshioke; J Bates; D Morton; MRB Keighley. Univeraity Department of Surgery, Queen Elizabeth Hospital, Birmingham.

IMrmoducrion: Proper bowel cleansing is essential for colonoscopy. Sodium picosulphate is regarded by many as the standard preparation for endoscopy and elective surgery. Some colonoscopic studies suggest that oral sodium phosphate is superior to most other agents used for bowel preparation.

AIM: To compare oral sodium phosphate and oral sodium picosulphate in preparation for colonoscopy. Wrmod: One hundred and ix patients who had colonoscopy were randomly allocated into two groups: patients having oral sodium phosphate $45 \mathrm{ml}$ twice day before investigation $(n=51)$ and those having oral sodium picosulphate 2 sachets the day before investigation $(n=55)$.

REsurrs: Linear analogue scale for patient's acceptability including abdominal pain, nausea, embarrassment, fear and fatigue showed that the score of fear was significantly greater in sodium phosphate group compared to sodium picosulphate group (p<0.02). Scoring of the faecal residue in the colon revealed that sodium phosphate was more effective in the ascending ( $p<0.05$ ). descending $(p<0.01)$ and whole colon ( $p<0.05)$ compared to the remainder. However, no significant difference was found in the observed area of the mucosa between the two groups.

conchusion: These results suggest that oral sodium phosphate is well tolerated and a satisfactory agent for preparation in colonoscopy. In terms of bowel preparation sodium phosphate is superior to sodium picosulphate.
THERAPEUTIC SMALL BOWEL ENDOSCOPY. C P Swain. Royal London Hospital, Whitechapel, London El IBB

Aim: To assess the indications and outcome of therapeutic small bowel endoscopy. Patients \& methods: From a series of enterscopic examinations in 207 patients results of therapeutic enteroscopy in $\mathbf{5 0}$ cases were assessed. Most cases were performed without overtube or screening. Indications \& results: Bleeding: Angiodysplasia of jejunum 14 (6 single, 8 multiple), bleeding diverticulum 1, amyloid 2, inoperable malignancy 2 . No further bleeding occurred in $8 / 14$ angiodysplasia and the diverticulum. Bleeding rate appeared reduced from the malignancies but not the amyloid cases. Bipolar probe was used for 11 and Nd:YAG laser for 8. The laser fiber was easier to pass through the scope to use at distal sites. In $15 \%$ of patients referred for enteroscopy for bleeding lesions accessible to the gastroscope had been missed and were treated using the enteroscope. A bleeding duodenal ulcer, 3 gastric angiomas, linear erosions in hiatus hernia, 2 Dieulafoy ulcers and 3 watermelon stomachs were treated with bipolar or laser treatment and had no further bleeding. Polypectomy. 8 hamartomatous polyps were removed from the small bowel and 14 from stomach in 3 patients with Peutz Jeger syndrome. A duodenal carcinoid tumour was completely excised. Feeding: Feeding tubes were placed beyond the ligament of Treitz in 10 patients using a $0.35 \mathrm{~mm}, 400 \mathrm{~cm}$ guidewire, passing a feeding tube over the wire and then rerouting it through the nose. Direct puncture percutaneous jejunostomy with radiological assistance was used in 5 patients with gastric stasis or obstruction. Dilatation: Stricture dilatation with TTS hydraulic balloons was used in 3 patients, 2 for Crohn's and one for 1 patient with a low grade lymphoma. Manometry: An enteroscope was used to place small bowel manometry tubes in 4 patients. Interventional cholangiography: a pigtail stent was inserted via an enteroscopically placed guidewire into a bile-duct anastomotic stricture joining a Roux en $\mathrm{Y}$ loop in $1 / 2$ patients. No fatalities, perforations or induced bleeding occurred in this series. Conclusions: Therapeutic enteroscopy offers effective haemostasis for a subgroup of patients with bleeding found at enteroscopy and can be used safely for a range of other therapeutic options. 


\section{PREDICTION OF RESECTABILITY OF GASTRIC TUMOURS}

\section{USING ENDOSCOPIC ULTRASOUND}

SA Norton, D Alderson.

\section{Dept. of Surgery, Bristol Royal Infirmary, Bristol BS2 8HW}

The accurate assessment of the resectability of gastric tumours can be difficult using conventional imaging investigations. Posterior invasion may not be apparent on computed tomography (CT) and so patients may be subjected to inappropriate laparotomy. Endoscopic ultrasound (EUS) can clearly visualise the layers of the stomach wal and adjacent structures, including regional lymph nodes and so the locoregional staging of gastric tumours can be determined. This procedure can be performed immediately following the initial diagnostic endoscopy.

Twenty four patients with histologically proven gastric cancer underwent EUS. Eleven patients were deemed to have resectable tumours on EUS. This was confirmed at operation. Ten patients were felt to have irresectable tumours using EUS. Of these, five underwent laparotomy and palliative bypass due to extensive tumour invasion. Five patients were unfit for surgical intervention or had evidence of metastatic spread.

CT predicted resectability in 3 irresectable tumours and 5 resectable tumours but was valuable in providing information regarding metastatic spread.

Endoscopic ultrasound is more accurate than $\mathrm{CT}$ in predicting irresectability of gastric tumours and therefore has a valuable role in the assessment of tumours in patients who would not otherwise require palliative bypass

\section{TOTAL INTRAVENOUS ANAESTHESIA IN PAEDIATRIC GASTROINTESTINAL ENDOSCOPY Depts. of Paediatrics's and Anaesthesiology ${ }^{2}$, University Hospital Leiden, the Nether-}

Gastrointestinal endoscopy (GE) has become a useful diagnostic method for gastrointestinal diseases in childhood. In recent years, new developments in the administration of analgesic and anaesthetic drugs have greatly facilitated the technique of total intravenous ansesthesia for GE. However, this kind of anaesthesia is often associated with delay during $G E$

Aim of the (pilot) study: To analyse the benefits and drawbacks of total intravenous anaes-thesia during upper GE in children. Patients: 22 children (10 girls), mean age 7.5 gastroand 3 percutaneous endoscopic gastrostomies (PEG). Method: Total intravenous ansesthesia at the discretion of the supervising ansesthesist was given to the children. The time-lag from the start of the ansesthesia to the introduction of the endoscope, the duration of the GE and the recovery time from anaesthesia were assessed. In addition blood pressure, heart rate, and $\mathrm{SaO} 2$ were non-invasively monitored and automatically recorded. Anxiety before GE was independently asseseed, using a scoring linear virua

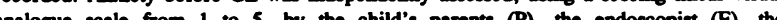
anesthesist (A) and the nurses (N).

Children older than 6 years were asked to assess their own anxiety $(\mathrm{Ch})$. The agitation, degree of discomfort and quality of operating conditions were assessed too.

\begin{tabular}{|c|c|c|c|c|}
\hline $\begin{array}{l}\text { DEAYY FROM } \\
\text { SCHEDULED TME }\end{array}$ & 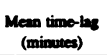 & MEASUREMENTS & Mean neavils & $\begin{array}{l}\text { ANXIETY } \\
\text { CHILD }\end{array}$ \\
\hline 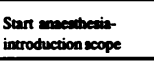 & 15.59 & Symodic RR & $96.7 \mathrm{~mm} \mathrm{~Hz}$ & By $A=2.6$ \\
\hline $\begin{array}{l}\text { Time CE: } \\
\text { GIF (n-19) } \\
\text { DDB (n-9) } \\
\text { PEG (n-3) }\end{array}$ & $\begin{array}{l}18.33 \\
12.44 \\
28.50\end{array}$ & $\underset{\substack{\mathrm{Hean} \\
\mathrm{SaC2} 2 \mathrm{Oex}}}{2}$ & $\begin{array}{l}109.0 \text { p.m.m. } \\
96.8 \pi\end{array}$ & $\begin{array}{l}\text { By } N=2.7 \\
\text { By } P=2.9\end{array}$ \\
\hline Recovery & 26.52 & $\begin{array}{l}\text { Operating } \\
\text { conditions }\end{array}$ & Optimal & By $E=3.5$ \\
\hline $\begin{array}{l}\text { Exran GE-ime } \\
\text { tool }\end{array}$ & 43.45 & $\begin{array}{l}\text { Physical } \\
\text { retarin }\end{array}$ & Nor neoded & By $\mathrm{Ch}=3.6$ \\
\hline
\end{tabular}

Conclusions: Our preliminary results show a total mean extra endoscopy time of $\mathbf{4 3 . 4 5}$ minutes for total intravenous anaesthesia in paediatric upper GE, of which 15.6 minutes in the endoscopy room. The operating conditions were optimal. The anxiety before GE was experienced by the child as more suressful than observed by the adults.

\section{Motility TH164-TH176}

TH164

\section{THE SPECTRIM OF ENTERIC DYSMOTILITY REVEALED} BY PROLONGED SMALL BOWEL MANOMETRY. DL Wingate, FD Castillo, T Nomura, MF Benson, DF Evans. GI Science Research Unit, St Bartholomew's and Royal London School of Medicine, London, UK.

Clinical small bowel manometry (SBM) can identify differences between groups of subjects, but its diagnostic value remains uncertain We used computer-analysed SBM in 47 studies in 18 healthy controls to construct a database of normal values of 20 variables of the migrating motor complex (MMC); the diagnostic potential of this technique was supported by a study of Chagas'.disease in Brazil, in which 21/21 patients had $\geq 2$ variables outside the normal range. We used prolonged SBM as a diagnostic test in 63 UK tertiary referral patients with suspected dysmotility. Subjects were studied for $24 \mathrm{hrs}$ with a triple-sensor nasojejunal manometric catheter linked to a digital datalogger; data from the sensor located at the $d-j$ flexure was used to calculate the 20 variables. SBM failed in 6 subjects $(10 \%)$. Motility was judged to be normal in 17 subjects, with $\leq 1$ abnormal variable. The remaining 40 patients with $\geq 2$ abnormal variables (range $2-9$, median 4) included all 14 patients with known pathology - diabetic neuropathy (5), vagotomy diarthoea (3), scleroderma (2), enteric myopathy (3), CNS disease (1) - and 4/4 'irritable bowel' patients with refractory urgent and frequent defaecation. Abnormal records were marked by distortion, and, in 5 , by abolition of the normal difference between diurnal and nocturnal activity. In 7 , there was marked attenuation or absence of a motor response to food (not all patients could tolerate a normal meal). In 4, there were 'Chagas-like' prolonged Phase 3 and slow propagation of the MMC: another 7 had one or other of these abnormalities. In contrast, ultra-rapid MMC propagation was seen in 3/5 diabetics, and 2 others with diarrhoea. Low amplitude contractions were seen in 3 (scleroderma 2, dilated bowel 1) but net in patients with myopathy. 3 had MMCs by day but not at night, and 3 had excess MMCs throughout. We suggest that computer-analysed 24 $\mathrm{hr}$ SBM is an objective and reproducible diagnostic technique; it reveals diverse patterns of dysmotility that probably reflect different pathologies of gut muscle and nerves. 


\section{ANOVH MIGIHOD FOR 24 HOUR PANCOLONIC} AMBULATORY MANOMITRY

R Hagger ${ }^{1}$. D Kumar ${ }^{1}$. M Benson ${ }^{2}$. A Grundy ${ }^{3}$. Dept. of

Surgery1, Div. of Gastroenterology 2 and Dept. of Radiology 3

St. George's Hospital, London, United Kingdom.

Normal colonic motility patterns have not been clearly defined. The aim of this study was to establish a new technique and describe colonic motor patterns using 24 hour ambulatory pancolonic manometry.

Five healthy volunteers were recruited to the study. Colonic motility was measured using two silicon coated catheterg(OD-3mm) with 5 pressure transducers at $15 \mathrm{~cm}$ intervals. The proximal catheter was introduced transnasally and it's tip positioned at the splenic flexure under fluoroscopic control. The distal catheter was introduced transanally in an unprepared colon and it's tip positioned in the descending colon with the help of a colonoscope. No sedation was used for the colonoscopy. The tip of the distal catheter was clipped to the colonic mucosa with a titanium clip. The transducers spanned the bowel from the terminal ileum to the rectum. Data was recorded continuously on a portable data logger (MMS Universal Portable System). All subjects were fully ambulant and ate their own meals.

Recordings were made for a total of 116 hours in 5 subjects. The colon exhibited high amplitude propagating contractions(HAPC), migrating motor complexes(MMC) and rectal motor complexes(RMC). Mean number of HAPC was 5.24/24hrs, $16 \%$ occurring within 1 hour of waking and 28\% preceding defecation. Mean number of MMC was $11.8 / 24 \mathrm{hrs}, 33.5 \%$ of which propagated into the caecum. Mean number of RMC was $10.6 / 24 \mathrm{hrs}, 17.8 \%$ propagated aborally and $9.8 \%$ propagated orally.

The human colon exhibits phasic activity which is propagated from the terminal ileum. The rectum shows complexes which are propagated in an orad as well as aborad direction.
GASTRIC ARRHYTHMIAS IN THE FUNCTIONAL BOWEL DISORDERS

A.C.B. Leahy, C. Clayman, I Mason, K Besherdas, O. Epstein. Centre of Gastroenterology, Royal Free Hospital, London NW3 2QG

Cutaneous electrogastrography (EGG) abnormalities including arrhythmias and a postprandial power decrease have been described in functional dyspepsia (FD). EGG arrhythmias have been well correlated with antral dysmotility. The aim of this study was to substantiate EGG abnormalities in FD, and to compare FD patients with patients suffering from irritable bowel syndrome (IBS). Methods: Patients studied inchuded 105 with dyspepsia with a normal endoscopy and abdominal ultrasound scan, 60 with IBS diagnosed by the Rome criteria and 30 healthy controls. Two cutaneous bipolar electrodes were placed over the stomach and connected to an EGG recording unit (Synectics, Stockholm, Sweden). EGG was performed according to a standard protocol which included a 2 hour pre/postprandial study. Bradygastria was defined as $0-2 \mathrm{cpm}$; normal slow wave activity as 2 4cpm; and tachygastria as 4-9cpm. Postprandial power change was calculated. Statistical analysis was performed by the Student's t-test. 26 patients had a radiolabelled gastric emptying study performed to correlate EGG abnormalities with gastric emptying. Abnormal EGG was defined as $<70 \%$ normal slow wave activity either preprandially or postprandially. Results: A postprandial power decrease was observed in 8 controls and this was not considered to be an abnormality when present alone. Two controls had $<70 \%$ normal slow wave activity either preprandially or postprandially. EGG abnormalities were present in $32(30 \%)$ FD patients and $6(10 \%)$ IBS patients. 35 IBS patients also had dyspepsia, including all 6 patients with abnormal EGG. Mean $\%$ normal slow wave activity pre/postprandially were: controls 86.9/90.0; FD 81.6/82.9(p<0.02); IBS 86.6/88.9. No correlation was found between EGG arrhythmias and delayed gastric emptying. Conclusions: 1. EGG has a high $(93 \%)$ diagnostic specificity. 2 . Postprandial power decrease is observed in healthy controls. 3. 30\% of FD patients have abnormal EGG suggesting antral dysmotility. 4. In IBS, EGG abnormalities only occur when dyspepsia is present.
VOLITIONAL SWALLOWING MODULATES CORTICAL SWALLOWING PATHWAYS VIA BRAINSTEM MEDIATED INTERACTIONS

S. Hamdy, Q. Aziz, J.C. Rothwell, D.G. Thompson

Department of Gastroenterology, University of Manchester, and the Institute of Neurology, London, UK.

Background: Swallowing is an complex process exhibiting both excitatory and inhibitory influences over the muscles of the upper digestive and respiratory tracts. Furthermore, the cortex has an important role in the initiation and modulation of swallowing and respiration. Despite these observations, the functional interactions between volitional swallowing and the cortical pathways to human swallowing and respiratory musculature are unknown. Aims: To determine how volitional swallowing interacts with the cortico-fugal pathways to swallowing and respiratory musculature in man. Methods:. Swallowing musculature (Mylohyoid) and respiratory musculature (Diaphragm) were studied in 8 healthy volunteers $(7 \mathrm{male}$, age range 24-32 yrs). Mylohyoid and diaphragm EMG responses to transcranial magnetic stimulation of the cortex were recorded, in maximal inspiration, at intervals of: $100 \mathrm{msec}$ between $0-1 \mathrm{sec}, 2 \mathrm{sec}$ and $5 \mathrm{sec}$, after a $5 \mathrm{ml}$ water bolus swallow or a control task (hand contraction). Results: When compared to the control task, swallowing facilitated the mylohyoid responses between 0 and $0.4 \mathrm{sec}$ (swallowing: $670 \pm 21 \mu \mathrm{V}$, control: $565 \pm 36 \mu \mathrm{V}, \mathrm{p}<0.02$ ) before inhibiting them between 0.6 and 2 $\sec$ (swallowing: $460 \pm 20 \mu \mathrm{V}$, control: $637 \pm 26 \mu \mathrm{V}, \mathrm{p}<0.01$ ). In contrast, the diaphragm responses were consistently inhibited from $0.4 \mathrm{sec}$ onwards (swallowing: $150 \pm 11 \mu \mathrm{V}$, control: $187 \pm 10 \mu \mathrm{V}, \quad \mathrm{p}<0.05$ ). Conclusions: Volitional swallowing modulates the cortical pathways to human swallowing and respiratory musculature, via excitatory and inhibitory influences, a finding that reflects processing by the brainstem swallowing centre.
HISTOLOGICAL PHENOTYPINGOF ENTERIC SMOOTH MUSCLEDISEASECAUSINGFUNCTIONAUNTESTINAL OBSTRUCTION IN CHILDHOOD

Smith VV and Milla PJ

Histopathology. Great Ormond Street Hospital for Children, Great Ormond Street, London WC1N 3JH, UK

Functional intestinal obstruction or chronic idiopathic intestinal pseudo-obstruction is due to defects either in the enteric innervation or in the smooth muscle.

We have studied full-thickness intestinal samples from 27 patients with functional intestinal obstruction due to enteric smooth muscle disease, using routine histology, electron microscopy, histochemical and immunohistochemical techniques to detect changes in the intestinal smooth muscle.

Two patients presenting at the age of 6 months and 18 months had an acquired intestinal myopathy as a result of an autoimmune process. In 25 the disorders were congenital, and of these $7 \mathrm{had}$ segmental abnormalities limited to the rectum and distal colon and 18 a diffuse disease affecting both the small and large bowel. We identified five apparent histological phenotypes of enteric muscle disease. Three of these represent abnormalities in morphogenesis resulting in alterations in intestinal muscle layering. Two probably exemplify intrinsic myocyte defects or changes in the extracellular matrix.

Phenotyping these patients carefully is important both in devising optimal treatment and in understanding the underlying defect. Recognition of the autoimmune smooth muscle disease is helpful, since making the diagnosis influences the patient's management. The histological phenotype alludes to probable aetiology thus allowing investigation of the possible molecular and genetic defects. 
INTERSTITIAL CELLS OF CAJAL (ICC) IN THE HUMAN COLON: REGIONAL DENSITY VARIATIONS

R Hagger. C Finlayson*. S Gharaie*. and D Kumar. Dept. of Surgery and Dept. of Histopathology*, St. George's Hospital, London, United Kingdom.

To determine the regional variation of density of ICC in the wall of the normal human colon, we have studied 109 colonic tissue blocks.

ICC were identified in the colon by

immunohistochemical staining, using a rabbit polyclonal anti-c-kit antibody (Oncogene Science). Normal colonic tissue was defined as non-involved tissue obtained at surgical resection for a non-obstructing carcinoma of the colon. The regions of interest were right, transverse and left colon. Density of ICC was graded on the basis of the number of ICC per high power field. Statistical analysis was performed using chisquared tests.

In the myenteric plexus the transverse colon $(p=0.009)$ and right colon $(p=0.05)$ had a significantly higher density of ICC than the left colon. Although not statistically significant, there was a trend for the density of ICC to be higher in the transverse colon than the right colon in the myenteric plexus. In the circular muscle layer, the right colon had the highest density of ICC, this was significant in comparison to the left colon $(P=0.02)$ but not the transverse colon. No significant regional variations in ICC density were identified in the longitudinal muscle layer.

Regional variations in the density of ICC are present in the colon. The highest density of ICC in the myenteric plexus was observed in the transverse colon, the proposed site of pacemaker activity.
TACHYODDIA INDEPENDENT FROM THE DUODENAL MIGRATING MOTOR COMPLEX MAY BE A PART OF SPHINCTER OF ODDI DYSFUNCTION. EA Stoner, CC Ainley, DF Evans, V Kulhalli, AJK Piotrowicz. St . Bartholomew's and the Royal London School of Medicine and Dentistry, London.

Manometric measurements of the sphincter of Oddi (SO) have enabled a better understanding of its physiology and recognition of the condition of sphincter of oddi dysfunction (SOD). Presently SOD is only reliably diagnosed by an elevated basal pressure. Previously SO phasic activity has been shown to closely follow the migrating motor complexes(MMCs) with maximal frequency during phase 3 of the MMC. A raised frequency of contractions $(>8 \mathrm{cpm})$ has been termed as tachyoddia however it is not regarded as clinically significant.

Aims 1)To determine the incidence of tachyoddia.2) To look at the relationship between tachyoddia, duodenal activity. and SOD

Methods SOM was performed using a triple lumen catheter ( Wilson-Cook, USA), the central channel being continually aspirated. A station pull through technique was employed. The duodenal motility was measured using a single lumen 5 French catheter taped to the outside of the duodenoscope.

Results 65 patients with post cholecystectomy pain, idiopathic pancreatitis or biliary pain underwent SOM. 15 of the $65(23 \%)$ patients had at least one episode of tachyoddia.

\begin{tabular}{|l|l|l|l|}
\hline $\begin{array}{l}\text { Basal } \\
\text { pressure }\end{array}$ & $\begin{array}{l}\text { Tachyoddia } \\
\text { synchronous } \\
\text { with MMC }\end{array}$ & $\begin{array}{l}\text { Tachyoddia } \\
\text { independent } \\
\text { of MMC }\end{array}$ & Total \\
\hline Raised & 1 & 4 & 5 \\
\hline Normal & 9 & 1 & 10 \\
\hline Total & 10 & 5 & 15 \\
\hline
\end{tabular}

A raised basal SO pressure is significantly associated with independent tachyoddia (Fisher's exact test $\mathrm{p}<0.05$.)

Conclusion. The SO may have its own pacemaker which is dissociated from the control of the MMC in patients with SOD.

Tachyoddia independent of the MMC should now be regarded as part of sphincter of Oddi dysfunction.
GENDER DIFFERENCES AND REPRODUCIBILITY OF WHOLE GUT VISCERAL SENSITIVITY. CY Erancis, LA Houghton, PJ Whorwell. Dept of Medicine, University Hospital of South Manchester.

Abnormalities in gut visceral sensation are currently regarded as being important in the pathophysiology of functional bowel disorders. However, its inter-subject variation, its reproducibility (or intra-subject variation) and the effect of gender on these parameters has received little attention. Repeat studies on 8 healthy female (aged 20-37 yrs; median $23 \mathrm{yrs}$ ) and 10 healthy male (aged $20-57 \mathrm{yrs}$; median $22 \mathrm{yrs}$ ) volunteers were carried out to assess the sensory responses of the oesophagus [O], duodenum [D], jejunum [J], ileum [I], colon [C] and rectum [R] to isovolumic balloon distension. The order in which these regions were distended was randomised, and there were 3 to 47 weeks (median 9 weeks) between studies.

Results Female subjects tended to be more sensitive than male subjects to distension of the $O$ [vol to discomfort $(\mathrm{ml})$ : females 15 (7.5-20) geometric mean (range) v males 24 (10-110); $p=0.16], D$ [73 (40-110) v 99 (50-150); $\mathrm{p}=0.08], J[58(40-70)$ v $70(30-170) ; \mathrm{p}=0.32], I$ [55(30-100) v 92 (40-150); $p=0.029], C[177(110-280)$ v $235(150-$ $500) ; p=0.23]$ and $R$ [191 (100-400) v $211(150-325) ; p=0.58]$. Furthermore, it can be seen from the above ranges that the inter- (or between-) female variation was less than the inter-male variation; this difference reaching significance in the $O(p=0.05)$ and $J(p=0.0015)$. However, the intra- (or within-) female variation was not apparently different from the intra-male variation in the $O$ [difference from 1st to 2nd study: $2.5(0-7.5)$ median (range) v $5(0-40)], D[10(0-30)$ v 20 (0$50)], J[20(20(0-30)$ v $30(0-90)], I[40(10-40)$ v $10(0-70)], C[40(10-$ $140)$ v $60(20-220)]$ and $R[70(0-125)$ v $65(0-125)]$. These male-female differences were not related to differences in anxiety between the female [HAD score, 4.5 (0-8) median (range)] and male [5.0 (3-9); $p=0.41]$ volunteers.

Conclusion Because males are less sensitive and have a wider intersubject variation than females, they may be less prone to abnormalities in visceral sensation following exposure to noxious stimuli. This might help to explain the preponderance of female to male patients with functional bowel disorders.
GASTRIC EMPTYING (GE) AND GASTROINTESTINAL REGULATORY PEPTIDES (GRP) IN CHILDREN WITH RECURRENT EPIGASTRIC PAIN (REP)

A Papadopoulou, A Vazeou, E Kitsiou',A Papadimitriou'2, C Bartsocas

" P \& A Kyriakou" Children's Hospital, ' 'Laiko" Hospital, and

2 "Nevy's" Hospital, Athens, Greece

Recurrent epigastric pain is often of uncertain aetiology and it is therefore attributed to psychological causes. Gastrointestinal motility disorders have been implicated in the pathogenesis of abdominal pain and regulatory enteropeptides, in the pathogenesis of intestinal dysmotility. However, the incidence of gastric dysmotility and the role of GRP in children with REP are poorly defined. We therefore, carried out a prospective study in 36 children (mean age 10.4 years, 18 males) with REP of uncertain aetiology, in order to detect the incidence of gastric dysmotility and the role of serum motilin. In 28 patients, REP were associated with non-ulcer dyspepsia : early satiety, postprandial abdominal bloating and/or distention. In 8, REP was paroxysmal, precipitated by prolonged fasting. Seventeen patients $(47 \%)$ were found to have abnormal gastric emptying assessed by gastric scintigraphic studies : $12(43 \%)$ of the 28 patients with dyspepsia (mean age 9.4 yrs) were found to have delayed emptying of a solid

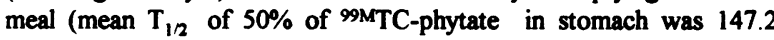
minutes); 5 of the $8(62 \%)$ patients with paroxysmal pain (mean age 13.4 yrs) had rapid gastric emptying (mean $\mathrm{T}_{1 / 2}$ of $50 \%$ of $99 \mathrm{MTC}$ phytate in stomach was 55 minutes). Fasting serum motilin concentrations were lower in the patients with REP compared with 26 healthy controls $(p<0.0001)$. However, no significant correlations were found between serum motilin concentrations and the duration or the severity of REP or gastric emptying time. The treatment with cisapride and/or erythromycin was associated with resolution of symptoms in all of the patients with delayed gastric emptying. Similarty, dietary modifications were associated with a relief in symptoms in children with rapid gastric emptying. In conclusion, GE abnormalities are common in children with REP of uncertain aetiology. The role of GRP in children with REP should be further investigated 
THE USE OF RADIOTRANSMITTING CAPSULES TO MEASURE INTESTINAL TRANSIT SI Lewis and KW Heaton. Department of Medicine, Bristol Royal Infirmary, Bristol BS2 8HW.

Because luminal $\mathrm{pH}$ increases as the duodenum is entered then falls on entry into the caecum, the $\mathrm{pH}$ radiotransmitting capsule can be used to measure small bowel transit-time. It can also be used to measure wholegut transit-time (WGTT) and, by subtraction colonic transit-time. However the latter is a valid exercise only if WGTT is not itself altered by the capsule.

We set out to see if WGTT measured by the $\mathrm{pH}$ radiotransmitting capsules differed from WGTT measured simultaneously using the traditional barium impregnated plastic pellet method.

13 healthy volunteers had their WGTT measured using plastic marker pellets of different shapes, then collecting two stool samples and $x$-raying them. At the same time a pH radiotransmitting capsule was swallowed and tracked. These measurements were then repeated with the volunteers taking in order wheat bran, senna then loperamide in maximally tolerated amounts.

No significant differences were seen between the two sets of measurements on baseline diet or if the intestinal transit was altered using wheat bran, senna or loperamide.

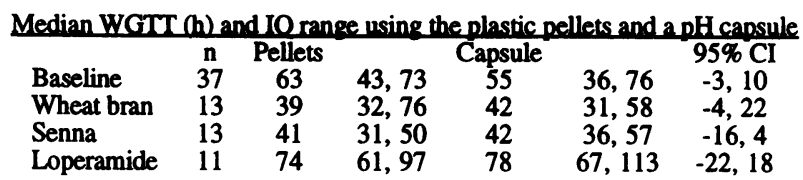

We found no systematic difference in measured WGTT between results with the traditional plastic marker pellets and with the $\mathrm{pH}$ radiotransmitting capsule. This was true even if WGTT was artificially increased or decreased. In addition the $\mathrm{pH}$ radiotransmitting capsule gives information on small bowel transit and caecal anal transit-times, thus negating the need to use separate techniques for each or the use of radioactive isotopes. This $\mathrm{pH}$ radiotransmitting capsules may be a useful method of assessing small and large intestinal transit-times.
TH175

ALOSETRON SLOWS COLONIC TRANSTT IN PATTENTS WTH IRRTABII DOWE SYNDROME (IBS) M Foner LA Houghton, PJ Whorwell. Depertmeat of Modicine, University Hospital of South Menchester, M20 2LR, UK

The seloctive SHT, entryonixt, alosetron reduces cbdominal puin/discomfort in petients with IBS (Berthen of al, Gentroenterol 1996;110:630) and slows whole gut and colonic transit in boolthy voluntees (Honghton of al, Gestroenterol 1995;108:264). However, its efiect on gentrointeetinal transit in patients with IBS hes not been previously invectigned. Twelve IBS patients (aged 23-56 yrs) disenosed by the Rome criteris were therefore catered into a rendomised, donble blind, croseover andy, compering the effects of oral alosetron (2mg bd $\times 8$ days) with placobo on whole gut (month to anus), amall bowel (month to ceocum) and colonic tranit. Meen whole gut transit (MWGT) wes determined by the number and time of excretion of 3 difierent radio-opeque menken ingested on 3 conececutive days (days 2,3 and 4). Small bowal trmait (SBT) was meanured $\infty$ the time from ingestion of a standard meal of meshed poteto, sausmes and beens (non-absorbable carbohydrate) to a riee in breeth hydrogen of 3 ppen enstained for $30 \mathrm{~min}$ (day 5). Colonic (CT), left colonic (LCT), right colonic (RCT) and rectosigmoid (RST) transit were ovaluatod by abdominal X-ray (day 5).

\begin{tabular}{|c|c|c|c|}
\hline WGT (maker 1 ; hrs) & $\begin{array}{l}\text { Placebs } \\
68(21-125)\end{array}$ & $\begin{array}{l}\text { Alescition } \\
\text { 82(14-159) }\end{array}$ & $\begin{array}{l}P \\
0.09\end{array}$ \\
\hline WGT (marker $2 ; \mathrm{hrs}$ ) & $67(16-137)$ & $73(24-144)$ & $0.07^{*}$ \\
\hline WGT (maker $3 ; \mathrm{hrs}$ ) & $52(16-119)$ & $54(13-120)$ & 0.47 \\
\hline MWGT (hrs) & $59(18-114)$ & $72(20-141)$ & 0.13 \\
\hline SBT (min) & $335(190-490)$ & $330(200-510)$ & 0.51 \\
\hline CT (hrs) & $38(1-67)$ & $49(1-72)$ & $0.07 *$ \\
\hline LCT (hrs) & $12(0-23)$ & $23(0-52)$ & 0.006 \\
\hline RCT (hrs) & $7(1-23)$ & $7(0-31)$ & 0.57 \\
\hline RST (hrs) & $8(0-24)$ & $5(0-23)$ & 0.38 \\
\hline
\end{tabular}

Conclogion Alosetron delays colonic transit by prolonging left colonic transit. These results add further to the body of evidence that alosetron may have a therapeutic role in irritable bowel syndrome. "This research was funded by GlaxoWellcome, UK"
SUMATRIPTAN AT A THERAPEUTIC DOSE ALTERS OESOPHAGEAL MOTILITY. IM Foster, LA Houghton, PJ Whorwell. Dept of Medicine, University Hospital of South Manchester.

3-5\% of patients taking the $5 \mathrm{HT}_{1 \mathrm{D}}$ agonist sumatriptan (S) for migraine experience chest discomfort, potentially suggesting a cardiac origin. However, we have recently suggested that the oesophagus may be the cause of this chest discomfort, as a supratherapeutic dose of $S(16 \mathrm{mg}, \mathrm{sc})$ significantly alters oesophageal motility without affecting the ECG. The aim of this study was to investigate whether a therapeutic dose of $S$ (6mg, sc) also affects oesophageal motility. Lower oesophageal sphincter (LOS), oesophageal body (4 sites), gastric and pharyngeal (to monitor swallows) pressures were recorded using a perfused manometric catheter with sleeve sensor in 16 healthy volunteers (aged 19-32 yrs; 9 male) before and after administration of $S$ or saline control. Sequences of 6 consecutive $5 \mathrm{ml}$ water swallows with a minimum interval of $20 \mathrm{sec}$ between each swallow, were carried out $-15,-5,5,15,30,45,60,80$, $100,120,150$ and $180 \mathrm{~min}$ post-injection. Treatment order was randomised and double-blind; throughout the study ECG and symptoms were monitored. Results $S$ significantly increased the amplitude of oesophageal contractions (mean increase from pre-injection: $S 4.8 \mathrm{mmHg}$, placebo $-4.5 \mathrm{mmHg}$; difference $9.3 \mathrm{mmHg}, 95 \% \mathrm{CI} 4.1-14.5 \mathrm{mmHg}$, $p=0.002$ ); an effect that was maintained throughout the whole of the 3 $\mathrm{hr}$ recording period. In addition, $S$ induced a transient increase in LOS pressure immediately after injection $(S 10.9 \mathrm{mmHg}$, placebo $5.1 \mathrm{mmHg}$; difference $5.8 \mathrm{mmHg},-0.7-12.3 \mathrm{mmHg}$ ), although it had no overall effect on LOS pressure over the time period studied $(S 1.9 \mathrm{mmHg}$, placebo $2.1 \mathrm{mmHg}$; difference $0.2 \mathrm{mmHg},-3.9-4.2 \mathrm{mmHg}$ ). $S$, however, did not affect the duration $(S 0.3 \mathrm{~s}$, placebo $-0.1 \mathrm{~s}$; difference $0.4 \mathrm{~s}, 0.2-0.5 \mathrm{~s}$ ) or velocity of propagation $(S-0.09 \mathrm{~cm} / \mathrm{s}$, placebo $-0.12 \mathrm{~cm} / \mathrm{s}$; difference $0.03 \mathrm{~cm} / \mathrm{s},-0.15-0.21 \mathrm{~cm} / \mathrm{s}$ ) of oesophageal contractions. Chest discomfort was only experienced in one subject and although this subject did show a change in oesophageal motility, there was no correlation with the degree of change. No subject exhibited any ECG abnormalities. Conclusion At therapeutic doses $S$ also has an effect on oesophageal motor function, and this provides further evidence of a possible oesophageal cause of $S$-induced chest symptoms.
GASTRIC EMPTYING IN HUMAN IMMUNODEFICIENCY VIRUS (HIV) INFECTED INDIVIDUALS: RELATIONSHIP TO SYMPTOMS, AUTONOMIC FUNCTION AND GASTROINTESTINAL (GI) PATHOGENS. PJ Neild R Jewkes, BG Gazzard. Chelsea and Westminster Hospital, London, U.K

Symptoms suggestive of delayed gastric emptying are common in HIV seropositive (HIV + ) individuals, as is autonomic neuropathy, though often subclinical. We tested the hypothesis that GI symptoms may be related to objective delay in gastric emptying and that this may be associated with autonomic dysfunction and/or the presence of opportunistic GI pathogens. Methods: $19 \mathrm{HIV}+$ subjects with enteric infections (HIV/P) and 37 HIV+ subjects with no identifiable pathogens (HIV/NP) were compared with 12 presumed HIV-ve healthy controls (cont). Subjects completed a symptom score and underwent a series of autonomic function tests (aft), and a scintigraphic solid gastric emptying test, using a single headed gamma camera with anterior and posterior views. Results: Gastric half emptying time $\left(t_{1 / 2}\right)$ was increased in HIV+ subjects and significantly so in those with GI pathogens, though lag phase $\left(t_{\text {lag }}\right)$ and the proximal emptying component $\left(\mathrm{pt}_{1 / 2} / \mathrm{t}_{1 / 2}\right)$ were less affected GI symptoms and autonomic dysfunction were significantly increased in HIV+ subjects compared with controls but did not correlate with gastric emptying $\left(r^{2}=0.021\right.$ and 0.012 respectively). $t_{1 / 2}$ was related to $C D 4$ count $\left(r^{2}=0.13, p=0.006\right)$ and \%weight loss $\left(r^{2}=0.21, p=0.0004\right)$

\begin{tabular}{|c|c|c|c|}
\hline results expressed as meantSEM & cont & HIV+NP & HIV+/P \\
\hline symptom score/15 & $0.08 \pm 0.08$ & $5.54 \pm 0.63^{* *}$ & $6.9 \pm 0.86^{* *}$ \\
\hline SD of R-R intervals (SDRR) (ms) & $61.56 \pm 4.12$ & $39.95 \pm 3.8^{*}$ & $33.29 \pm 4.31^{* *}$ \\
\hline gastric $\mathrm{t}_{12}(\min )$ & $66.9 \pm 5.16$ & $92.38 \pm 8.04^{M}$ & $158.3 \pm 20.9 * *$ \\
\hline$t_{\operatorname{man}}(\min )$ & $22.08 \pm 3.54$ & $29.08 \pm 3.02$ & $48.5 \pm 9.42$ \\
\hline$p t_{1 / 2} / t_{1,2}$ & $0.75 \pm 0.05$ & $0.63 \pm 0.03$ & $0.60 \pm 0.03$ \\
\hline
\end{tabular}

${ }^{+} p<0.05, * p<0.01, * * p<0.001$ wrt cont. ${ }^{\wedge} p<0.001$ wit HIV/P

Conclusions: Gastric emptying is disturbed in a number of HIV+ subjects, particularly those with small intestinal GI pathogens, but neither gastric symptoms or autonomic dysfunction can predict those with abnormalities. Delay may result from local production of cytokines, eg tumour necrosis factor alpha, or duodenal dysmotility causing reflex inhibition of emptying. 